\section{Pacific Northwest}

National Laboratory

Operated by Battelle for the

U.S. Department of Energy

\title{
Storage and Aging Effects on Spherical Resorcinol-Formaldehyde Resin Ion Exchange Performance
}

\author{
S. K. Fiskum \\ S. T. Arm \\ M. K. Edwards \\ M. J. Steele \\ K. K. Thomas
}

September 2007

Prepared for the U.S. Department of Energy under Contract DE-AC05-76RL01830 


\title{
DISCLAIMER
}

This report was prepared as an account of work sponsored by an agency of the United States Government. Neither the United States Government nor any agency thereof, nor Battelle Memorial Institute, nor any of their employees, makes any warranty, express or implied, or assumes any legal liability or responsibility for the accuracy, completeness, or usefulness of any information, apparatus, product, or process disclosed, or represents that its use would not infringe privately owned rights. Reference herein to any specific commercial product, process, or service by trade name, trademark, manufacturer, or otherwise does not necessarily constitute or imply its endorsement, recommendation, or favoring by the United States Government or any agency thereof, or Battelle Memorial Institute. The views and opinions of authors expressed herein do not necessarily state or reflect those of the United States Government or any agency thereof.

\author{
PACIFIC NORTHWEST NATIONAL LABORATORY \\ operated by \\ BATTELLE \\ for the \\ UNITED STATES DEPARTMENT OF ENERGY \\ under Contract DE-ACO5-76RL01830
}

Printed in the United States of America
Available to DOE and DOE contractors from the
Office of Scientific and Technical Information,
P.O. Box 62, Oak Ridge, TN 37831-0062;
ph: (865) 576-8401
fax: (865) 5765728
email: reports@adonis.osti.gov

\author{
Available to the public from the National Technical Information Service, \\ U.S. Department of Commerce, 5285 Port Royal Rd., Springfield, VA 22161 \\ ph: (800) 553-6847 \\ fax: (703) 605-6900 \\ email: orders@nits.fedworld.gov \\ online ordering: http://www.ntis.gov/ordering.htm
}




\title{
Storage and Aging Effects on Spherical Resorcinol- Formaldehyde Resin Ion Exchange Performance
}

\author{
S. K. Fiskum \\ S. T. Arm \\ M. K. Edwards \\ M. J. Steele \\ K. K. Thomas
}

September 2007

Test specification: 24590-PTF-TSP-RT-06-0001, Rev. 0

Test plan: TP-RPP-WTP-440, Rev. 0

Test exceptions: None

R\&T focus area: Pretreatment

Test Scoping Statement(s): A-219

Pacific Northwest National Laboratory

Richland, Washington 99352 
WTP-RPT-148, Rev. 0

\section{COMPLETENESS OF TESTING}

This report describes the results of work and testing specified by Test Specification 24590-PTF-TSP-RT-06-0001, Rev. 0 and Test Plan TP-RPP-WTP-440, Rev. 0. The work and any associated testing followed the quality assurance requirements outlined in the Test Specification/Plan. The descriptions provided in this test report are an accurate account of both the conduct of the work and the data collected. Test plan results are reported. Also reported are any unusual or anomalous occurrences that are different from expected results. The test results and this report have been reviewed and verified.

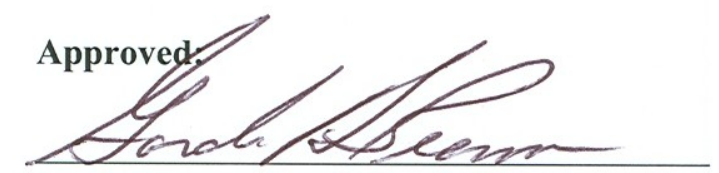

Gordon H. Beeman, Manager WTP R\&T Support Project

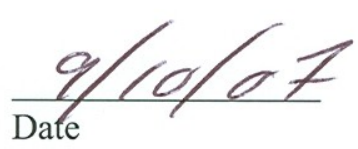




\section{Contents}

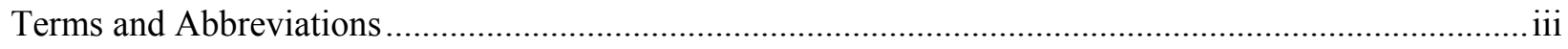

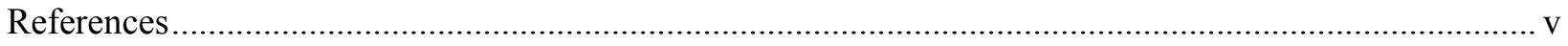

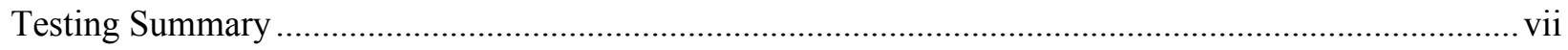

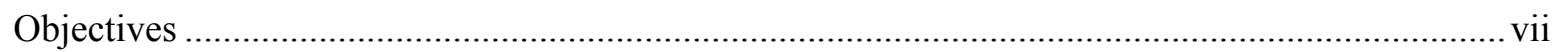

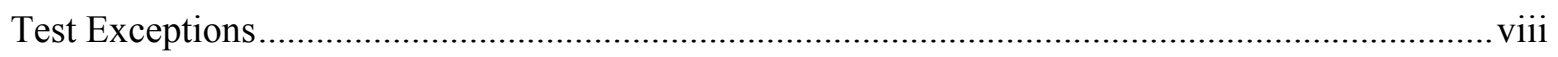

Results and Performance Against Success Criteria ................................................................... viii

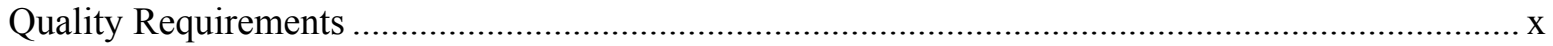

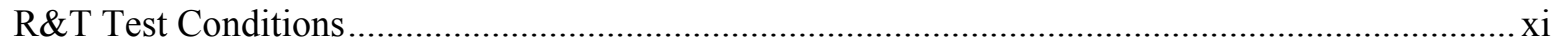

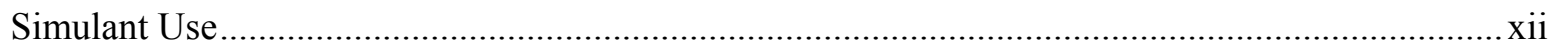

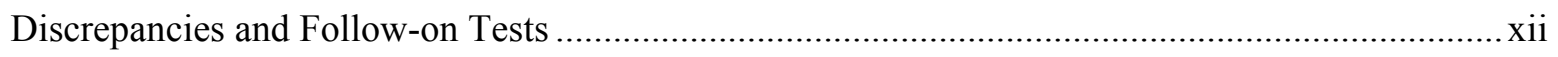

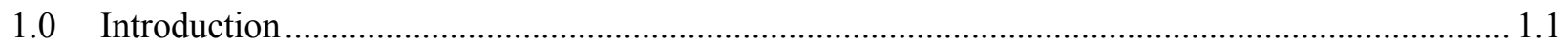

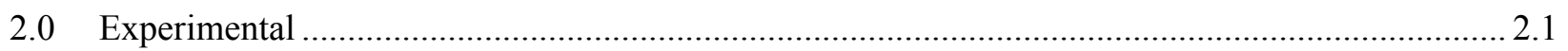

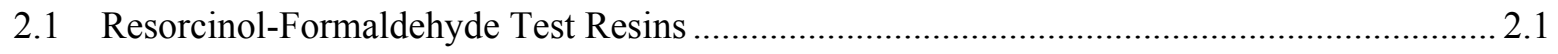

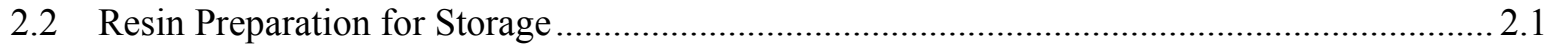

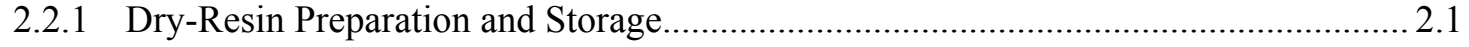

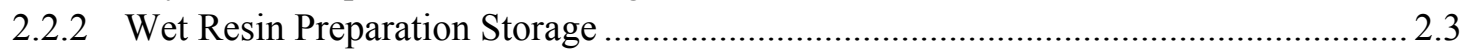

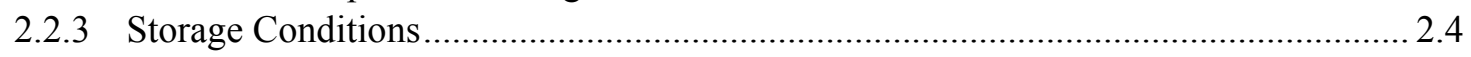

2.3 Test Resin Selection for Ion Exchange Processing ….................................................... 2.5

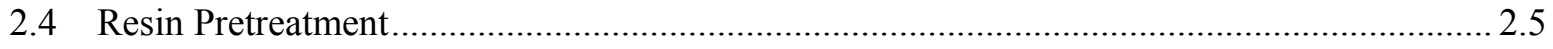

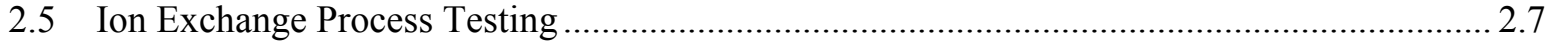

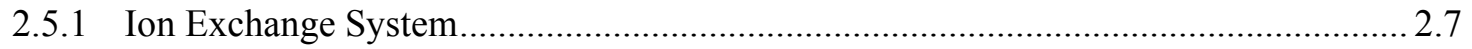

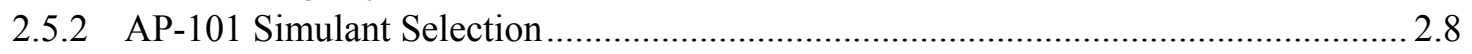

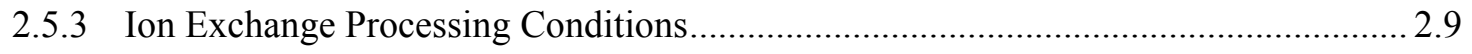

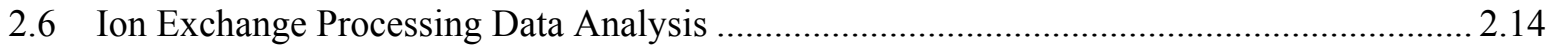

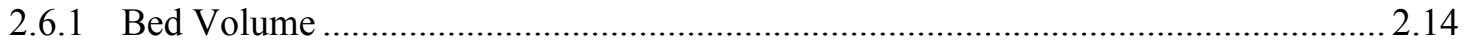

2.6.2 Resin Mass in Column ...................................................................................... 2.14

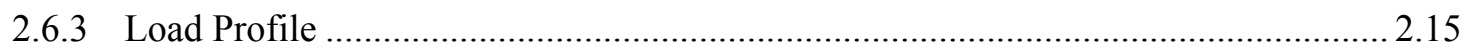

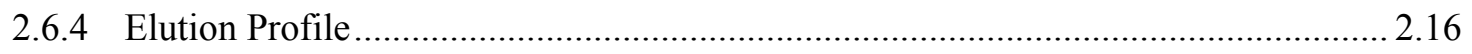

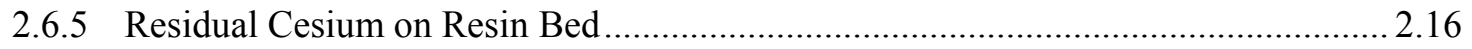

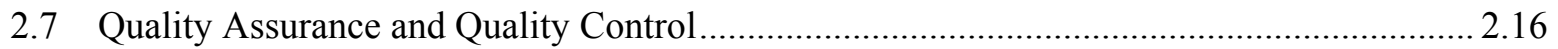

2.7.1 Application of WTPSP Quality Assurance Requirements...................................... 2.16

2.7.2 Conduct of Experimental and Analytical Work................................................... 2.17

2.7.3 Internal Data Verification and Validation.............................................................. 2.18 


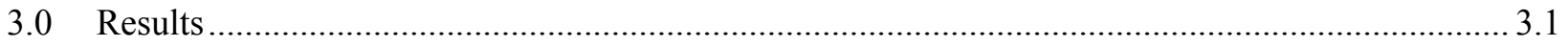

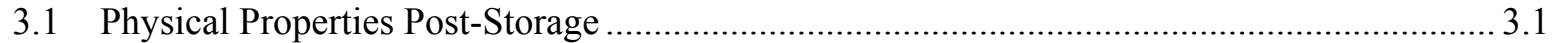

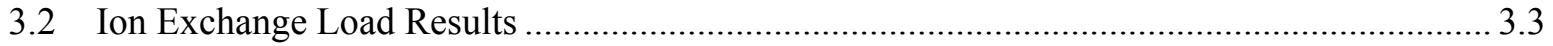

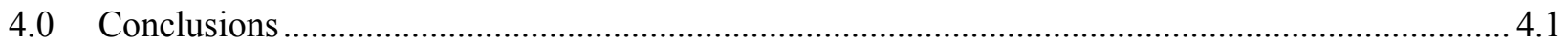

Appendix A: Direction for Resin Testing from the BNI R\&T Lead .................................................. A.1

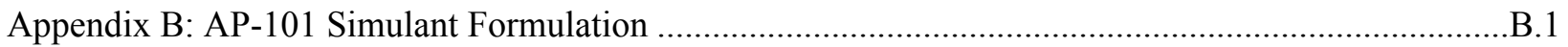

Appendix C: Photographs of Retrieved Resins Following Storage ....................................................... 1 


\section{Figures}

S.1. Effects from Various Storage Conditions Demonstrated by Cs Ion Exchange Loading Performance Using AP-101 Simulant Feed (a) Resin Lot 5J-370/686, Stored Wet and Dry at Ambient and $45^{\circ} \mathrm{C}$ and (b) Resin Lot $6 \mathrm{C}-370 / 745$, Stored Wet at Ambient, 35 and $45^{\circ} \mathrm{C}$ ix

2.1. Resin Storage Chambers (Left to Right: $45^{\circ} \mathrm{C}, 35^{\circ} \mathrm{C}$, Ambient) ................................................ 2.4

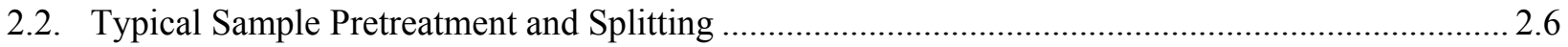

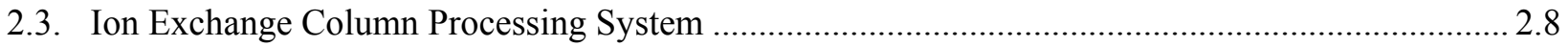

2.4. In-Column Pretreatment Processing (a) Green Column (MB 6C-370/745 stored wet at $35^{\circ} \mathrm{C}$ ) During H-Form Conversion and (b) White Column (MB 6C-370/745 stored wet at ambient temperature) During Na-Form Conversion............................................................................ 2.13

3.1. Microbeads Spherical RF Resin Lot 6C-370/745 Cesium Breakthrough Profiles After One Year Storage and Aging at Three Temperatures.......................................................................... 3.3

3.2. Microbeads Spherical RF Lot number 5J-370/686 Cesium Breakthrough Profiles After One Year Storage and Aging at Two Temperatures

3.3. Microbeads Spherical RF Lot Number 5J-370/686 Cesium Breakthrough Profiles After One Year Storage and Aging in Wet and Dry Condition at $45^{\circ} \mathrm{C}$

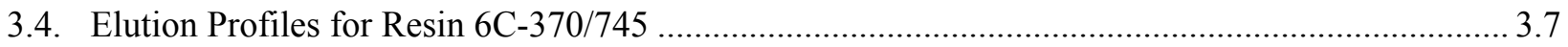

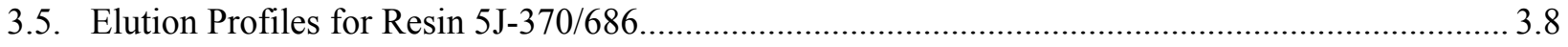

3.6. Residual Cs Concentration on Resin 6C-370/745 as a Function of Elution Volume ......................3.9

3.7. Residual Cs Concentration on Resin 5J-370/686 as a Function of Elution Volume ....................... 3.9

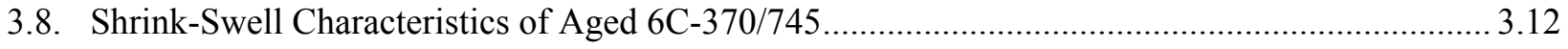

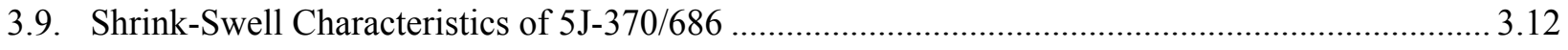




\section{Tables}

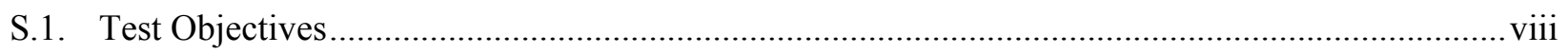

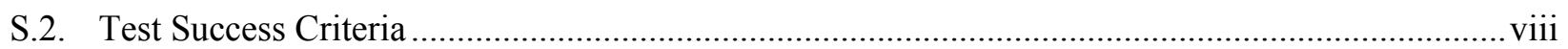

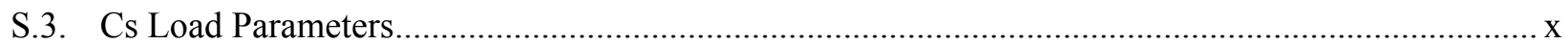

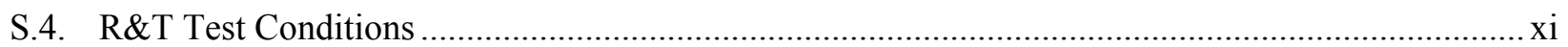

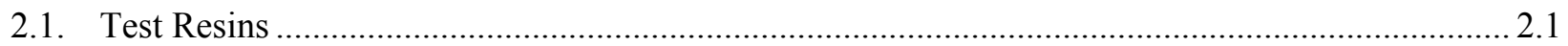

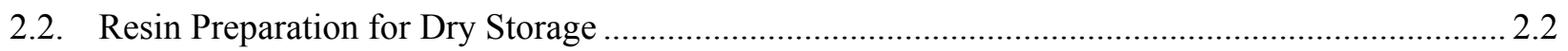

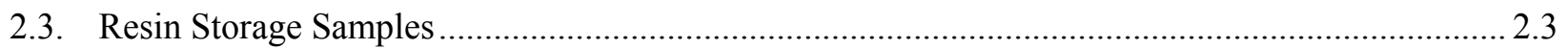

2.4. Selected Resins for Ion Exchange Processing ...................................................................... 2.5

2.5. AP-101 Stock 2 (Lot \#144254/1.1) Simulant Composition-Major Analytes ............................... 2.9

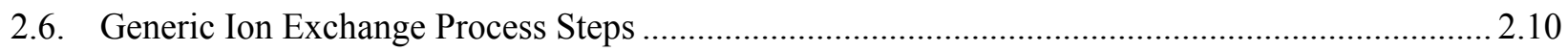

2.7. Experimental Conditions for Microbeads Lot 6C-370-744 Stored Wet at Ambient

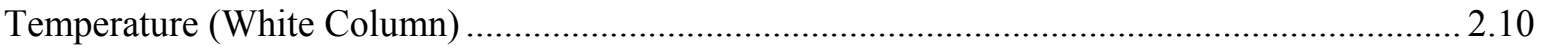

2.8. Experimental Conditions for Microbeads Lot $6 \mathrm{C}-370-744$ Stored Wet at $35^{\circ} \mathrm{C}$

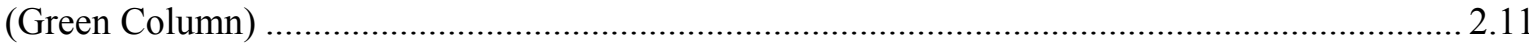

2.9. Experimental Conditions for Microbeads Lot $6 \mathrm{C}-370-744$ Stored Wet at $45^{\circ} \mathrm{C}$

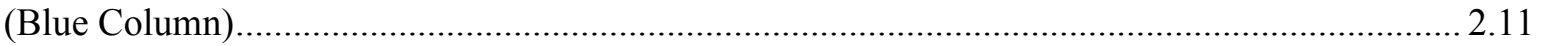

2.10. Experimental Conditions for Microbeads Lot 5J-370-686 Stored Wet at Ambient

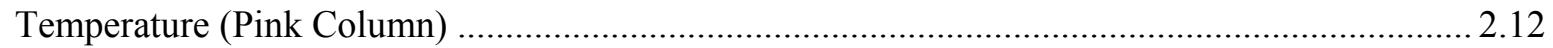

2.11. Experimental Conditions for Microbeads Lot 5J-370-686 Stored Wet at $45^{\circ} \mathrm{C}$ (Red Column)

2.12. Experimental Conditions for Microbeads Lot 5J-370-686 Stored Dry at $45^{\circ} \mathrm{C}$ (Yellow Column)

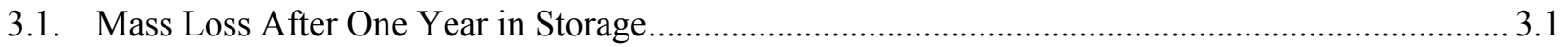

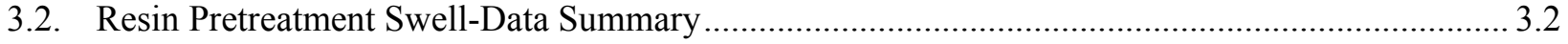

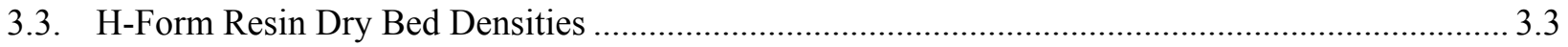

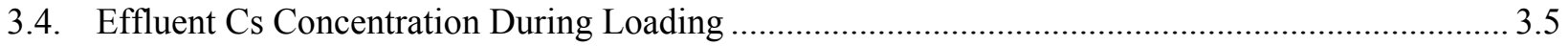

3.5. Cs Loading Parameters for Resin Lot MB 6C-370/745 ......................................................... 3.6 


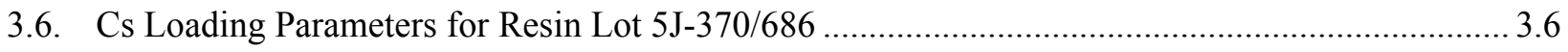

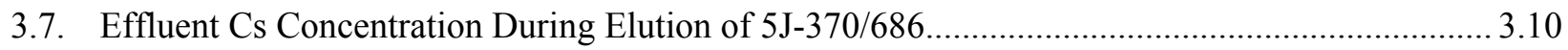

3.8. Effluent Cs Concentration During Elution of 6C-370/745 …............................................... 3.11

3.9. Actual Resin Volume as a Function of Feed Matrix ................................................................. 3.13 


\section{Terms and Abbreviations}

\begin{tabular}{|c|c|}
\hline AP-101 & AP-101 tank waste simulant diluted to $5 \mathrm{M} \mathrm{Na}$ \\
\hline ASR & analytical services request \\
\hline ASTM & American Society for Testing and Materials \\
\hline AV & apparatus volume \\
\hline $\mathrm{BNI}$ & Bechtel National, Inc. \\
\hline BSC & Boulder Scientific Corporation \\
\hline BT & breakthrough \\
\hline BV & bed volume \\
\hline $\mathrm{DF}$ & decontamination factor \\
\hline DI & deionized (water) \\
\hline DOE & U.S. Department of Energy \\
\hline EDI & water rinse following elution \\
\hline FD & feed displacement \\
\hline FDI & water rinse following feed displacement \\
\hline FMI & Fluid Metering, Inc., Syosset, NY \\
\hline GEA & gamma energy analysis \\
\hline HLW & high-level waste \\
\hline IBC & IBC Advanced Technologies, Inc., American Fork, Utah \\
\hline LAW & low-activity waste \\
\hline MB & Microbeads \\
\hline M\&TE & measuring and test equipment \\
\hline ORP & Office of River Protection (DOE) \\
\hline PNNL & Pacific Northwest National Laboratory \\
\hline PNWD & Battelle-Pacific Northwest Division \\
\hline QA & quality assurance \\
\hline QAM & Quality Assurance Manual \\
\hline QAPjP & Quality Assurance Project Plan \\
\hline QARD & Quality Assurance Requirements and Descriptions \\
\hline QC & quality control \\
\hline RF & resorcinol-formaldehyde \\
\hline
\end{tabular}




$\begin{array}{ll}\text { RPD } & \text { relative percent difference } \\ \text { RPP-WTP } & \text { River Protection Project-Waste Treatment and Immobilization Plant } \\ \text { RPL } & \text { Radiochemical Processing Laboratory (PNNL facility) } \\ \text { R\&T } & \text { research and technology } \\ \text { RTD } & \text { resistance temperature detector } \\ \text { RV } & \text { resin volume } \\ \text { SRTC } & \text { Savannah River Technology Center } \\ \text { T } & \text { temperature } \\ \text { TSS } & \text { technical scoping statement } \\ \text { WTP } & \text { Hanford Tank Waste Treatment and Immobilization Plant } \\ \text { WTPSP } & \text { Waste Treatment Plant Support Project }\end{array}$

\section{Terms of Measurement}

$\begin{array}{ll}\mu \mathrm{Ci} & \text { microcurie } \\ \mu \mathrm{g} & \text { microgram } \\ \mathrm{C} / \mathrm{C}_{\mathrm{o}} & \text { analyte concentration in column effluent divided by analyte concentration in feed } \\ \text { F-factor } & \text { ratio of dry resin mass to wet resin mass } \\ \mathrm{g} & \text { gram } \\ \mathrm{h} & \text { hour } \\ \mathrm{M} & \text { molarity } \\ \mathrm{mL} & \text { milliliter } \\ \mathrm{psi} & \text { pounds per square inch }\end{array}$




\section{References}

Arm, ST, DL Blanchard, DR Weier. 2004. Aging Effects of Stored SuperLig ${ }^{\circledR} 644$ Ion Exchange Resin. PNWD-3389, Battelle-Pacific Northwest Division, Richland, WA.

Bray LA, KJ Carson, RJ Elovich, CK Carlson, JR DesChane, and DE Kurath. 1996. Initial Evaluation of Two Organic Resins and Their Ion Exchange Column Performance for the Recovery of Cesium from Hanford Alkaline Wastes. PNNL-11124, Pacific Northwest National Laboratory, Richland WA.

Brown GN, RJ Elovich, and LA Bray. 1995a. Evaluations and Comparison of SuperLig ${ }^{\circledR ~ 644, ~}$ Resorcinol-Formaldehyde and CS-100 Ion Exchange Materials for the Removal of Cesium from Simulated Alkaline Supernate. PNL-10486, Pacific Northwest Laboratory, Richland WA.

Brown GA, SR Adami, LA Bray, SA Bryan, CD Carlson, KJ Carson, JR DesChane, RJ Elovich, SJ Forbes, JA Franz, JC Linehan, WJ Shaw, PK Tanaka, and MR Telander. 1995b. Chemical and Radiation Stability of SuperLig ${ }^{\circledR}$ 644, Resorcinol-Formaldehyde, and CS-100 Cesium Ion Exchange Materials. PNL-10772, Pacific Northwest Laboratory, Richland, WA.

Buckingham JS. 1967. Waste Management Technical Manual. ISO-100 DEL, Hanford Atomic Products Operation, Richland, WA.

Fiskum SK, DL Blanchard, and ST Arm. 2005. "Cesium Removal from Simulated and Actual Hanford Tank Waste Using Ion Exchange.” Separation Science and Technology 40(1):51-67.

Fiskum SK, BS Augspurger, KP Brooks, WC Buchmiller, RL Russell, MJ Schweiger, LA Snow, MJ Steele, KK Thomas, DE Wallace, NH Wong, JD Yeager, and DL Blanchard, Jr. 2004. Comparison Testing of Multiple Resorcinol-Formaldehyde Resins for the River Protection Project-Waste Treatment Plant. PNWD-3387, Rev. 0, Battelle-Pacific Northwest Division, Richland, WA.

Fiskum SK, ST Arm, WC Buchmiller, T Trang-Le, JE Martinez, J Matyas, MJ Steele, KK Thomas, DL Blanchard, Jr. 2006. Comparison Testing of Multiple Spherical Resorcinol-Formaldehyde Resins for the River Protection Project-Waste Treatment Plant. RPT-WTP-143, Battelle_Pacific Northwest Division, Richland, WA.

Hassan NM, and K Adu-Wusu. 2005. "Cesium Removal from Hanford Tank Waste Solution Using Resorcinol-Formaldehyde Resin.” Solvent Extraction and Ion Exchange 23(3):375-389.

Helfferich F. 1962. Ion Exchange. McGraw-Hill Book Company, New York.

Russell RL, SK Fiskum, LK Jagoda, and AP Poloski. 2003. AP-101 Diluted Feed (Envelope A) Simulant Development Report. PNWD-3248, Battelle-Pacific Northwest Division, Richland, WA. 



\section{Testing Summary}

Bechtel National, Inc. (BNI) is evaluating the alternate Cs ion exchange resin, spherical resorcinolformaldehyde (RF), for use in the River Protection Project-Waste Treatment Plant (RPP-WTP). ${ }^{\text {(a) }}$ Previous test activities with spherical RF indicate that it has adequate capacity, selectivity, and kinetics to perform in the plant according to the flowsheet needs. It appears to have better elution and hydraulic properties than the existing alternatives: ground-gel RF and SuperLig ${ }^{\circledR} 644$ (SL-644). ${ }^{\text {(b) }}$ To date, the spherical RF performance testing has been conducted on freshly manufactured resin (within $\sim 2$ months of manufacture).

The ion exchange resins will be subjected to a storage interval defined as the time from resin manufacture to its use at the WTP. Changes in the resin properties during storage could reduce the capacity of the resin to remove $\mathrm{Cs}$ from low-activity waste solutions. Active sites on organic SL-644 resin have been shown to degrade during storage (Arm et al. 2004). Additional testing was needed to study the effects of storage conditions and aging on spherical RF ion exchange performance. Variables that could have a significant impact on ion exchange resins during storage include storage temperature, medium, and time.

Battelle-Pacific Northwest Division (PNWD) was contracted to test the effects of various storage conditions on spherical RF resin. Data obtained from the testing will be used by the WTP operations to provide direction for suitable storage conditions and manage the spherical RF resin stock. Storage test conditions included wet and dry resin configurations under nitrogen at three temperatures.

Work was initially conducted under contract number 24590-101-TSA-W000-00004 satisfying the needs defined in Appendix C of the Research and Technology Plan ${ }^{(\mathrm{c})}$ TSS A-219 to evaluate the impact of storage conditions on RF resin performance. In February 2007, the contract mechanism was switched to Pacific Northwest National Laboratory (PNNL) Operating Contract DE-AC05-76RL01830.

\section{Objectives}

The test objective and discussion are provided in Table S.1.

(a) R Peterson, H Babad, L Bray, J Carlson, F Dunn, A Pajunen, I Papp, and J Watson. 2002. WTP Pretreatment Alternative Resin Selection, 24590-PTF-RPT-RT-02-001, Rev. 0, Bechtel National, Inc., Richland, WA.

(b) SL-644 is solely available through IBC Advanced Technologies, Inc., American Fork, UT.

(c) S Barnes, R Roosa, and R Peterson. 2003. Research and Technology Plan, 24590-WTP-PL-RT-01-002, Rev. 2, Bechtel National, Inc., Richland, WA. 
Table S.1. Test Objectives

\begin{tabular}{|l|l|l||}
\hline Test Objective & Objective Met? & Discussion \\
\hline $\begin{array}{l}\text { Provide test data showing } \\
\text { how spherical RF resin Cs } \\
\text { ion exchange performance } \\
\text { changes with storage } \\
\text { temperature (ambient, 35, } \\
\left.\text { and } 45^{\circ} \mathrm{C}\right), \text { medium (wet or } \\
\text { dry), and age (12 months). }\end{array}$ & $\begin{array}{l}\text { Yesins from three RF production lots were sub-sampled } \\
\text { and split for testing. One large-volume set was dried to } \\
\text { free-flowing under nitrogen gas flow. The wet and dried } \\
\text { resins were packaged and placed in one of three } \\
\text { environmentally controlled chambers at ambient, 35, and } \\
45^{\circ} \mathrm{C} \text { for 1 year. }\end{array}$ \\
& $\begin{array}{l}\text { A subset of six test resins was selected for column testing } \\
\text { where Cs loading and elution performance data were } \\
\text { collected. The Cs was traced with }{ }^{137} \mathrm{Cs} \text { at } \sim 0.15 \mu \mathrm{Ci} / \mathrm{mL} \\
\text { such that a decontamination factor of } \geq 50,000 \text { could be } \\
\text { discerned. Test results are summarized in Section } 3.0 .\end{array}$ \\
\hline
\end{tabular}

\section{Test Exceptions}

No test exceptions were applied to the test scope.

\section{Results and Performance Against Success Criteria}

The test success criteria are listed in Table S.2.

Table S.2. Test Success Criteria

\section{Success Criteria}

Data supplied supporting the selection of a spherical RF storage condition relative to time, temperature, and medium.

\section{Explanation}

Samples from three different spherical RF resin lots were stored in the as-received (i.e., no preconditioning) $\mathrm{H}$-form both dry and wet, at ambient, 35 , and $45^{\circ} \mathrm{C}$, for 1 year under nitrogen gas.

After storage, the relative Cs load and elution performances of six selected test resins were compared to the pre-storage condition previously reported by Fiskum et al. (2006). Comparison of relative $\mathrm{Cs}$ ion exchange performance reductions allows the research and technology (R\&T) lead to select appropriate storage conditions for spherical RF.

Results of Cs loading profiles from six stored resin samples are summarized in Figure S.1. A tabular summary comparison of initial versus aged resin is provided in Table S.3. There was no significant reduction in Cs loading performance or resin capacity as a result of aging for 1 year at up to $45^{\circ} \mathrm{C}$. In fact, the increased storage temperature effectively improved Cs exchange performance, most probably driven by increased resin cross-linking. The wet versus dry storage form at $45^{\circ} \mathrm{C}$ resulted in no significant differences in Cs loading characteristics. Two resin lots were evaluated with similar results. 
(a)

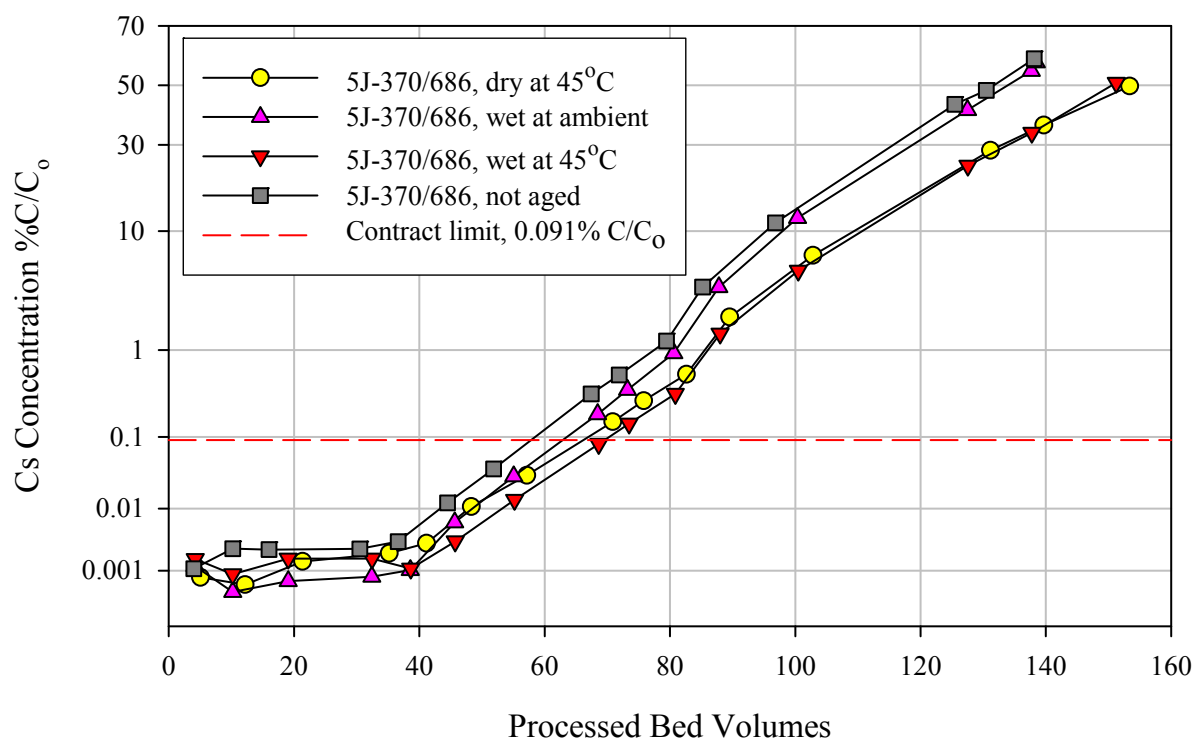

(b)

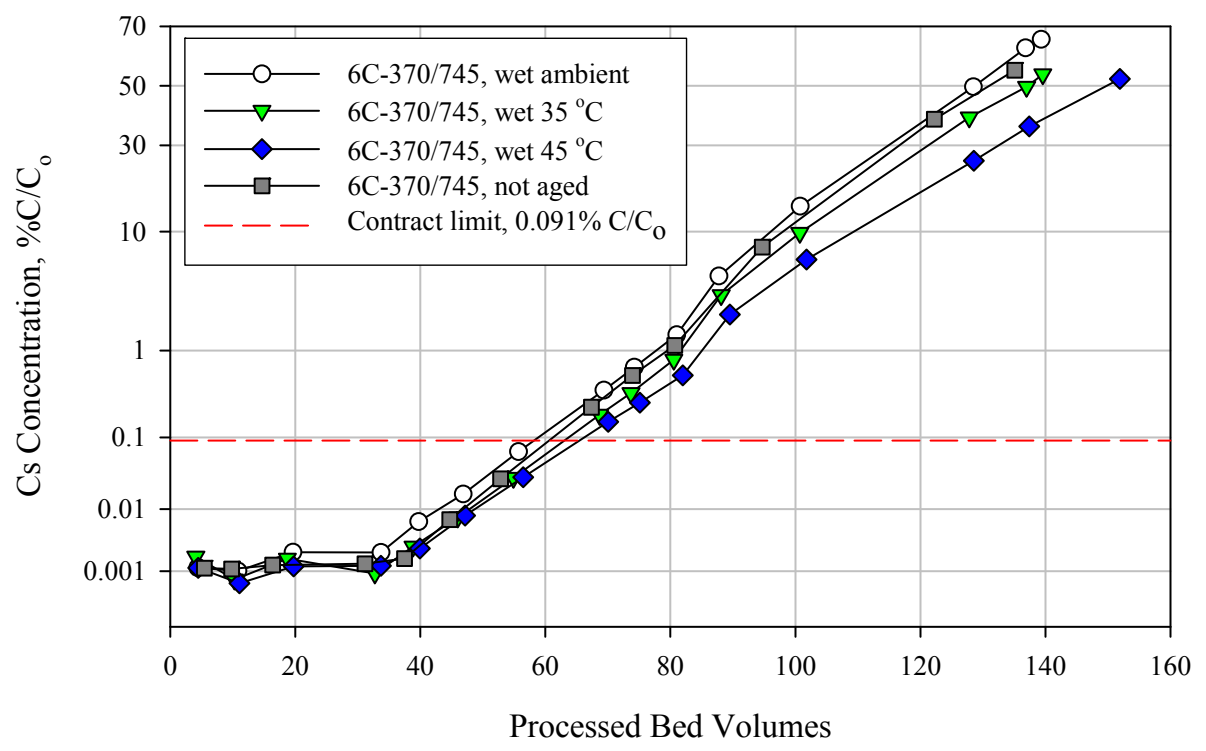

Figure S.1. Effects from Various Storage Conditions Demonstrated by Cs Ion Exchange Loading Performance Using AP-101 Simulant Feed (a) Resin Lot 5J-370/686, Stored Wet and Dry at Ambient and $45^{\circ} \mathrm{C}$ and (b) Resin Lot $6 \mathrm{C}-370 / 745$, Stored Wet at Ambient, 35 and $45^{\circ} \mathrm{C}$

Process Parameter

Simulant

Flowrate

Process temperature

$\mathrm{Na}$ concentration

$\mathrm{K}$ concentration

Cs concentration
Process Conditions

AP-101

$1.5 \mathrm{BV} / \mathrm{h}$ (0 to $80 \mathrm{BVs}), 3 \mathrm{BV} / \mathrm{h}$ (>80 BVs)

19 to $24^{\circ} \mathrm{C}$

$4.89 \mathrm{M}$

$0.679 \mathrm{M}$

$5.86 \mathrm{mg} / \mathrm{L}$ 
Table S.3. Cs Loading Parameters

\begin{tabular}{|c|c|c|c|c|}
\hline \multirow{2}{*}{$\begin{array}{l}\text { Parameter } \\
\text { Microbeads Lot 6C-370/745 }\end{array}$} & \multirow[b]{2}{*}{ Un-aged } & \multicolumn{3}{|c|}{ Aged } \\
\hline & & Wet at $\sim 22^{\circ} \mathrm{C}$ & Wet at $35^{\circ} \mathrm{C}$ & Wet at $45^{\circ} \mathrm{C}$ \\
\hline Cs breakthrough onset, BV & 37 & 34 & 37 & 37 \\
\hline Cs contract limit breakthrough, BV & 61 & 58 & 63 & 65 \\
\hline $50 \%$ Cs breakthrough, BV & 131 & 129 & 137 & 150 \\
\hline \multirow[t]{2}{*}{ Change in $50 \%$ Cs breakthrough } & -- & $-1.5 \%$ & $+4.6 \%$ & $+15 \%$ \\
\hline & & \multicolumn{3}{|c|}{ Aged } \\
\hline Microbeads Lot 5J-370/686 & Un-aged & Wet at $\sim 22^{\circ} \mathrm{C}$ & Wet at $45^{\circ} \mathrm{C}$ & Dry at $45^{\circ} \mathrm{C}$ \\
\hline Cs breakthrough onset, BV & $35-40$ & 40 & 40 & 40 \\
\hline Cs contract limit breakthrough, BV & 58 & 63 & 70 & 66 \\
\hline $50 \%$ Cs breakthrough, BV & 132 & 134 & 150 & 154 \\
\hline Change in $50 \%$ Cs breakthrough & -- & $+1.5 \%$ & $+14 \%$ & $+17 \%$ \\
\hline
\end{tabular}

Elution was slightly slower for the resins stored at higher temperatures than those stored at ambient temperature. However, in all cases, the residual Cs concentrations on the resin beds following elution were $\leq 0.4 \mu \mathrm{g} / \mathrm{g}$ dry H-form resin. Physical properties (resin bed density and shrink-swell characteristics) of the aged resins were similar to those of the fresh or un-aged resins.

\section{Quality Requirements}

The data represented in this report will refer to PNWD (in support of Bechtel National, Inc. Support Project [BNI-SP] before February 12, 2007) or PNNL (in support of Waste Treatment Plant Support Program [WTPSP] following February 12, 2007). Work was performed for both of these projects to the same QA program.

PNNL implemented the RPP-WTP quality requirements by performing work in accordance with the River Protection Project - Waste Treatment Plant Support Program (RPP-WTP) Quality Assurance Plan (RPP-WTP-QA-001, QAP). Work was performed to the quality requirements of NQA-1-1989 Part I, Basic and Supplementary Requirements, NQA-2a-1990, Part 2.7, and DOE/RW-0333P, Rev 13, Quality Assurance Requirements and Descriptions (QARD). These quality requirements were implemented through the River Protection Project - Waste Treatment Plant Support Program (RPP-WTP) Quality Assurance Manual (RPP-WTP-QA-003, QAM). The quality assurance requirements of DOE/RW-0333P, Rev 13, Quality Assurance Requirements and Descriptions (QARD) and DOE Order 414.1C were not identified as a requirement for this work in the test specification.

PNNL addressed internal verification and validation activities by conducting an Independent Technical Review of the final data report in accordance with PNNL's procedure QA-RPP-WTP-604, part of PNNL's RPP-WTP Quality Assurance Manual. This review verified that the reported results were traceable, inferences and conclusions were soundly based, and the reported work satisfied the Test Plan objectives. 


\section{R\&T Test Conditions}

Table S.4 summarizes the various R\&T test conditions and briefly discusses how the test condition was followed.

Table S.4. R\&T Test Conditions

\begin{tabular}{|c|c|}
\hline R\&T Test Condition & Were Test Condition(s) Followed? \\
\hline Sub-sampling & $\begin{array}{l}\text { Yes. Three lots of resins (Microbeads } 5 \mathrm{~J}-370 / 686 \text {, Microbeads } 6 \mathrm{C}-370 / 745 \text {, } \\
\text { and BSC } 3380-3-0200 \text { ) were sub-sampled using the coring technique in } \\
\text { suitable volumes for follow-on testing. }\end{array}$ \\
\hline Prepare Wet RF Resin & $\begin{array}{l}\text { Yes. Wet resins were placed in suitably sized vials or bottles (dependent on } \\
\text { the volume tested). Headspace was filled with water leaving a nominal } 10 \% \\
\text { gaseous headspace. Fluid was de-oxygenated by passing nitrogen gas } \\
\text { through the sample. Sample vials and bottles were overpacked into a plastic } \\
\text { sleeve that was flushed with nitrogen then sealed. }\end{array}$ \\
\hline Prepare Dry RF Resin & $\begin{array}{l}\text { Yes. Large aliquots of wet as-received resin were dried assisted with a } \\
\text { nitrogen gas flush. The dried resin was mixed and aliquoted for testing into } \\
\text { glass vials. F-factor analysis of the starting materials showed that the } \\
\text { residual water content was } \sim 20 \text { weight percent (F-facter } \sim 0.8 \text { ). Interstitial } \\
\text { oxygen was flushed from each resin sample with nitrogen gas. The vials } \\
\text { were overpacked into plastic sleeves that were in turn flushed with nitrogen } \\
\text { and sealed. }\end{array}$ \\
\hline Store Resins & $\begin{array}{l}\text { Yes. Resins samples were transferred into one of three storage chambers: } \\
\text { ambient, } 35^{\circ} \mathrm{C} \text {, and } 45^{\circ} \mathrm{C} \text {. Chambers were evacuated and then backfilled to } \\
3 \text { psig with nitrogen gas. The temperature and pressure were monitored for } \\
1 \text { year. }\end{array}$ \\
\hline $\begin{array}{l}\text { Select Resins for Ion } \\
\text { Exchange Performance }\end{array}$ & $\begin{array}{l}\text { Yes. Resins were selected in consultation with the R\&T contact. The } \\
\text { following resins were selected for testing: } \\
\text { 1. Resin } 6 \mathrm{C}-370 / 745 \text { (same as labeled as MB lot } 6 \mathrm{C}-370 / 744 \text { in the test } \\
\text { plan): stored for } 1 \text { year submerged in water at } 45^{\circ} \mathrm{C} \text {. } \\
\text { 2. Resin } 6 \mathrm{C}-370 / 745 \text { : stored for } 1 \text { year submerged in water at } 35^{\circ} \mathrm{C} \text {. } \\
\text { 3. Resin } 6 \mathrm{C}-370 / 745 \text { : stored for } 1 \text { year submerged in water at } 22^{\circ} \mathrm{C} \text {. } \\
\text { 4. Resin } 5 \mathrm{~J}-370 / 686 \text { : stored for } 1 \text { year submerged in water at } 45^{\circ} \mathrm{C} \text {. } \\
\text { 5. Resin } 5 \mathrm{~J}-370 / 686 \text { : stored for } 1 \text { year submerged in water at } 22^{\circ} \mathrm{C} \text {. } \\
\text { 6. Resin } 5 \mathrm{~J}-370 / 686 \text { : stored for } 1 \text { year dry at } 45^{\circ} \mathrm{C} \text {. }\end{array}$ \\
\hline $\begin{array}{l}\text { Test Ion Exchange } \\
\text { Performance }\end{array}$ & $\begin{array}{l}\text { Yes. The loading and elution testing was conducted according to the process } \\
\text { conditions defined in the test plan, Table } 2 \text {. Cesium ion exchange load and } \\
\text { elution characteristics were tested downflow in a single-column format. } \\
\text { Resin BVs were nominally } 20 \text {-mL in a } 2-\mathrm{cm} \text { ID glass column with a nominal } \\
\text { length-to-diameter ratio of } 3 \text { when the resin was in the Na-form. Testing was } \\
\text { conducted with the AP-101 simulant. All feeds were spiked with }{ }^{137} \mathrm{Cs} \text { tracer } \\
\text { to allow for rapid determination of Cs concentration by gamma energy } \\
\text { analysis (GEA). Load and elution processing was conducted according to } \\
\text { nominal plant design and throughput. The AP-101 simulant was loaded at } \\
1.5 \mathrm{BV} / \mathrm{h} \text {; after processing } \sim 80 \mathrm{BVs} \text {, the flow rate for AP- } 101 \text { was increased } \\
\text { to } 3.0 \mathrm{BV/h} \text {. Elution was conducted at } 1.4 \mathrm{BV} / \mathrm{h} \text {. After elution and water } \\
\text { rinse, the column assemblies (resin bed plus glassware) were counted directly } \\
\text { by GEA to evaluate residual Cs content on the resin. The individual steps are } \\
\text { too numerous to describe in this summary; see the experimental section. }\end{array}$ \\
\hline
\end{tabular}




\section{Simulant Use}

Because of inherent problems with obtaining and handling radioactive tank wastes, tank waste simulant was used for column testing. A simulant solution of Envelope A waste Tank AP-101 supernatant was previously developed (Russell et al. 2003) and was used for the testing described here.

The use of simulants for this testing scope provided an adequate basis for resin performance comparisons. The use of actual tank wastes was not necessary to evaluate relative effects of storage and aging conditions in resin performance. All test data described in this report, as well as comparison data of un-aged materials, were associated with one production lot of simulant AP-101 to allow easy cross comparisons.

\section{Discrepancies and Follow-on Tests}

None. 


\subsection{Introduction}

Bechtel National Inc. (BNI) is constructing the Waste Treatment and Immobilization Plant (WTP) for the Department of Energy Office of River Protection (DOE-ORP) in southeast Washington at the Hanford Site. ${ }^{\text {(a) }}$ The WTP will contain three main facilities: a pretreatment facility, a low-activity waste (LAW) vitrification facility, and a high-level waste (HLW) vitrification facility. Pretreatment operations will include the separation of ${ }^{137} \mathrm{Cs}$ and (in some cases) transuranic materials from the large volume and mass of non-radioactive components (such as sodium, nitrate, sulfate, phosphate, carbonate, etc.). Thus, a large fraction of the waste volume, although still radiologically contaminated, can be handled and disposed of as LAW. The remaining volume and mass of HLW, which requires an exceedingly more expensive disposal pathway in a geologic repository, will be dramatically reduced relative to the input volume.

The ${ }^{137} \mathrm{Cs}$ separation unit operation in the pretreatment plant incorporates ion exchange. Cesium ion exchange operations have been successfully demonstrated using SuperLig ${ }^{\circledR}-644^{(\mathrm{b})}$ (SL-644) (Fiskum et al. 2005) and resorcinol-formaldehyde (RF) (Brown et al. 1995a; Bray et al. 1996; Fiskum et al. 2004; Hassan and Adu-Wusu 2005) on small-scale column studies with simulated and actual Hanford tank wastes. Both ion exchange products are prepared from condensation polymerization (yielding K-functionalized exchange sites) and physically ground and screened to a pre-selected particle mesh size. Both resins are elutable and can be regenerated for repeated use.

Microbeads (Skedsmokorset, Norway) patented a process to prepare RF resin in a size-engineered spherical bead form using an acid-catalyzed process. The spherical resin form is desirable because of the superior hydraulic performance in large-scale columns ${ }^{(\mathrm{c})}$ relative to the granular material SL-644. Scaleup manufacturing of spherical-form RF resin in large-scale (60-gal) production lots with tight particle size distribution and reproducible Cs ion exchange performance qualities was recently reported (Fiskum 2006). ${ }^{(\mathrm{d})}$

Several factors associated with resin storage conditions may lead to resin performance degradation. These include storage time, temperature, resin form, and media (wet versus dry and inert versus oxygenated environment). Specific effects on resin performance depend on the resin chemical composition and the synergistic effects of the storage conditions. The SL-644 and RF resins have been shown to be susceptible to oxidative attack (Brown et al. 1995b; Fiskum et al. 2006). A 6-month storage and aging study conducted with SL-644 (Arm et al. 2004) determined that the best storage conditions were in the acid form, submerged under water at $22^{\circ} \mathrm{C}$ and under inert cover gas. Under these conditions, the SL-644 Cs capacity dropped $36 \%$ after a 6 -month storage time.

(a) The Hanford Site was the location of plutonium production supporting the U.S. nuclear defense arsenal from 1942 through 1980. Currently, the site contains 177 underground storage tanks holding about 54 million gallons of Pu production byproduct waste. The tank waste is composed of complex mixtures of inorganic and organic salts dominated by sodium, nitrate, nitrite, sulfate, and phosphate. The tank waste is contaminated with fission and activation products. Manipulation of any significant volume requires remote-handling operations due largely to the high ${ }^{137} \mathrm{Cs}$ and ${ }^{90} \mathrm{Sr}$ concentrations.

(b) SL-644 is a proprietary formulation manufactured by IBC Advanced Technologies, American Fork, UT. It is prepared in a granular form.

(c) The WTP designed columns of nominal 415- to 600-gal capacity with a 55-in. diameter.

(d) Spherical RF resin was produced by Microbeads (Skedsmokorset, Norway) under proprietary conditions. 
A study was required for the spherical RF resin to better understand the extent of reduced performance as a result of storage and aging conditions. Contributions from oxidative attack were eliminated from the study by using an inert blanket over the test specimens. Only the acid-form (i.e., the form received from the production process) of the resin was evaluated. Three temperature variables (ambient, 35, and $45^{\circ} \mathrm{C}$ ), two media (wet and dry), and one cover gas (nitrogen) were tested. The storage duration was bounded at 12 months.

In 2006, Battelle-Pacific Northwest Division (PNWD) was contracted to provide data to evaluate the various spherical RF resin storage conditions according to Technical Scoping Statement TSS-A-219 under contract number 24590-101-TSA-W000-00004. In February 2007, the contract mechanism was switched to the operating contract of the Pacific Northwest National Laboratory (PNNL), DE-AC0576RL01830. The objectives of this work were to provide data to BNI for their use in determining the appropriate storage conditions for spherical RF. All work was conducted according to Test Specification 24590-PTF-TSP-RT-06-0001, Rev. 0, ${ }^{(a)}$ Test Plan TP-RPP-WTP-440, Rev. 0. ${ }^{\text {(b) }}$

(a) MR Thorson. March 2006. Storage and Aging of Spherical Resorcinol Formaldehyde Resin. 24590-PTF-TSPRT-06-0001, Rev. 0, River Protection Project-Waste Treatment Plant, Bechtel National Inc., Richland, WA.

(b) JJ Toth. April 2006. Consequences of Storage and Aging Conditions of Spherical Resorcinol-Formaldehyde Resin Performance. Rev. 0., Battelle-Pacific Northwest Division, Richland, WA. 


\subsection{Experimental}

This section describes the test resins, subsampling and preparation for storage, storage conditions, and post storage ion exchange test conditions. All raw data generated in support of this testing are maintained in the project files at PNNL under Project 53017 records inventory and disposition system.

\subsection{Resorcinol-Formaldehyde Test Resins}

Three spherical RF resins were selected for the storage and aging tests. The resins were manufactured by Microbeads (Skedsmokorset, Norway) and Boulder Scientific Corporation (BSC, Mead, $\mathrm{CO}$ ) in nominal 60-gal production lots. ${ }^{\text {(a) }}$ The resin manufacturer, lot number, and manufacture date are cross-referenced in Table 2.1. Resins were subsampled on 5/11/06 to prepare for the storage condition. The resin storage between production and sampling for the aging test varied from 1 to 8 months. The resins were stored wet, as-received, at ambient temperature, with a nitrogen cover gas during this interim. The results of this test indicated that this initial storage interim would not be expected to adversely affect resin performance or the experimental conclusions.

Table 2.1. Test Resins

\begin{tabular}{||l|l|c|c||}
\hline \hline Manufacturer & Lot Number & Production Date & Interim Storage $^{(a)}$ \\
\hline Microbeads & $5 \mathrm{~J}-370 / 686$ & $9 / 05$ & 8 months \\
\cline { 2 - 4 } & $6 \mathrm{C}-370 / 745$ & $4 / 06$ & 1 month \\
\hline Boulder Scientific Corp. & $3380-3-0200$ & $11 / 05$ & 6 months \\
\hline $\begin{array}{l}\text { (a) The interim storage is the interval between the production date and sub-sampling } \\
\text { for the aging and storage test. }\end{array}$ \\
\hline
\end{tabular}

\subsection{Resin Preparation for Storage}

The resin-preparation activities were conducted according to Test Instruction TI-RPP-WTP-451, Initial RF Resin Processing Supporting the Storage and Aging Test. ${ }^{(b)}$ As-received, H-form, wet resin aliquots were sub-sampled using the coring technique consistent with American Society for Testing and Materials (ASTM) method 2687. Sampled volumes were measured in appropriately sized graduated cylinders after settling (using tapping with a bung) to constant volume.

\subsubsection{Dry-Resin Preparation and Storage}

Dry-resin storage conditions required initial drying of the test resin. Large volumes of wet resin were taken from each lot as shown in Table 2.2. The resins were transferred into tared 1-L glass bottles. Residual free-flowing fluid was removed with transfer pipets. The bottles with damp resin were capped and weighed. The bottle caps were replaced with a rubber stopper equipped with gas inlet and outlet lines. The bottles were turned such that resins coated much of the interior glass surfaces, thus allowing for more surface-area exposure to the flush gas. Nitrogen gas (99.9\%) was flushed into each bottle

(a) A 60-gal production lot in the as-received condition is equivalent to 100-gal Na-form resin.

(b) SK Fiskum, TI-RPP-WTP-451, May 2006, Battelle—Pacific Northwest Division, Richland, WA. 
(through the rubber stopper connection) to help remove the residual moisture from the resin and maintain a relatively inert environment by minimizing oxygen exposure. Drying continued at ambient temperature for 3 to 4 days assisted with the nitrogen flush. The progress of the drying process was periodically assessed by evaluating changes in the gross mass. The water loss rate was $\sim 1.26 \mathrm{~g} / \mathrm{h}$. Resins were considered sufficiently dry for storage when they were free-flowing, and no condensed moisture was observed on the interior glass bottle walls.

Table 2.2. Resin Preparation for Dry Storage

\begin{tabular}{|l|c|c|c|c||}
\hline Lot Number & $\begin{array}{c}\text { Wet Volume, } \\
\text { mL }\end{array}$ & $\begin{array}{c}\text { Free-Flowing } \\
\text { Resin Mass, } \mathbf{g}\end{array}$ & F-factor (RPD) & $\begin{array}{c}\text { Corrected } \\
\text { Dry Mass, } \mathbf{g}\end{array}$ \\
\hline 5J-370/686 & 241 & 157 & $0.745(14)$ & 117 \\
\hline 6C-370/745 & 140 & 83.7 & $0.813(7.4)$ & 68.0 \\
\hline 3380-3-0200 & 141 & 79.1 & $0.850(3.6)$ & 67.2 \\
\hline RPD $=$ relative percent difference, a measure of precision between duplicate samples. \\
\hline
\end{tabular}

The dried resins were mixed by tumbling the bottles by hand. Sub-samples of the dried resins were aliquoted into a series of labeled and tared $20-\mathrm{mL}$ glass scintillation sample vials.

Duplicate F-factor ${ }^{(a)}$ samples were taken, one before and one after the sequence of sub-sampling into vials for the storage test. The F-factor samples were used to measure the initial moisture content of the resins presented for the storage test. The F-factor samples were dried in a vacuum oven set at $50^{\circ} \mathrm{C}$. The net resin masses were periodically determined. Once constant mass $(<0.5 \%$ change over a 7 -h period $)$ was obtained, the F-factor was calculated according to Equation 2.1, where $\mathrm{M}_{\mathrm{D}}$ is the dry-resin mass, and $\mathrm{M}_{\mathrm{I}}$ is the starting-resin mass.

$$
\mathrm{F}=\frac{\mathrm{M}_{\mathrm{D}}}{\mathrm{M}_{\mathrm{I}}}
$$

The dried-stock resin F-factor was required to be $>0.5$ before transferring resins to storage. In all cases, the F-factors met this requirement; F-factor values are shown in Table 2.2. In two cases (5J-370/686 and 6C-370/745), the relative percent differences (RPD) exceeded 5\%. The high RPD was attributed to continued water evaporation from the stock material over the time duration that the multiple samples were taken and weighed.

Each sample vial was virtually filled to capacity with the test resin sample, minimizing the gaseous headspace. Each vial was sparged $\sim 2$ min with nitrogen in an effort to remove oxygen from the interstitial spaces. The vials were immediately capped and weighed. The sample vials were then sealed in an autoclaveable plastic bag. The bag was flushed with nitrogen before the final seal was applied. Each sealed bag was checked for integrity. The sampled dry resin IDs, masses, and targeted storage temperatures are provided in Table 2.3.

(a) The F-factor is a measure of the relative fraction of residual water in the resin structure. As the F-factor approaches 1 (highest possible), the residual water decreases. 
Table 2.3. Resin Storage Samples

\begin{tabular}{|c|c|c|c|c|c|c|}
\hline \multirow[b]{2}{*}{ Lot Number } & \multirow{2}{*}{$\begin{array}{l}\text { Storage } \\
\text { Temp. }{ }^{\circ} \mathrm{C} \\
\text { (Range) }\end{array}$} & \multicolumn{2}{|c|}{ Dry-Storage Condition } & \multicolumn{3}{|c|}{ Wet-Storage Condition } \\
\hline & & Sample ID & Mass, $\mathrm{g}$ & Sample ID & $\begin{array}{c}\text { Volume, } \\
\text { mL }^{(a)}\end{array}$ & $\begin{array}{l}\text { Slurry } \\
\text { Mass, g }\end{array}$ \\
\hline \multirow[t]{9}{*}{ MB 5J-370/686 } & \multirow{3}{*}{$\begin{array}{l}\text { Ambient } \\
(18-24)\end{array}$} & MBJ-DL-1 & 14.0502 & MBJ-WL-1 & 42 & 65.8446 \\
\hline & & MBJ-DL-2 & 14.3535 & MBJ-WL-2 & 42 & 63.7703 \\
\hline & & MBJ-DL-3 & 14.0107 & MBJ-WL-3 & 10 & 21.2112 \\
\hline & \multirow{3}{*}{$\begin{array}{c}35 \\
(34-36)\end{array}$} & MBJ-DM-1 & 15.0752 & MBJ-WM-1 & 42 & 63.4589 \\
\hline & & MBJ-DM-2 & 13.8502 & MBJ-WM-2 & 42.5 & 61.9615 \\
\hline & & MBJ-DM-3 & 13.9357 & MBJ-WM-3 & 10 & 21.3874 \\
\hline & \multirow{3}{*}{$\begin{array}{c}45 \\
(44-46)\end{array}$} & MBJ-DH-1 & 14.0833 & MBJ-WH-1 & 42 & 65.8533 \\
\hline & & MBJ-DH-2 & 13.6257 & MBJ-WH-2 & 41.5 & 63.6072 \\
\hline & & MBJ-DH-3 & 13.2992 & MBJ-WH-3 & 10 & 21.7435 \\
\hline \multirow[t]{6}{*}{ MB 6C-370/745 } & \multirow{2}{*}{$\begin{array}{c}\text { Ambient } \\
(18-24) \\
\end{array}$} & MBC-DL-1 & 12.4324 & MBC-WL-1 & 42 & 63.3100 \\
\hline & & MBC-DL-2 & 12.7062 & MBC-WL-2 & 10 & 21.9383 \\
\hline & \multirow{2}{*}{$\begin{array}{c}35 \\
(34-36) \\
\end{array}$} & MBC-DM-1 & 12.7691 & MBC-WM-1 & 42 & 62.4620 \\
\hline & & MBC-DM-2 & 11.9977 & MBC-WM-2 & 10 & 21.5962 \\
\hline & \multirow{2}{*}{$\begin{array}{c}45 \\
(44-46) \\
\end{array}$} & MBC-DH-1 & 12.3511 & MBC-WH-1 & 42 & 62.5680 \\
\hline & & MBC-DH-2 & 11.8932 & MBC-WH-2 & 10 & 21.2054 \\
\hline \multirow[t]{6}{*}{ BSC 3380-3-0200 } & \multirow{2}{*}{$\begin{array}{l}\text { Ambient } \\
(18-24)\end{array}$} & BSC-DL-1 & 12.6375 & BSC-WL-1 & 42 & 62.6357 \\
\hline & & BSC-DL-2 & 13.0956 & BSC-WL-2 & 10 & 21.9569 \\
\hline & \multirow{2}{*}{$\begin{array}{c}35 \\
(34-36) \\
\end{array}$} & BSC-DM-1 & 12.9437 & BSC-WM-1 & 42 & 64.7641 \\
\hline & & BSC-DM-2 & 13.1426 & BSC-WM-2 & 10 & 21.9231 \\
\hline & \multirow{2}{*}{$\begin{array}{c}45 \\
(44-46)\end{array}$} & BSC-DH-1 & 12.3955 & BSC-WH-1 & 42 & 61.9618 \\
\hline & & BSC-DH-2 & 13.1245 & BSC-WH-2 & 10 & 22.4915 \\
\hline
\end{tabular}

\subsubsection{Wet Resin Preparation Storage}

The wet-resin samples were slurried into $60-\mathrm{mL}$ bottles ( $\sim 42-\mathrm{mL}$ settled-volume aliquots) or $20-\mathrm{mL}$ glass vials (10-mL settled-volume aliquots). Each container void space was filled with deionized (DI) water, leaving $\sim 10 \%$ gas void volume to allow space for potential fluid expansion. Each sample slurry was flushed with nitrogen gas by immersing the gas line to near the bottom of the container for $7 \mathrm{~min}$ 
under constant gas flowrate. The nitrogen flowrate was not determined. ${ }^{(a)}$ Immediately after flushing with nitrogen, the container was capped and weighed. Each container was overpacked into an autoclavable bag, which in turn was flushed with nitrogen before sealing. Each sealed bag was checked for integrity. The sampled wet resin IDs, volumes, slurry masses, and targeted storage temperatures are provided in Table 2.3.

\subsubsection{Storage Conditions}

Three storage chambers were prepared. A 2.5-gal Speedaire paint tank (Dayton Electric Mfg., Chicago, IL) was used to store samples at ambient temperature, and Isotemp Model 280A vacuum ovens (Fisher Scientific, Pittsburg, PA) were used to store samples at 35 and $45^{\circ} \mathrm{C}$. The doors on the two vacuum ovens were modified to seal under slight pressurized conditions. All systems were plumbed to a nitrogen gas distribution system and the building vacuum system. The vacuum oven temperatures were monitored with a thermometer (TEL-TRU, Rochester, NY) placed inside the oven with the readout visible through the window in the door. The accuracy of the thermometers was within $\pm 2^{\circ} \mathrm{C}$. The ambient chamber system had no window visibility, and the temperature was measured with a resistance temperature detector (RTD) thermocouple (PR-11-2-100-1/8-6-E, Omega, Stamford, CT) and readout (HH 612P2C, Omega, Stamford, CT) placed near the chamber. In all cases, temperatures were recorded to the nearest $1{ }^{\circ} \mathrm{C}$. The chamber pressures were measured using one of two gauges (one vacuum and one pressure). ${ }^{\text {(b) }}$ A photograph of the three storage chambers and associated configurations is shown in Figure 2.1.

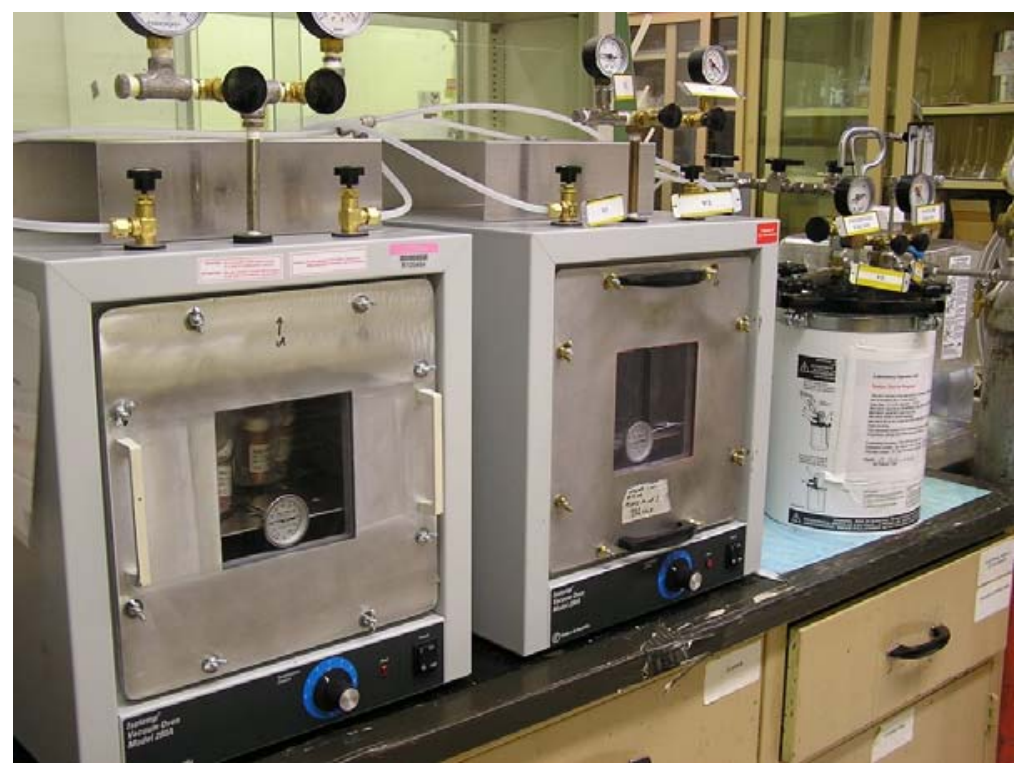

Figure 2.1. Resin Storage Chambers (Left to Right: $45^{\circ} \mathrm{C}, 35^{\circ} \mathrm{C}$, Ambient)

(a) A water sample (no resin) flushed with the nitrogen under identical flowrate resulted in $1 \mathrm{ppm}$ dissolved $\mathrm{O}_{2}$ (indication-only) after 7 min.

(b) Gauges were supplied by three different vendors: Ashcroft (Stratford CT), Wika (Toledo, OH), and Busch (Troy, NY). 
The sample storage and condition monitoring were conducted according to Test Procedure TPR-RPPWTP-439, Storage of Ion Exchange Resins Material in Modified Laboratory Vacuum Ovens. ${ }^{\text {(a) }}$ The heated chambers were equilibrated for $\sim 4 \mathrm{~h}$ at temperature before loading the test samples. Immediately after loading the samples, the storage chambers were evacuated (-18-in. $\mathrm{Hg}$ ) and then backfilled with nitrogen to nominally 3 psig. The temperature and pressure were monitored at least once per week. Observed temperature ranges are shown in Table 2.3. When the pressure in the storage chamber dropped below $1.5 \mathrm{psig}$, it was re-established to $3 \mathrm{psig}$. The pressure drop was only noted for the ambient storage condition (paint can). In this case, the pressure was re-equilibrated to 3 psig once per week starting after 2 months of storage and then twice per week after 3 months of storage.

The sample storage duration was 1 year (initiated on May 15, 2006, 4:35 p.m. and concluded on May 14, 2007, 4:05 p.m.) Observations of samples were taken at the conclusion of the storage period; microscopic evaluation of beads (to discern breakage) was not conducted.

\subsection{Test Resin Selection for Ion Exchange Processing}

Six resins were selected in conjunction with the BNI R\&T Lead ${ }^{(b)}$ for ion exchange performance testing and are shown in Table 2.4. No specific visual results drove the test resin selection. The test resins were selected based on evaluating the test temperature range for two resin lots stored wet, and a single-point evaluation of what was thought to be the most austere storage condition: dry at high temperature.

Table 2.4. Selected Resins for Ion Exchange Processing

\begin{tabular}{|l|l|c|c|c||}
\hline Lot Number & $\begin{array}{l}\text { PNNL Stored } \\
\text { Sample ID }\end{array}$ & $\begin{array}{c}\text { Storage } \\
\text { Temperature }\end{array}$ & $\begin{array}{c}\text { Storage } \\
\text { Condition }\end{array}$ & $\begin{array}{c}\text { Ion Exchange } \\
\text { Color Code }\end{array}$ \\
\hline MB 5J-370/686 & MBJ-WL-1 & ambient & Wet & Pink \\
\hline MB 5J-370/686 & MBJ-WH-2 & $45^{\circ} \mathrm{C}$ & Wet & Red \\
\hline MB 5J-370/686 & MBJ-DH-3 & $45^{\circ} \mathrm{C}$ & Dry & Yellow \\
\hline MB 6C-370/745 & MBC-WL-1 & ambient & Wet & White \\
\hline MB 6C-370/745 & MBC-WM-1 & $35^{\circ} \mathrm{C}$ & Wet & Green \\
\hline MB 6C-370/745 & MBC-WH-1 & $45^{\circ} \mathrm{C}$ & Wet & Blue \\
\hline \hline
\end{tabular}

The ion exchange process tests were color-coded; these codes are cross-referenced to the test resins in Table 2.4.

\subsection{Resin Pretreatment}

Resin pretreatment utilized a full resin expansion and contraction cycle in an open-beaker format followed by another expansion and contraction cycle in the column, consistent with the protocol, P1-RF, Spherical Resin Sampling from Containers, Resin Pretreatment, F-Factor, and Resin Loading to

(a) JJ Toth, April 2006, Battelle—Pacific Northwest Division, Richland, WA.

(b) BNI directions on resin selection and processing conditions are provided in Appendix A. 
Column. ${ }^{(a)}$ The P1-RF pretreatment steps were further delineated in test instruction TI-RPP-WTP-470, Load and Elute Column Testing of Spherical RF Resin after Storage and Aging Test ${ }^{(\mathrm{b})}$ where specific sample processing information was recorded. The pretreatment (P1-RF protocol) steps are summarized in Figure 2.2.

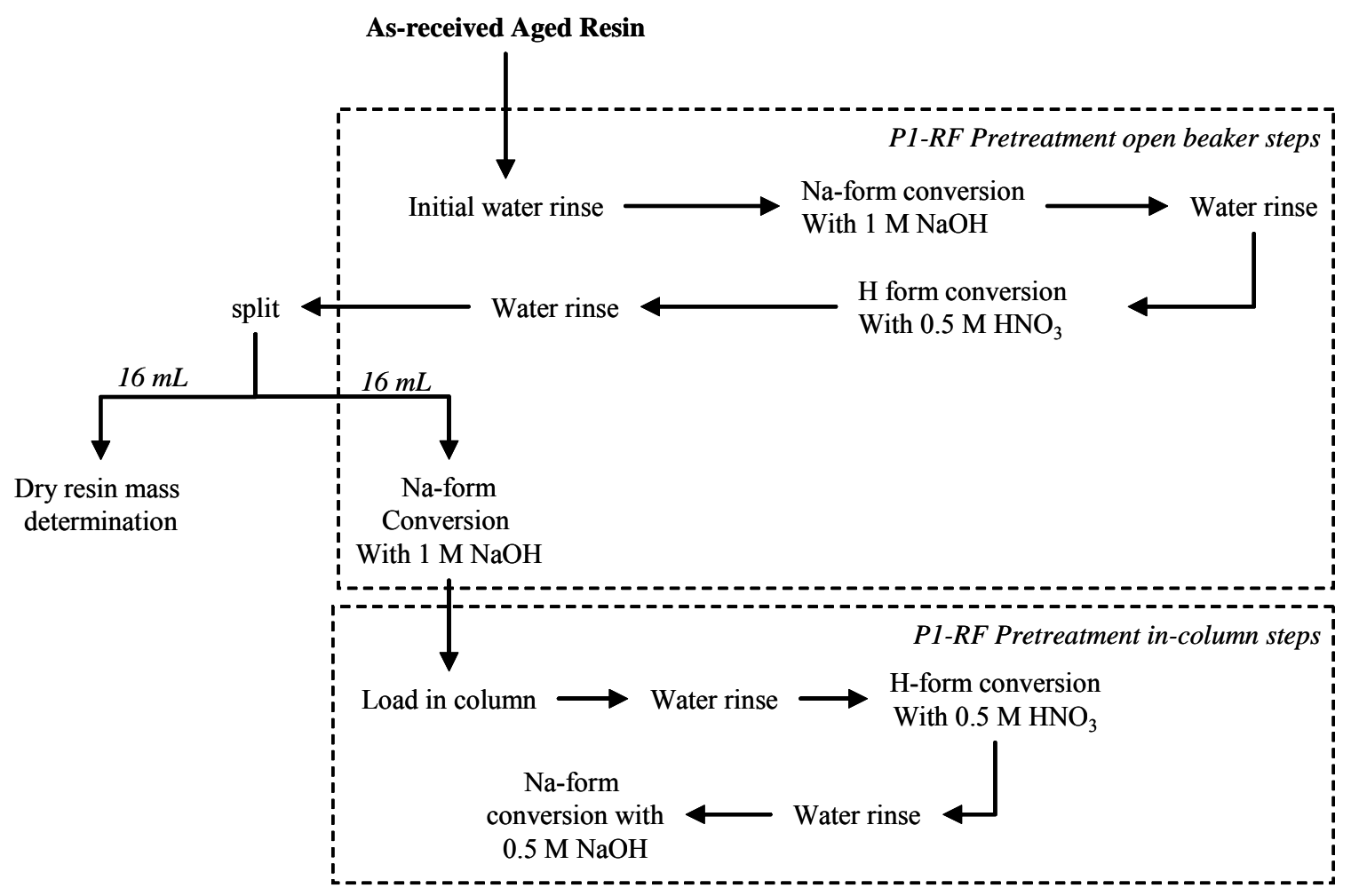

Figure 2.2. Typical Sample Pretreatment and Splitting

The entire quantity of aged resin stored under the given parameter was pretreated in the open-beaker format. After this first shrink-swell cycle, the smaller-volume (16-mL H-form resin) was further pretreated in the column. The nominal resin volumes shown in Figure 2.2 represent settled resin in graduated cylinders. The resin was settled in the graduated cylinder by tapping with a bung. The resin volumes (RV) were recorded once a constant volume was achieved.

The aliquot was transferred to a beaker and soaked for $30 \mathrm{~min}$ in $5 \mathrm{RVs}$ DI water; the slurry was agitated every $10 \mathrm{~min}$. After allowing the resin to settle, the water was removed, and $5 \mathrm{RVs}$ of $1 \mathrm{M}$ $\mathrm{NaOH}$ was added. The slurry was agitated by gently swirling the beaker contents every 10 -min during the first hour, and then the mixture was soaked overnight. The contact solution was verified to be basic after the first $30 \mathrm{~min}$ and again after soaking overnight. The solution was removed, and the resin was washed three successive times with $3 \mathrm{RVs}$ water; each rinse contacted the resin for $30 \mathrm{~min}$ with agitation every $10 \mathrm{~min}$. The $\mathrm{pH}$ of the final water-rinse supernatant was generally between 12.5 and 13.0. The

(a) WTP 097893, CA Nash and CE Duffey, August 17, 2004, Hanford RPP-WTP Alternate Resin Program Protocol P1-RF: Spherical Resin Sampling from Containers, Resin Pretreatment, F-Factor, and Resin Loading to Column.

(b) SK Fiskum, TI-RPP-WTP-470, March 2007. 
resin was converted back to the $\mathrm{H}$-form by removing the final water-rinse supernatant and soaking the washed resin in $10 \mathrm{RVs} 0.5 \mathrm{M} \mathrm{HNO}_{3}$ for $2 \mathrm{~h}$ with agitation every $10 \mathrm{~min}$. This was followed by three successive rinses with $3 \mathrm{RVs}$ of DI water; each rinse contacted the resin for $30 \mathrm{~min}$ with agitation every $10 \mathrm{~min}$. The pretreated resin volume was measured, and then the resin was sub-divided into the appropriate processing fractions as shown in Figure 2.2 for column testing and dry-mass determination.

The H-form pretreated resin sample taken for column testing was soaked in $1 \mathrm{M} \mathrm{NaOH}$ at a 10:1 solution volume to the pre-treated resin volume ratio in a beaker to allow for unconstrained resin expansion. After the resin was soaked for $\sim 1$ hour $^{(\mathrm{a})}$ in the caustic medium, the $\mathrm{NaOH}$ was decanted, and the resin was slurried with an equivalent volume of DI water. The resin slurry was then transferred to the column. The column was tapped gently to settle the bed. Once process flows started, the resin beds were not disturbed, vibrated, or tapped. The resin bed was successively rinsed downflow with DI water, $0.5 \mathrm{M}$ $\mathrm{HNO}_{3}$, DI water, and then $0.5 \mathrm{M} \mathrm{NaOH}$ in preparation for the AP-101 simulant feed.

\subsection{Ion Exchange Process Testing}

The system configuration, simulant test solution, and processing conditions are summarized in this section. The ion exchange column systems, processing conditions, and feed simulant stock used in the current aged-resin ion exchange performance tests were the same as those used in the initial or un-aged resin ion exchange performance test. The ion exchange column testing was conducted according to TIRPP-WTP-470. Six ion exchange process systems were available for concurrent testing. Columns were color-coded (pink, green, yellow, white, blue, and red) for ease of sample and data tracking (see Table 2.4 for cross-reference).

\subsubsection{Ion Exchange System}

Figure 2.3 shows a schematic of a typical ion exchange column assembly. A system consisted of one glass column containing the ion exchange resin, a small metering pump, three valves, a pressure gauge, and a pressure-relief valve. Valves 1, 2, and 3 were three-way valves that could be turned to the columnflow position or an exhaust position to expel trapped air or fluids from the column input/output lines. Valve 1 was placed at the outlet of the pump and was used to isolate the column from the pump. Valve 3 was primarily used to obtain samples and isolate the system during storage periods.

Columns were prepared at the Kontes Custom Glass Shop (Vineland, NJ). Each column was 10-cm tall with an inside diameter of $2.0 \mathrm{~cm}$ (corresponding to a resin volume of $3.1 \mathrm{~mL} / \mathrm{cm}$ ) and a $2.8-\mathrm{mm}$ wall thickness. The glass was safety coated with polyvinyl chloride. Stainless steel, 200-mesh screens, provided by Savannah River Technology Center (SRTC), supported the resin beds. The screens were stabilized with snug-fitting O-rings. The cavity below the screen support was filled with 3-mm-diameter glass beads, reducing the fluid-filled volume from $11 \mathrm{~mL}$ to $6 \mathrm{~mL}$. The height of the resin bed (and thus shrinkage and swelling) was measured with a millimeter-scale ruler (the associated measurement error was estimated to be $\pm 2 \mathrm{~mm}$ ). The fluid level in the column was maintained at nominally the 10 -cm height. Depending on whether the resin was expanded $(\sim 6.4 \mathrm{~cm}$ tall $)$ or contracted $(\sim 5.3 \mathrm{~cm}$ tall $)$, the fluid volume above the resin bed varied between $\sim 11 \mathrm{~mL}$ and $\sim 15 \mathrm{~mL}$, respectively. Hold-up volumes in

(a) The soak time in $1 \mathrm{M} \mathrm{NaOH}$ varied from $0.75 \mathrm{~h}$ to $1.7 \mathrm{~h}$. The differences in soak times were an artifact of time logistics associated with multiple resin transfers to multiple ion exchange columns. 
various sections of the ion exchange apparatus were identical to those previously reported (Fiskum et al. 2006).

The polyethylene connecting tubing was $1 / 8$-in. OD and $1 / 16$-in. ID. The column end fittings were standard Kontes Chromaflex column end fittings with ethylene tetrafluoroethylene ferrules. The inlet sample line ended at the column fitting. The column assembly contained an in-line Swagelok Poppet pressure relief check valve with a 10-psi trigger (Solon, OH) and a 15-psi pressure gauge (McDaniel Controls Model \#SA, Luling, LA). Valved quick-disconnects (Cole Parmer, Vernon Hills, IL) were installed in-line to allow for ease of column removal from the system. Fluid Metering, Incorporated (FMI) QVG50 pumps (Syosset, NY) equipped with ceramic and Kynar ${ }^{\circledR}$ coated low-flow piston pump heads were used to introduce all fluids. The flowrate was controlled with a remotely operated FMI stroke-rate controller. The pump was set up to deliver flowrates from $0.2-$ to $1.2-\mathrm{mL} / \mathrm{min}$. The volume actually pumped was determined using the mass of the fluid collected divided by the fluid density. The holdup volume of the entire ion exchange system, which was the summed volume of all fluid-filled parts, was $\sim 47 \mathrm{~mL}$.

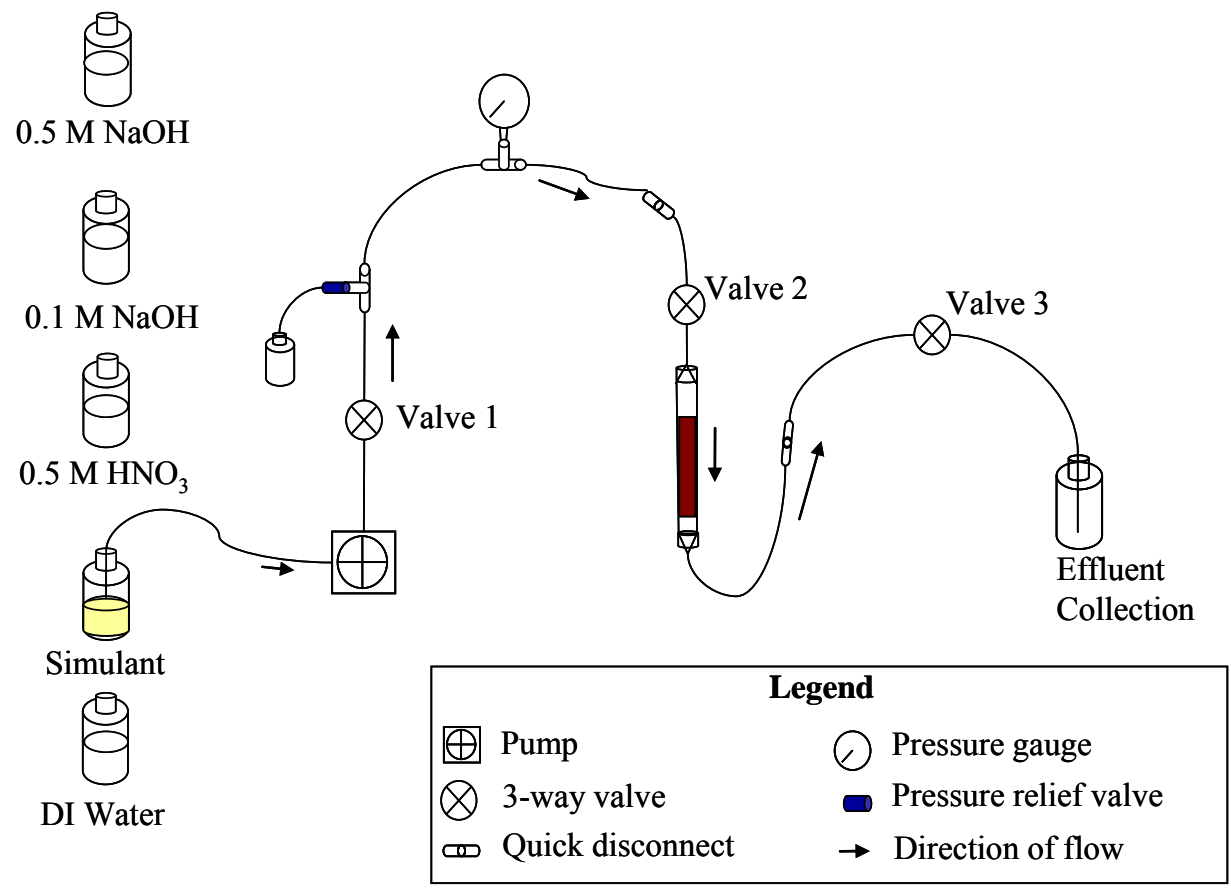

Figure 2.3. Ion Exchange Column Processing System

\subsubsection{AP-101 Simulant Selection}

Wastes containing high $\mathrm{K}$ concentrations, such as found with AP-101 and AW-101, create a more difficult challenge to the RF ion exchange material because the $\mathrm{K}$ competes with $\mathrm{Cs}$ for active exchange sites. The AP-101 matrix, with $0.7 \mathrm{M} \mathrm{K}$ (when diluted to $5 \mathrm{M} \mathrm{Na}$ ), was considered to bound the worstcase Cs loading condition. The AP-101 simulant had been used previously for testing the un-aged RF resin lots and would provide a baseline reference point for degradation effects associated with the aging and storage conditions. Therefore, the AP-101 simulant matrix was selected for evaluating the effects of aging and storage conditions on cesium loading performance. 
Noah Technologies (San Antonio, TX) prepared a 100-L lot of AP-101 simulant (\# 144354/1.1) in April 2005 according to the simulant recipe reported by Russell et al. (2003). This simulant lot was used in previous testing, and details of analysis were reported (Fiskum et al. 2006). The composition summary is re-produced in Table 2.5. The AP-101 simulant formulation is provided in Appendix B, which delineates the trace component additions. All analytes, especially those that may affect Cs ion exchange, were assumed to remain in solution during the 2-y simulant storage period.

Table 2.5. AP-101 Stock 2 (Lot \#144254/1.1) Simulant Composition-Major Analytes

\begin{tabular}{|c|c|c|c|c|c|c|c|}
\hline Analyte & $\begin{array}{c}\text { Prep } \\
\text { Blank } \\
\mu \mathrm{g} / \mathrm{mL} \\
\end{array}$ & $\begin{array}{l}\text { Sample } \\
\mu \mathrm{g} / \mathrm{mL}\end{array}$ & $\begin{array}{c}\text { Duplicate } \\
\mu \mathrm{g} / \mathrm{mL}\end{array}$ & $\begin{array}{c}\text { Average } \\
\mu \mathrm{g} / \mathrm{mL}\end{array}$ & $\begin{array}{c}\text { Average } \\
\mathbf{M} \\
\end{array}$ & $\begin{array}{c}\text { Target } \\
\text { M } \\
\end{array}$ & $\begin{array}{c}\% \text { of } \\
\text { Target } \\
\end{array}$ \\
\hline Cs & $<0.062$ & 5.90 & 5.82 & 5.86 & 4.40E-5 & $4.51 \mathrm{E}-5$ & 98 \\
\hline $\mathrm{Al}$ & $<1.7$ & 6,540 & 6,675 & 6608 & $2.45 \mathrm{E}-1$ & $2.59 \mathrm{E}-1$ & 95 \\
\hline $\mathrm{Cr}$ & $<0.13$ & 143 & 146 & 144 & $2.77 \mathrm{E}-3$ & $2.92 \mathrm{E}-3$ & 95 \\
\hline $\mathrm{K}$ & $<64$ & 26,300 & 26,800 & 26,550 & $6.79 \mathrm{E}-1$ & $7.10 \mathrm{E}-1$ & 96 \\
\hline $\mathrm{Na}$ & $<6.1$ & 110,000 & 115,000 & 112,500 & $4.89 \mathrm{E}+0$ & $5.00 \mathrm{E}+0$ & 98 \\
\hline $\mathrm{P}$ & $<1.7$ & 376 & 386 & 381 & $1.23 \mathrm{E}-2$ & $1.24 \mathrm{E}-2$ & 99 \\
\hline $\mathrm{Cl}^{-}$ & $<8$ & 1,770 & 1,790 & 1,780 & $5.02 \mathrm{E}-2$ & $4.09 \mathrm{E}-2$ & $123^{(\mathrm{a})}$ \\
\hline $\mathrm{NO}_{2}^{-}$ & $<120$ & 33,900 & 33,400 & 33,600 & $7.32 \mathrm{E}-1$ & $7.07 \mathrm{E}-1$ & 104 \\
\hline $\mathrm{NO}_{3}^{-}$ & $<150$ & 107,000 & 106,000 & 106,500 & $1.72 \mathrm{E}+0$ & $1.68 \mathrm{E}+0$ & 102 \\
\hline $\mathrm{PO}_{4}^{3-}$ & $<1.9$ & 1,120 & 1,090 & 1,105 & $1.16 \mathrm{E}-2$ & $1.24 \mathrm{E}-2$ & 94 \\
\hline $\mathrm{SO}_{4}^{2-}$ & $<12$ & 3,610 & 3,550 & 3,580 & $3.73 \mathrm{E}-2$ & $3.73 \mathrm{E}-2$ & 100 \\
\hline $\mathrm{OH}^{-}$ & 0 & 32,000 & 32,400 & 32,200 & $1.89 \mathrm{E}+0$ & $1.94 \mathrm{E}+0$ & 98 \\
\hline $\mathrm{C}$ as $\mathrm{CO}_{3}{ }^{2-}$ & NA & 5,400 & 5,600 & 5,500 & $4.58 \mathrm{E}-1$ & $4.46 \mathrm{E}-1$ & 103 \\
\hline Analyte & $\begin{array}{c}\text { Temp. } \\
{ }^{\circ} \mathrm{C} \\
\end{array}$ & $\begin{array}{c}\text { Sample } \\
\mathrm{g} / \mathrm{mL}\end{array}$ & $\begin{array}{c}\text { Duplicate } \\
\text { g/mL }\end{array}$ & \multicolumn{2}{|c|}{$\begin{array}{c}\text { Average } \\
\mathrm{g} / \mathrm{mL}\end{array}$} & $\begin{array}{c}\text { Target } \\
\text { g/mL }\end{array}$ & $\begin{array}{c}\% \text { of } \\
\text { Target } \\
\end{array}$ \\
\hline Density & 22 & 1.251 & 1.251 & \multicolumn{2}{|c|}{1.251} & 1.26 & 99.3 \\
\hline $\begin{array}{l}\text { (a) The ch } \\
\text { the sin } \\
\text { Notes: } \\
\text { The overall } \\
\text { Analytical } \\
\text { Noah Techr }\end{array}$ & $\begin{array}{l}\text { ride result e } \\
\text { lant compos }\end{array}$ & $\begin{array}{l}\text { eeded the a } \\
\text { on as report }\end{array}$ & $\begin{array}{l}\text { ceptance crit } \\
\text { ed. }\end{array}$ & ion of $\pm 15 \%$ & of target. & e R\&T lea & cepted \\
\hline
\end{tabular}

\subsubsection{Ion Exchange Processing Conditions}

The targeted processing parameters are summarized in Table 2.6. These parameters generally mimic expected plant operating conditions and were either established in the test plan or through consultation with the BNI R\&T lead (see Appendix A). The cumulative BV pumped was calculated based on the effluent collection mass and density. With one exception, these parameters were known to three significant figures. The solution density changed rapidly during transition and mixing from the regeneration solution to the simulant feed $(1.02 \mathrm{~g} / \mathrm{mL}$ to $1.25 \mathrm{~g} / \mathrm{mL}$, respectively); the transition was essentially complete after processing one apparatus volume. An average density of $1.13 \mathrm{~g} / \mathrm{mL}$ was 
applied to the net mass measurement obtained associated with the first sampling event. This represented an absolute volume uncertainty of $\sim 6 \mathrm{~mL}$ or $0.3 \mathrm{BVs}$. This uncertainty was considered negligible in the overall process.

Table 2.6. Generic Ion Exchange Process Steps

\begin{tabular}{|l|l|c|c||}
\hline Process step & Feed Solution & $\begin{array}{c}\text { Process } \\
\text { Volume, BV }\end{array}$ & $\begin{array}{c}\text { Process } \\
\text { Flowrate, BV/h }\end{array}$ \\
\hline Water rinse & DI water & 8 & 3 \\
\hline Acid wash & $0.5 \mathrm{M} \mathrm{HNO}_{3}$ & 8 & 3 \\
\hline Water rinse & DI water & 3 & 1.4 \\
\hline Regeneration & $0.5 \mathrm{M} \mathrm{NaOH}$ & 6 & 3 \\
\hline Loading column & $\mathrm{AP}-101 \mathrm{Simulant}$ & 80 & 1.5 \\
\hline Loading column & $\mathrm{AP}-101 \mathrm{Simulant}$ & $\sim 70$ & 3 \\
\hline Feed displacement & $0.1 \mathrm{M} \mathrm{NaOH}$ & 3 & 3 \\
\hline Rinse & DI water & 3 & 3 \\
\hline Elution & $0.45 \mathrm{M} \mathrm{HNO}$ & 20 & 1.4 \\
\hline Rinse & DI water & 3 & 1.4 \\
\hline
\end{tabular}

Specific parameters for each column test are identified in Table 2.7 through Table 2.12. All processing was conducted downflow. The AP-101 simulant processing runs were started at $1.5 \mathrm{BV} / \mathrm{h}$. After an initial $\sim 80 \mathrm{BVs}$ were processed, the flowrate was increased to the nominal limit for Envelope A waste of $3 \mathrm{BV} / \mathrm{hr}$. The flowrate selection rationale has been previously described (Fiskum et al. 2006) and they corresponded to previous test conditions for direct comparability of results.

Table 2.7. Experimental Conditions for Microbeads Lot 6C-370-744 Stored Wet at Ambient Temperature (White Column)

\begin{tabular}{|c|c|c|c|c|c|c|c|c|}
\hline \multirow[b]{2}{*}{ Process step } & \multirow[b]{2}{*}{ Solution } & \multicolumn{3}{|c|}{ Total Volume } & \multicolumn{2}{|c|}{ Flowrate } & \multirow{2}{*}{$\begin{array}{c}\text { Time } \\
\mathbf{h} \\
\end{array}$} & \multirow[b]{2}{*}{$\mathbf{T},{ }^{\circ} \mathrm{C}$} \\
\hline & & $\mathbf{B V}^{(\mathbf{a})}$ & $\mathbf{A V}^{(\mathbf{b})}$ & $\mathbf{m L}$ & BV/h & $\mathrm{mL} / \mathrm{min}$ & & \\
\hline \multicolumn{9}{|c|}{ In-situ Preconditioning (5/18/07) } \\
\hline Water rinse & DI water & 7.77 & 3.27 & 154 & 2.99 & 0.986 & 2.60 & 22 \\
\hline Acid wash & $0.5 \mathrm{M} \mathrm{HNO}_{3}$ & 8.10 & 3.41 & 160 & 2.98 & 0.984 & 2.72 & 22 \\
\hline Water rinse & DI water & 2.98 & 1.25 & 59.0 & 1.29 & 0.424 & 2.32 & 23 \\
\hline \multicolumn{9}{|c|}{ Cycle 1 (Start 5/21/07) } \\
\hline Regeneration & $0.5 \mathrm{M} \mathrm{NaOH}$ & 5.91 & 2.49 & 117 & 2.77 & 0.914 & 2.13 & 20 \\
\hline Loading column & AP-101 Simulant & 81.0 & -- & 1,604 & 1.50 & 0.494 & 54.0 & $22-23$ \\
\hline Loading column & AP-101 Simulant & 58.4 & -- & 1,124 & 2.93 & 0.967 & 19.9 & $23-24$ \\
\hline Feed displacement & $0.1 \mathrm{M} \mathrm{NaOH}$ & 2.73 & 1.15 & 53.9 & 2.73 & 0.899 & 1.00 & 23 \\
\hline Rinse & DI water & 2.72 & 1.15 & 53.9 & 2.72 & 0.898 & 1.00 & 24 \\
\hline Elution & $0.45 \mathrm{M} \mathrm{HNO}_{3}$ & 20.1 & -- & 399 & 1.40 & 0.463 & 14.3 & $22-24$ \\
\hline Rinse & DI water & 3.00 & 1.26 & 59.4 & 1.42 & 0.468 & 2.12 & 24 \\
\hline $\begin{array}{ll}\text { (a) } & \mathrm{BV}=\text { bed volun } \\
\text { (b) } & \mathrm{AV}=\text { apparatus } \\
\end{array}$ & $\begin{array}{l}\mathrm{e}(19.8 \mathrm{~mL} \text { in } \mathrm{Na} f \mathrm{fc} \\
\text { volume }(47 \mathrm{~mL})\end{array}$ & & & & & & & \\
\hline
\end{tabular}


Table 2.8. Experimental Conditions for Microbeads Lot 6C-370-744

Stored Wet at $35^{\circ} \mathrm{C}$ (Green Column)

\begin{tabular}{|c|c|c|c|c|c|c|c|c|}
\hline \multirow[b]{2}{*}{ Process step } & \multirow[b]{2}{*}{ Solution } & \multicolumn{3}{|c|}{$\begin{array}{ll}\text { Total Volume } \\
\end{array}$} & \multicolumn{2}{|c|}{ Flowrate } & \multirow{2}{*}{$\begin{array}{c}\text { Time } \\
\mathbf{h} \\
\end{array}$} & \multirow[b]{2}{*}{$\mathbf{T},{ }^{\circ} \mathbf{C}$} \\
\hline & & $\mathbf{B V}^{(\mathbf{a})}$ & $\mathbf{A V ^ { ( \mathbf { b } ) }}$ & $\mathbf{m L}$ & $\mathbf{B V} / \mathbf{h}$ & $\mathrm{mL} / \mathrm{min}$ & & \\
\hline \multicolumn{9}{|c|}{ In-situ Preconditioning (5/18/07) } \\
\hline Water rinse & DI water & 8.01 & 3.37 & 158.4 & 3.72 & 1.23 & 2.15 & 22 \\
\hline Acid wash & $0.5 \mathrm{M} \mathrm{HNO}_{3}$ & 8.66 & 3.65 & 171.4 & 3.44 & 1.13 & 2.52 & 22 \\
\hline Water rinse & DI water & 2.99 & 1.26 & 59.1 & 1.49 & 0.493 & 2.00 & 23 \\
\hline \multicolumn{9}{|c|}{ Cycle 1 (Start 5/21/07) } \\
\hline Regeneration & $0.5 \mathrm{M} \mathrm{NaOH}$ & 6.16 & 2.59 & 122 & 2.76 & 0.909 & 2.23 & 20 \\
\hline Loading column & AP-101 Simulant & 80.6 & -- & 1,594 & 1.49 & 0.491 & 53.9 & $22-23$ \\
\hline Loading column & AP-101 Simulant & 59.0 & -- & 1,168 & 2.99 & 0.987 & 19.9 & $23-24$ \\
\hline Feed displacement & $0.1 \mathrm{M} \mathrm{NaOH}$ & 2.81 & 1.18 & 55.5 & 2.90 & 0.958 & 0.97 & 23 \\
\hline Rinse & DI water & 3.17 & 1.34 & 62.8 & 2.93 & 0.966 & 1.08 & 24 \\
\hline Elution & $0.45 \mathrm{M} \mathrm{HNO}_{3}$ & 19.8 & -- & 392 & 1.41 & 0.466 & 14.0 & $22-24$ \\
\hline Rinse & DI water & 2.93 & 1.23 & 58.0 & 1.42 & 0.468 & 2.07 & 24 \\
\hline $\begin{array}{l}\text { (a) } \mathrm{BV}=\text { bed volum } \\
\text { (b) } \mathrm{AV}=\text { apparatus } \\
\end{array}$ & $\begin{array}{l}(19.8 \mathrm{~mL} \text { in } \mathrm{Na} \text { fo } \\
\text { olume }(47 \mathrm{~mL})\end{array}$ & & & & & & & \\
\hline
\end{tabular}

Table 2.9. Experimental Conditions for Microbeads Lot 6C-370-744

Stored Wet at $45^{\circ} \mathrm{C}$ (Blue Column)

\begin{tabular}{|c|c|c|c|c|c|c|c|c|}
\hline \multirow[b]{2}{*}{ Process step } & \multirow[b]{2}{*}{ Solution } & \multicolumn{3}{|c|}{ Total Volume } & \multicolumn{2}{|c|}{ Flowrate } & \multirow{2}{*}{$\begin{array}{c}\text { Time } \\
\mathbf{h} \\
\end{array}$} & \multirow[b]{2}{*}{$\mathbf{T},{ }^{\circ} \mathrm{C}$} \\
\hline & & $\mathbf{B V}^{(\mathbf{a})}$ & $\mathbf{A V}^{(\mathbf{b})}$ & $\mathrm{mL}$ & BV/h & $\mathrm{mL} / \mathrm{min}$ & & \\
\hline \multicolumn{9}{|c|}{ In-situ Preconditioning (5/18/07) } \\
\hline Water rinse & DI water & 8.24 & 3.36 & 158 & 3.34 & 1.07 & 2.47 & 22 \\
\hline Acid wash & $0.5 \mathrm{M} \mathrm{HNO}_{3}$ & 8.11 & 3.31 & 155 & 3.02 & 0.965 & 2.68 & 22 \\
\hline Water rinse & DI water & 3.07 & 1.25 & 58.8 & 2.12 & 0.676 & 1.45 & 23 \\
\hline \multicolumn{9}{|c|}{ Cycle 1 (Start 5/21/07) } \\
\hline Regeneration & $0.5 \mathrm{M} \mathrm{NaOH}$ & 6.24 & 2.54 & 120 & 2.79 & 0.893 & 2.23 & 20 \\
\hline Loading column & AP-101 Simulant & 82.0 & -- & 1,571 & 1.53 & 0.487 & 53.9 & $22-23$ \\
\hline Loading column & AP-101 Simulant & 69.9 & -- & 1,340 & 2.94 & 0.940 & 24.0 & $23-24$ \\
\hline Feed displacement & $0.1 \mathrm{M} \mathrm{NaOH}$ & 3.00 & 1.22 & 57.5 & 2.86 & 0.912 & 1.05 & 23 \\
\hline Rinse & DI water & 3.13 & 1.28 & 60.0 & 2.89 & 0.923 & 1.08 & 24 \\
\hline Elution & $0.45 \mathrm{M} \mathrm{HNO}_{3}$ & 20.1 & -- & 385 & 1.42 & 0.453 & 14.2 & $22-24$ \\
\hline Rinse & DI water & 2.97 & 1.21 & 56.9 & 1.40 & 0.448 & 2.12 & 24 \\
\hline $\begin{array}{l}\text { (a) } \mathrm{BV}=\text { bed volun } \\
\text { (b) } \mathrm{AV}=\text { apparatus }\end{array}$ & $\begin{array}{l}(19.2 \mathrm{~mL} \text { in } \mathrm{Na} \text { forn } \\
\text { olume }(47 \mathrm{~mL})\end{array}$ & & & & & & & \\
\hline
\end{tabular}


Table 2.10. Experimental Conditions for Microbeads Lot 5J-370-686 Stored Wet at Ambient Temperature (Pink Column)

\begin{tabular}{|c|c|c|c|c|c|c|c|c|}
\hline \multirow[b]{2}{*}{ Process step } & \multirow[b]{2}{*}{ Solution } & \multicolumn{3}{|c|}{ Total Volume } & \multicolumn{2}{|c|}{ Flowrate } & \multirow{2}{*}{$\begin{array}{c}\text { Time } \\
\mathbf{h} \\
\end{array}$} & \multirow[b]{2}{*}{$\mathbf{T},{ }^{\circ} \mathrm{C}$} \\
\hline & & $\mathbf{B V}^{(\mathbf{a})}$ & $\mathbf{A V}^{(\mathbf{b})}$ & $\mathbf{m L}$ & $\mathbf{B V} / \mathbf{h}$ & $\mathrm{mL} / \mathrm{min}$ & & \\
\hline \multicolumn{9}{|c|}{ In-situ Preconditioning (5/18/07) } \\
\hline Water rinse & DI water & 7.81 & 3.29 & 155 & 2.99 & 0.985 & 2.62 & 22 \\
\hline Acid wash & $0.5 \mathrm{M} \mathrm{HNO}_{3}$ & 8.11 & 3.41 & 160 & 3.04 & 1.00 & 2.67 & 22 \\
\hline Water rinse & DI water & 2.97 & 1.25 & 58.8 & 1.41 & 0.466 & 2.10 & 23 \\
\hline \multicolumn{9}{|c|}{ Cycle 1 (Start 5/21/07) } \\
\hline Regeneration & $0.5 \mathrm{M} \mathrm{NaOH}$ & 6.20 & 2.61 & 123 & 2.84 & 0.937 & 2.18 & 20 \\
\hline Loading column & AP-101 Simulant & 80.6 & -- & 1,596 & 1.48 & 0.489 & 54.1 & $22-23$ \\
\hline Loading column & AP-101 Simulant & 57.9 & -- & 1,145 & 3.02 & 0.998 & 19.5 & $23-24$ \\
\hline Feed displacement & $0.1 \mathrm{M} \mathrm{NaOH}$ & 2.87 & 1.21 & 56.7 & 2.97 & 0.978 & 0.97 & 23 \\
\hline Rinse & DI water & 3.15 & 1.33 & 62.3 & 2.95 & 0.974 & 1.07 & 24 \\
\hline Elution & $0.45 \mathrm{M} \mathrm{HNO}_{3}$ & 19.8 & -- & 392 & 1.38 & 0.456 & 14.3 & $22-24$ \\
\hline Rinse & DI water & 2.91 & 1.22 & 57.5 & 1.39 & 0.460 & 2.08 & 24 \\
\hline $\begin{array}{l}\text { (a) } \mathrm{BV}=\text { bed volum } \\
\text { (b) } \mathrm{AV}=\text { apparatus }\end{array}$ & $\begin{array}{l}(19.8 \mathrm{~mL} \text { in } \mathrm{Na} \text { for } \\
\text { olume }(47 \mathrm{~mL})\end{array}$ & & & & & & & \\
\hline
\end{tabular}

Table 2.11. Experimental Conditions for Microbeads Lot 5J-370-686 Stored Wet at $45^{\circ} \mathrm{C}$ (Red Column)

\begin{tabular}{|c|c|c|c|c|c|c|c|c|}
\hline \multirow[b]{2}{*}{ Process step } & \multirow[b]{2}{*}{ Solution } & \multicolumn{3}{|c|}{ Total Volume } & \multicolumn{2}{|c|}{ Flowrate } & \multirow{2}{*}{$\begin{array}{c}\text { Time } \\
\mathbf{h}\end{array}$} & \multirow[b]{2}{*}{$\mathbf{T},{ }^{\circ} \mathbf{C}$} \\
\hline & & $\mathbf{B V}^{(\mathbf{a})}$ & $\mathbf{A V ^ { ( \mathbf { b } ) }}$ & $\mathbf{m L}$ & $\mathrm{BV} / \mathrm{h}$ & $\mathrm{mL} / \mathrm{min}$ & & \\
\hline \multicolumn{9}{|c|}{ In-situ Preconditioning (5/18/07) } \\
\hline Water rinse & DI water & 8.09 & 3.30 & 155 & 3.30 & 1.05 & 2.45 & 22 \\
\hline Acid wash & $0.5 \mathrm{M} \mathrm{HNO}_{3}$ & 8.36 & 3.41 & 160 & 3.08 & 0.983 & 2.72 & 22 \\
\hline Water rinse & DI water & 3.09 & 1.26 & 59.3 & 1.51 & 0.482 & 2.05 & 23 \\
\hline \multicolumn{9}{|c|}{ Cycle 1 (Start 5/21/07) } \\
\hline Regeneration & $0.5 \mathrm{M} \mathrm{NaOH}$ & 6.76 & 2.76 & 130 & 2.86 & 0.913 & 2.37 & 20 \\
\hline Loading column & AP-101 Simulant & 80.9 & -- & 1,550 & 1.49 & 0.475 & 54.1 & $22-23$ \\
\hline Loading column & AP-101 Simulant & 70.3 & -- & 1,348 & 3.02 & 0.964 & 23.6 & $23-24$ \\
\hline Feed displacement & $0.1 \mathrm{M} \mathrm{NaOH}$ & 2.96 & 1.21 & 56.7 & 2.96 & 0.945 & 1.00 & 23 \\
\hline Rinse & DI water & 3.18 & 1.30 & 61.0 & 2.98 & 0.953 & 1.07 & 24 \\
\hline Elution & $0.45 \mathrm{M} \mathrm{HNO}_{3}$ & 20.1 & -- & 386 & 1.40 & 0.447 & 14.4 & $22-24$ \\
\hline Rinse & DI water & 3.00 & 1.22 & 57.5 & 1.40 & 0.446 & 2.15 & 24 \\
\hline $\begin{array}{ll}\text { (a) } & \mathrm{BV}=\text { bed volum } \\
\text { (b) } \mathrm{AV}=\text { apparatus }\end{array}$ & $\begin{array}{l}(19.2 \mathrm{~mL} \text { in } \mathrm{Na} \text { for } \\
\text { olume }(47 \mathrm{~mL})\end{array}$ & & & & & & & \\
\hline
\end{tabular}


Table 2.12. Experimental Conditions for Microbeads Lot 5J-370-686 Stored Dry at $45^{\circ} \mathrm{C}$ (Yellow Column)

\begin{tabular}{|c|c|c|c|c|c|c|c|c|}
\hline \multirow[b]{2}{*}{ Process step } & \multirow[b]{2}{*}{ Solution } & \multicolumn{3}{|c|}{ Total Volume } & \multicolumn{2}{|c|}{ Flowrate } & \multirow{2}{*}{$\begin{array}{c}\text { Time } \\
\mathbf{h} \\
\end{array}$} & \multirow[b]{2}{*}{$\mathbf{T},{ }^{\circ} \mathrm{C}$} \\
\hline & & $\mathbf{B V}^{(\mathbf{a})}$ & $\mathbf{A V}^{(\mathbf{b})}$ & $\mathbf{m L}$ & $\mathbf{B V} / \mathbf{h}$ & $\mathrm{mL} / \mathrm{min}$ & & \\
\hline \multicolumn{9}{|c|}{ In-situ Preconditioning (5/18/07) } \\
\hline Water rinse & DI water & 7.91 & 3.17 & 149 & 3.04 & 0.956 & 2.60 & 22 \\
\hline Acid wash & $0.5 \mathrm{M} \mathrm{HNO}_{3}$ & 8.74 & 3.50 & 165 & 2.96 & 0.930 & 2.95 & 22 \\
\hline Water rinse & DI water & 3.14 & 1.26 & 59.2 & 0.928 & 0.292 & 3.38 & 23 \\
\hline \multicolumn{9}{|c|}{ Cycle 1 (Start 5/21/07) } \\
\hline Regeneration & $0.5 \mathrm{M} \mathrm{NaOH}$ & 6.26 & 2.51 & 118 & 2.78 & 0.873 & 2.25 & 20 \\
\hline Loading column & AP-101 Simulant & 82.6 & -- & 1,558 & 1.55 & 0.488 & 53.9 & $22-23$ \\
\hline Loading column & AP-101 Simulant & 68.3 & -- & 1,334 & 2.99 & 0.940 & 23.6 & $23-24$ \\
\hline Feed displacement & $0.1 \mathrm{M} \mathrm{NaOH}$ & 3.03 & 1.22 & 57.2 & 3.03 & 0.953 & 1.00 & 23 \\
\hline Rinse & DI water & 3.01 & 1.21 & 556.7 & 3.01 & 0.945 & 1.00 & 24 \\
\hline Elution & $0.45 \mathrm{M} \mathrm{HNO}_{3}$ & 20.4 & -- & 385 & 1.42 & 0.447 & 14.35 & $22-24$ \\
\hline Rinse & DI water & 2.99 & 1.20 & 56.4 & 1.41 & 0.444 & 2.12 & 24 \\
\hline $\begin{array}{l}\text { (a) } \mathrm{BV}=\text { bed volum } \\
\text { (b) } \mathrm{AV}=\text { apparatus }\end{array}$ & $\begin{array}{l}(18.8 \mathrm{~mL} \text { in } \mathrm{Na} \text { for } \\
\text { olume }(47 \mathrm{~mL})\end{array}$ & & & & & & & \\
\hline
\end{tabular}

Photographs of two ion exchange columns and resin beds are shown in Figure 2.4. The resin-bed appearances converting from the $\mathrm{Na}$-form to the $\mathrm{H}$-form (green-taped column) and converting from the $\mathrm{H}$-form to the Na-form (white-taped column) were typical for all tests. The conversion fronts were level across the bed and did not show fingering patterns associated with channeling. Also shown are the fluid levels above the resin beds, which constituted the mixing areas during feed transitions. The fluid level remained at the same height during resin expansions and contractions.

(a)

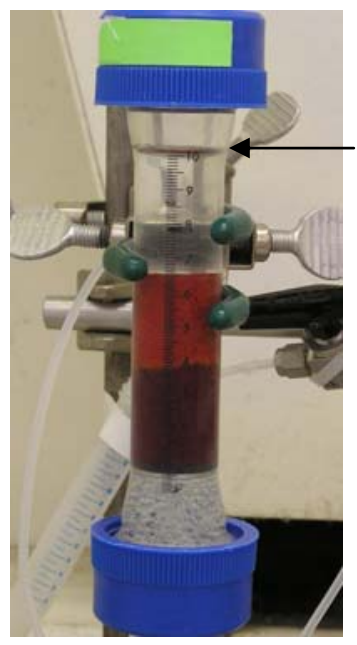

(b)

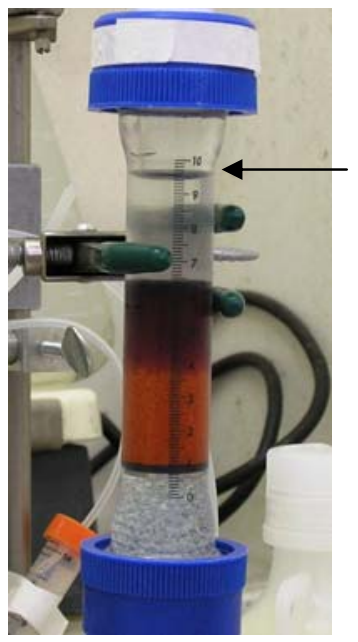

Figure 2.4. In-Column Pretreatment Processing (a) Green Column (MB 6C-370/745 stored wet at $35^{\circ} \mathrm{C}$ ) During H-Form Conversion and (b) White Column (MB 6C-370/745 stored wet at ambient temperature) During Na-Form Conversion. (The Na-form resin is darker than the H-form resin. Arrows point to the water level above the resin bed.) 
The AP-101 feed simulant was filtered through a $0.45-\mu \mathrm{m}$-pore-size nylon filter before use to remove any trace solid particulate matter. Approximately $3.5 \mathrm{~L}$ of AP-101 simulant per column test was prepared by spiking with a radioactive $\mathrm{Cs}$ tracer. The feed ${ }^{137} \mathrm{Cs}$ activity concentrations were $\sim 0.15 \mu \mathrm{Ci} / \mathrm{mL}$. This activity level was sufficient to discern a decontamination factor $\geq 50,000$.

Samples were collected periodically during the simulant feed processing to evaluate Cs breakthrough profiles. Feed effluent samples were collected three to four times per day in 10-mL aliquots; between sampling events, the effluent was collected as a composite. The temperature was recorded with each sampling event. Eluate samples were collected in nominal 1-BV increments. Other process solutions (feed displacement and DI water rinses) were collected separately as composite effluents. The Cs loading and elution characteristics were monitored from the sample ${ }^{137} \mathrm{Cs}$-tracer activity using gamma spectrometry.

After processing, the ion exchange column assembly was disconnected at the quick disconnects and removed from the fume-hood containment. The column assembly was mounted in front of a side-looking gamma energy analysis (GEA) detector to measure residual ${ }^{137} \mathrm{Cs}$. Care was taken to position the resin bed itself in front of the detector face. The column assembly in the counting chamber included the ion exchange resin, the interstitial fluid, glassware, the fluid head above the resin bed, and the fluid immediately below the resin bed. Thus, ${ }^{137} \mathrm{Cs}$ tracer in any of the non-resin areas could shine into the detector and bias the measurement. An approximate geometry correction was applied, although the exact geometry presented to the detector was neither calibrated nor was the Cs location on the system known. A conservative uncertainty of a factor of two was assigned to the column ${ }^{137} \mathrm{Cs}$-tracer measurements.

\subsection{Ion Exchange Processing Data Analysis}

The ion exchange process data manipulations are defined in this section.

\subsubsection{Bed Volume}

In all cases, one BV was defined as the $\mathrm{Na}$-form resin $\mathrm{BV}$ calculated after initial pretreatment cycling in the column. The $\mathrm{BV}$ was determined after completing the $0.5 \mathrm{M} \mathrm{NaOH}$ preconditioning rinse. The $\mathrm{BV}$ is an arbitrary value; the $\mathrm{H}$-form was typically $20 \%$ smaller than the $\mathrm{Na}$-form and was consistent with observed expansion and contractions before aging (Fiskum et al. 2006).

\subsubsection{Resin Mass in Column}

The dry $\mathrm{H}$-form resin mass loaded into the ion exchange columns was determined indirectly. Two duplicate volumes of settled $\mathrm{H}$-form resin slurries were measured in a $25-\mathrm{mL}$ graduated cylinder. One sample was used for column testing. Excess water was removed from the second sample, which was then taken to dryness under vacuum at $50^{\circ} \mathrm{C}$. Dryness was defined as a resin mass change of $<0.5 \%$ over a $7-\mathrm{h}$ period. The dry H-form resin mass in each ion exchange column was calculated relative to the measured volume splits and the dry mass of the dried split according to Equation 2.2. The mass uncertainty was estimated to be $\pm 2 \%$. 


$$
\mathrm{M}_{\mathrm{c}}=\frac{\mathrm{V}_{\mathrm{c}} * \mathrm{M}_{\mathrm{d}}}{\mathrm{V}_{\mathrm{d}}}
$$

where $\mathrm{M}_{\mathrm{c}}=$ mass of dry $\mathrm{H}$-form resin loaded in the column

$\mathrm{V}_{\mathrm{c}}=$ volume of wet $\mathrm{H}$-form resin transferred to the column

$\mathrm{V}_{\mathrm{d}}=$ volume of wet $\mathrm{H}$-form duplicate resin used for dry mass determination

$\mathrm{M}_{\mathrm{d}}=$ mass of dry H-form duplicate resin used for dry mass determination.

The dry H-form resin mass divided by the expanded wetted Na-form resin volume was calculated as the dry bed density $\left(\delta_{\mathrm{DRB}}\right)$ according to Equation 2.3.

$$
\delta_{D R B}=\frac{M_{c}}{B V}
$$

\subsubsection{Loading Profile}

The Cs loading profiles are provided for all resins tested. Each loading profile is plotted as $\% \mathrm{C} / \mathrm{C}_{\mathrm{o}}$ vs. the BVs of feed processed through each column. The $\mathrm{C}_{\mathrm{o}}$ value for the ${ }^{137} \mathrm{Cs}$ tracer was determined for each feed condition. In most cases, the $\mathrm{C} / \mathrm{C}_{\mathrm{o}}$ is plotted on a probability scale. A probability scale is the inverse of the Gaussian cumulative distribution function (characteristic of ideal ion exchange theory) such that a graph of the sigmoidally shaped Gaussian cumulative distribution function versus the log BV appears as a straight line (Buckingham 1967). The probability scale has two advantages: 1) making low $\mathrm{C} / \mathrm{C}_{\mathrm{o}}$ data easily readable such that the initial load performance is discernable and 2) easily estimating extrapolation (or interpolation) to 50\% breakthrough. Less-than values are recorded on the breakthrough profiles as actual values; the less-than values can be identified from the data-input tables. Also shown on each loading figure is the minimum Cs removal required for the effluent to meet design-basis ${ }^{137} \mathrm{Cs}$ loading in the vitrified glass product (contract limit). For the AP-101 actual tank waste, the maximum $\% \mathrm{C} / \mathrm{C}_{\mathrm{o}}$ is 0.091 , corresponding to a $\mathrm{DF}$ of 1100 . $^{\text {(a) }}$

Key measures of resin performance can be ascertained from the load profiles. The $50 \% \mathrm{Cs}$ breakthrough point is indicative of the breakthrough resin capacity. The higher the bed volumes processed before reaching $50 \%$ breakthrough, the higher the resin capacity. The onset of $\mathrm{Cs}$ breakthrough, defined as the $\mathrm{BVs}$ processed before the breakthrough $\mathrm{C} / \mathrm{C}_{\mathrm{o}}$ starts to increase, is a measure of selectivity and/or kinetics. The onset breakthrough volume decreases as resin selectivity for Cs or mass transfer rate diminishes. A faster Cs breakthrough results in smaller effluent composite volumes meeting WTP requirements. Ideally, one would want delayed observance of any Cs breakthrough and a very steep breakthrough curve where $50 \%$ breakthrough is observed after processing large volumes of feed. The total BVs processed before reaching the contract limit breakthrough is indicative of the usefulness of the resin in attaining the WTP processing requirements before regeneration is considered. Higher BVs processed before reaching the contract limit indicate higher feed volumes before regeneration is required.

(a) The contract limit is a function of ${ }^{137} \mathrm{Cs}$ and $\mathrm{Na}$ concentrations in the feed, the end-product glass Na loading, and the glass density. Because of radioactive decay, the ${ }^{137} \mathrm{Cs}$ feed concentration will decrease with time. The assumptions and calculations for the given AP-101 contract limit were previously reported (Fiskum et al. 2006). 


\subsubsection{Elution Profile}

Each elution profile is plotted as $\mathrm{C} / \mathrm{C}_{\mathrm{o}}$ (eluate $\mathrm{Cs}$ concentration normalized to the AP-101 simulant feed Cs concentration) versus the BVs of eluant processed through each column. As with the load profile, the $\mathrm{BV}$ represents the resin $\mathrm{BV}$ in the expanded Na-form (in $0.5 \mathrm{M} \mathrm{NaOH}$ ). The $\mathrm{C} / \mathrm{C}_{\mathrm{o}}$ is plotted on a $\log$ scale to better discern the low relative Cs concentrations associated with the elution tailing effect. Ideal elution behavior will cause Cs to be removed quickly with virtually no residual Cs on the column upon completion. As eluant volumes applied to effectively elute Cs from the ion exchanger decrease, the WTP plant operations are expected to improve. This is accomplished by reducing resin-regeneration process time, extending resin lifetime (lower resin exposure to dissolved oxygen), and improving the ability to meet spent-resin disposal requirements.

\subsubsection{Residual Cesium on Resin Bed}

The residual Cs on the resin following elution potentially affects follow-on processing with respect to Cs bleed into the effluent during the subsequent cycle and the spent-resin Cs loading at the end of the resin processing life. A mass-balance approach was used to determine the total Cs on the resin bed as a function of the elution and water-rinse volumes. The total Cs remaining on the resin bed, normalized to a per gram dry H-form basis, was calculated starting from the residual ${ }^{137} \mathrm{Cs}$ tracer in the resin bed. The Cs quantity on the resin bed as a function of eluate BV processed was calculated by adding the contribution of each eluate sample Cs quantity to the resin in reverse order. Working backward through the water rinse and elution process, the total $\mathrm{Cs}$ on the resin was reconstructed and normalized to the mass of dry $\mathrm{H}$-form resin. Thus, an alternate elution profile is presented of total Cs remaining on the resin bed on a per $\mathrm{g}$ dry $\mathrm{H}$-form resin basis as a function of the elution and water-rinse BVs.

The WTP design-basis residual Cs content in spent resin was determined to be $4.2 \mu \mathrm{g} / \mathrm{g}$ in spherical $\mathrm{RF}$ to allow for safe handling of the spent resin (Fiskum et al. 2006). The 4.2- $\mu \mathrm{g} / \mathrm{g}$ limit was used as a benchmark for comparing the elution performance of the various test resins.

\subsection{Quality Assurance and Quality Control}

The following sections describe the quality assurance (QA) program and quality control (QC) measures applied to the conduct of work. The data represented in this report will refer to PNWD (in support of Bechtel National, Inc. Support Project [BNI-SP] before February 12, 2007) or PNNL (in support of Waste Treatment Plant Support Program [WTPSP] following February 12, 2007). Both of these projects performed work to the same QA program.

\subsubsection{Application of WTPSP Quality Assurance Requirements}

As of February 2007, the QA program is described as follows:

PNNL's QA program is based on requirements defined in DOE Order 414.1C, Quality Assurance and 10 CFR 830, Energy/Nuclear Safety Management, Subpart A-Quality Assurance Requirements (a.k.a., the Quality Rule). PNNL has chosen to implement the requirements of DOE Order 414.1C and 10 CFR 830, Subpart A by integrating them into the laboratory's management systems and daily operating processes. The procedures necessary to implement the requirements are documented through PNNL's Standards-Based Management System. 
PNNL implemented the RPP-WTP quality requirements by performing work in accordance with the River Protection Project - Waste Treatment Plant Support Program (RPP-WTP) Quality Assurance Plan (RPP-WTP-QA-001, QAP). Work was performed to the quality requirements of NQA-1-1989 Part I, Basic and Supplementary Requirements, NQA-2a-1990, Part 2.7 and DOE/RW-0333P, Rev 13, Quality Assurance Requirements and Descriptions (QARD). These quality requirements are implemented through the River Protection Project - Waste Treatment Plant Support Program (RPP-WTP) Quality Assurance Manual (RPP-WTP-QA-003, QAM).

A matrix that cross-references the NQA-1, NQA-2a, and QARD requirements with PNNL's procedures for this work was given in the test plan, TP-RPP-WTP-440. ${ }^{\text {(a) }}$ It included justification for those requirements not implemented. The quality assurance requirements of DOE/RW-0333P, Rev 13, Quality Assurance Requirements and Descriptions (QARD) and DOE Order 414.1C were not identified as a requirement for this work in the test specification.

\subsubsection{Conduct of Experimental and Analytical Work}

Experiments that were not method-specific were performed in accordance with PNNL's procedures QA-RPP-WTP-1101 "Scientific Investigations" and QA-RPP-WTP-1201 "Calibration Control System," verifying that sufficient data were taken with properly calibrated measuring and test equipment (M\&TE) to obtain quality results.

As specified in the supporting Test Specification, 24590-PTF-TSP-RT-06-0001, Rev. 0, BNI's QAPjP, PL-24590-QA00001, was not applicable because the work was not performed in support of environmental/regulatory testing, and the data will not be used as such.

$\mathrm{A}{ }^{137} \mathrm{Cs}$ tracer was used to evaluate Cs loading and elution characteristics in the column process tests. Absolute ${ }^{137} \mathrm{Cs}$ concentrations in the effluent samples and residual ${ }^{137} \mathrm{Cs}$ on the resin bed were determined using a GEA system consisting of a multi-channel analyzer and a suitable detector, such as a high-purity germanium detector. Counting was performed according to the procedure Gamma Energy Analysis (GEA) and Low Energy Photon Spectroscopy (LEPS), PNL-ALO-450. The procedure Routine Research Operations, RPL-OP-001, was used to control counting of the elution samples on a Cobra II Series automated gamma counter (Packard Instruments Company, Meriden, CT). In this case, absolute counting efficiency and energy calibration were not required because the analyses were comparative. The automated GEA system was monitored for consistent operation by counting known volumes of the ${ }^{137} \mathrm{Cs}-$ traced process batch comparator samples both before and after one-day's analysis sequence. The instrument background was counted at least five times during each analysis sequence of ion exchange eluates. The elution results are reported for "indication-only" because the automated system was not calibrated with NIST-traceable standards.

Additional measuring and test equipment that were used included rulers, clocks, pressure gauges, thermometers, thermocouples with meter readouts, and balances. The clocks, rulers, and gauges were standard laboratory equipment for use as indicators only. The thermometers and thermocouple-meter combinations, used for monitoring chamber temperatures, are calibrated annually by the PNNL

(a) JJ Toth, TP-RPP-WTP-449. April 2006. Consequences of Storage and Aging Conditions on Spherical Resorcinol Formaldehyde Resin Performance. Rev. 0. Battelle-Pacific Northwest Division, Richland, WA. 
Instrument Calibration Facility. The thermometers were calibrated January 20, 2006. The recalibration was due before the chambers were opened. The as-found condition determined 5 months after the calibration expired (June 6, 2007) was within the allowed tolerance of $\pm 2^{\circ} \mathrm{C}$. Balances are calibrated annually by a certified contractor, QC Services, Portland, Oregon. A balance performance check was conducted each day the balance was used.

\subsubsection{Internal Data Verification and Validation}

PNNL addressed internal verification and validation activities by conducting an independent technical review of the final data report in accordance with PNNL's procedure QA-RPP-WTP-604, part of PNNL's RPP-WTP Quality Assurance Manual. This review verified that the reported results were traceable, that inferences and conclusions were soundly based, and that the reported work satisfied the Test Plan objectives. 


\subsection{Results}

This section describes experimental results from the storage and aging process. It also compares the Cs ion exchange loading and elution profiles with profiles generated before aging.

\subsection{Physical Properties Post-Storage}

The gross masses of the storage bottles and vials retrieved from storage were determined and compared to the ingoing gross masses. The initial net sample masses (inclusive of resin and storage fluid, as applicable) and mass losses are shown in Table 3.1. The average mass losses for the wet and dry storage conditions were negligible. This indicated that the containers were well-sealed for the test duration.

Table 3.1. Mass Loss After One Year in Storage

\begin{tabular}{|c|c|c|c|c|c|c|}
\hline \multirow[b]{2}{*}{ Lot Number } & \multicolumn{3}{|c|}{ Dry Storage Condition } & \multicolumn{3}{|c|}{ Wet Storage Condition } \\
\hline & Sample ID & $\begin{array}{l}\text { Initial Net } \\
\text { Mass, g }\end{array}$ & $\begin{array}{r}\text { Mass } \\
\text { Loss, } \mathrm{g}\end{array}$ & Sample ID & $\begin{array}{c}\text { Initial Net } \\
\text { Mass, } \mathbf{g}\end{array}$ & $\begin{array}{c}\text { Mass Loss, } \\
\mathrm{g}\end{array}$ \\
\hline \multirow[t]{9}{*}{ MB 5J-370/686 } & MBJ-DL-1 & 14.0502 & 0.0374 & MBJ-WL-1 & 65.8446 & 0.0139 \\
\hline & MBJ-DL-2 & 14.3535 & -0.0039 & MBJ-WL-2 & 63.7703 & 0.1430 \\
\hline & MBJ-DL-3 & 14.0107 & 0.0003 & MBJ-WL-3 & 21.2112 & 0.1362 \\
\hline & MBJ-DM-1 & 15.0752 & 0.0576 & MBJ-WM-1 & 63.4589 & 0.2541 \\
\hline & MBJ-DM-2 & 13.8502 & 0.0411 & MBJ-WM-2 & 61.9615 & 0.1935 \\
\hline & MBJ-DM-3 & 13.9357 & -0.0190 & MBJ-WM-3 & 21.3874 & 0.1361 \\
\hline & MBJ-DH-1 & 14.0833 & 0.1406 & MBJ-WH-1 & 65.8533 & 0.4088 \\
\hline & MBJ-DH-2 & 13.6257 & 0.1551 & MBJ-WH-2 & 63.6072 & 0.4516 \\
\hline & MBJ-DH-3 & 13.2992 & 0.1499 & MBJ-WH-3 & 21.7435 & 0.1918 \\
\hline \multirow[t]{6}{*}{ MB 6C-370/745 } & MBC-DL-1 & 12.4324 & -0.0037 & MBC-WL-1 & 63.3100 & 0.0460 \\
\hline & MBC-DL-2 & 12.7062 & -0.0024 & MBC-WL-2 & 21.9383 & 0.4492 \\
\hline & MBC-DM-1 & 12.7691 & 0.0430 & MBC-WM-1 & 62.4620 & 0.2250 \\
\hline & MBC-DM-2 & 11.9977 & 0.0550 & MBC-WM-2 & 21.5962 & 0.1759 \\
\hline & MBC-DH-1 & 12.3511 & 0.1507 & MBC-WH-1 & 62.5680 & 0.4815 \\
\hline & MBC-DH-2 & 11.8932 & 0.1635 & MBC-WH-2 & 21.2054 & 0.2586 \\
\hline \multirow[t]{6}{*}{ BSC 3380-3-0200 } & BSC-DL-1 & 12.6375 & 0.0034 & BSC-WL-1 & 62.6357 & 0.0400 \\
\hline & BSC-DL-2 & 13.0956 & -0.0016 & BSC-WL-2 & 21.9569 & 0.0849 \\
\hline & BSC-DM-1 & 12.9437 & -0.0200 & BSC-WM-1 & 64.7641 & 0.3371 \\
\hline & BSC-DM-2 & 13.1426 & -0.0097 & BSC-WM-2 & 21.9231 & 0.1123 \\
\hline & BSC-DH-1 & 12.3955 & 0.1553 & BSC-WH-1 & 61.9618 & 0.4756 \\
\hline & BSC-DH-2 & 13.1245 & 0.1818 & BSC-WH-2 & 22.4915 & 0.3511 \\
\hline \multicolumn{3}{|l|}{ Average mass loss } & 0.0607 & & & 0.2365 \\
\hline
\end{tabular}


Spherical RF has been shown to react with dissolved oxygen over time. The upper wet resin surface darkens as a physical manifestation of resin oxidation. This effect was noticed on past-archived resin sub-samples as well as during ion exchange processing. The resins retrieved from storage had virtually no black band at the top surface indicative of resin oxidation. This indicated that the resins were wellprotected from oxygen exposure. Photographs of the resins as retrieved from storage are provided in Appendix C.

The retrieved wet resin volumes for the five selected wet resins were compared to the measured resin volumes before storage. A slight $2.4 \%$ increase in resin volume from $42 \mathrm{~mL}$ to $43 \mathrm{~mL}$ may have occurred; the volume increase was difficult to discern above the uncertainty of the measurement. There was no difference in volume expansion as a function of storage temperature within the uncertainty of the measurements.

The resin pre-treatment shrink-swell data are summarized in Table 3.2. The aged resin expansion factors from the open beaker pretreatment processing were lower than previously observed for non-aged resins ( $\sim 21 \%$ versus $\sim 26 \%$, Fiskum et al. 2006). Combining the slight swelling observed during the storage period results in an average overall expansion of $\sim 24 \%$.

Table 3.2. Resin Pretreatment Swell-Data Summary

\begin{tabular}{|c|c|c|c|c|c|c|}
\hline \multirow[b]{2}{*}{ PNWD ID } & \multirow[b]{2}{*}{ Lot ID } & \multirow[b]{2}{*}{$\begin{array}{l}\text { Storage } \\
\text { condition }\end{array}$} & \multicolumn{3}{|c|}{ 1st Cycle Expansion } & \multirow[b]{2}{*}{$\begin{array}{c}\text { Combined } \\
\text { Expansion, } \\
\%^{(a)}\end{array}$} \\
\hline & & & $\begin{array}{l}\text { As-received } \\
\text { Aged } \\
\text { H-form, mL }\end{array}$ & $\begin{array}{c}\text { Pretreated } \\
\text { H-form, } \\
\text { mL }\end{array}$ & $\begin{array}{c}\text { Expansion, } \\
\%\end{array}$ & \\
\hline MBJ-DH-3 & $5 \mathrm{~J}-370 / 686$ & Dry, $45 \mathrm{C}$ & 21 & 25 & 20 & NM \\
\hline MBJ-WL-1 & $5 \mathrm{~J}-370 / 686$ & Wet, $18-24^{\circ} \mathrm{C}$ & 43 & 53 & 23 & 26 \\
\hline MBJ-WH-2 & $5 \mathrm{~J}-370 / 686$ & Wet, $45^{\circ} \mathrm{C}$ & 43 & 51 & 20 & 22 \\
\hline MBC-WL-1 & $6 C-370 / 745$ & Wet, $18-24^{\circ} \mathrm{C}$ & 43 & 53 & 24 & 26 \\
\hline MBC-WM-1 & $6 C-370 / 745$ & Wet, $35^{\circ} \mathrm{C}$ & 43 & 52 & 21 & 23 \\
\hline MBC-WH-1 & $6 C-370 / 745$ & Wet, $45^{\circ} \mathrm{C}$ & 43 & 51 & 19 & 21 \\
\hline
\end{tabular}

Table 3.3 summarizes the resin bed densities determined from pretreatment testing. The dry bed densities measured previously were 0.369 and $0.362 \mathrm{~g} / \mathrm{mL}$ for un-aged resin lots $5 \mathrm{~J}-370 / 686$ and 6C-370/745, respectively (Fiskum et al. 2006). The aging process and storage temperatures did not significantly alter the $\mathrm{H}$-form resin bed densities. However, the resins stored at $45^{\circ} \mathrm{C}$ appeared to have slightly higher bed densities (4\% higher than the non-aged resins) than the resins stored at ambient temperature ( 1 to $2 \%$ higher than the non-aged resins). Note that these differences are within the experimental uncertainties $\sim \pm 2 \%$. 
Table 3.3. H-Form Resin Dry Bed Densities

\begin{tabular}{|c|c|c|c|c|c|c|}
\hline $\begin{array}{l}\text { Resin ID } \\
\text { Lot \# }\end{array}$ & Lot ID & $\begin{array}{l}\text { Storage } \\
\text { condition }\end{array}$ & $\begin{array}{c}\text { Settled } \\
\text { Vol., mL }\end{array}$ & $\begin{array}{c}\text { Dry Mass, } \\
\text { g }\end{array}$ & $\begin{array}{l}\text { Settled Resin } \\
\text { Density, } \\
\text { g/mL }\end{array}$ & $\begin{array}{c}\text { Ratio of } \\
\text { Aged/ } \\
\text { Original }\end{array}$ \\
\hline MBJ-DH-3 & $5 \mathrm{~J}-370 / 686$ & Dry, $45^{\circ} \mathrm{C}$ & 9.6 & 3.6525 & 0.38 & $1.03^{(\mathrm{a})}$ \\
\hline MBJ-WL-1 & $5 \mathrm{~J}-370 / 686$ & Wet, $18-24^{\circ} \mathrm{C}$ & 16.0 & 6.0113 & 0.376 & 1.02 \\
\hline MBJ-WH-2 & $5 \mathrm{~J}-370 / 686$ & Wet, $45^{\circ} \mathrm{C}$ & 16.2 & 6.1955 & 0.382 & 1.04 \\
\hline MBC-WL-1 & $6 \mathrm{C}-370 / 745$ & Wet, $18-24^{\circ} \mathrm{C}$ & 16.0 & 5.8040 & 0.363 & 1.00 \\
\hline MBC-WM-1 & $6 C-370 / 745$ & Wet, $35^{\circ} \mathrm{C}$ & 15.9 & 5.8797 & 0.370 & 1.02 \\
\hline MBC-WH-1 & $6 \mathrm{C}-370 / 745$ & Wet, $45^{\circ} \mathrm{C}$ & 16.0 & 6.0200 & 0.376 & 1.04 \\
\hline
\end{tabular}

\subsection{Ion Exchange Loading Results}

The Cs ion exchange breakthrough profiles are shown in Figure 3.1 (Lot 6C-370/745) and Figure 3.2 (Lot 5J-370/686) for the resins that were stored in the wet condition. The direct comparison of the wet versus dry storage media is shown in Figure 3.3. The actual data points plotted in the three figures are provided in Table 3.4.

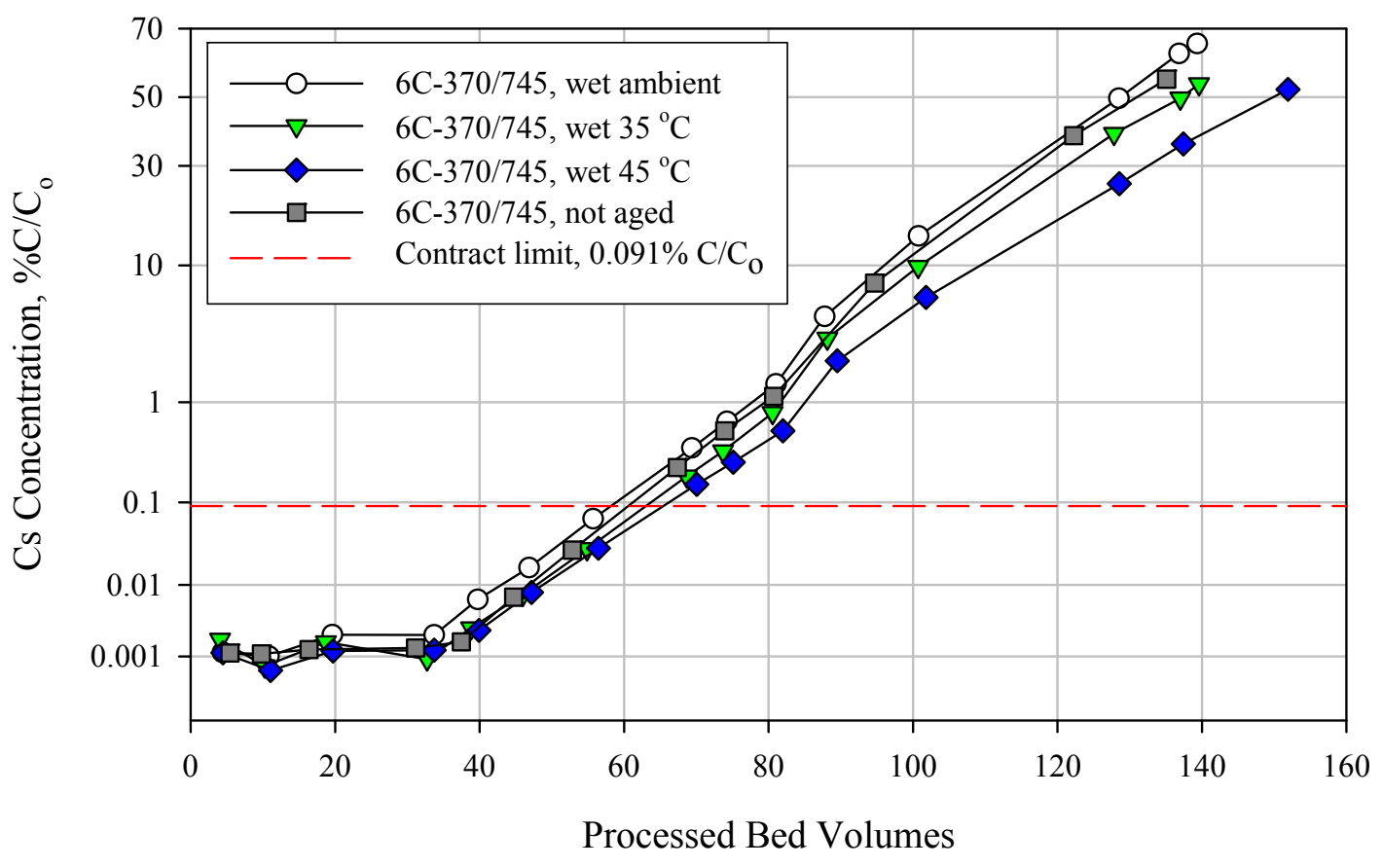

Figure 3.1. Microbeads Spherical RF Resin Lot 6C-370/745 Cesium Breakthrough Profiles After One Year Storage and Aging at Three Temperatures 


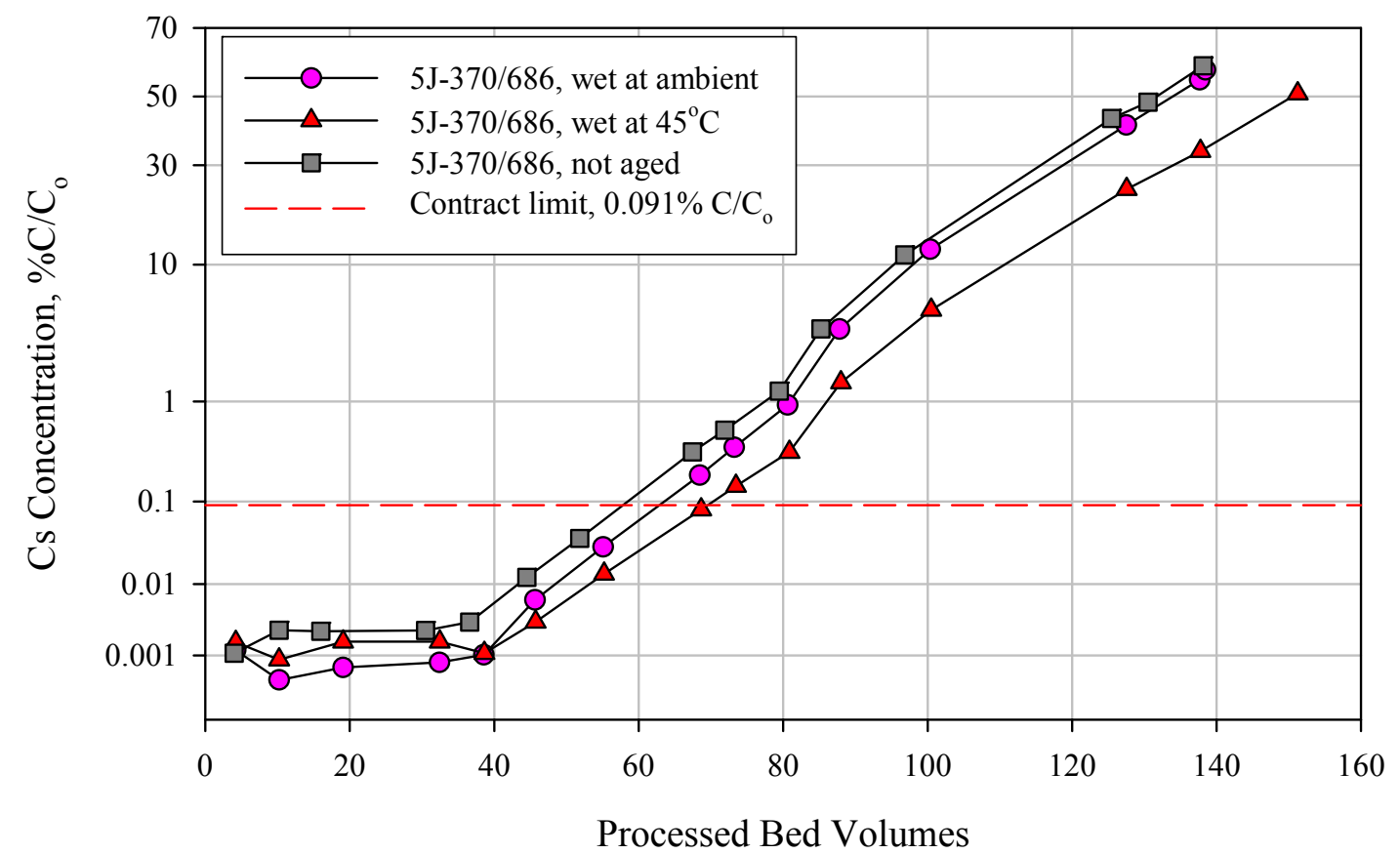

Figure 3.2. Microbeads Spherical RF Lot number 5J-370/686 Cesium Breakthrough Profiles After One Year Storage and Aging at Two Temperatures

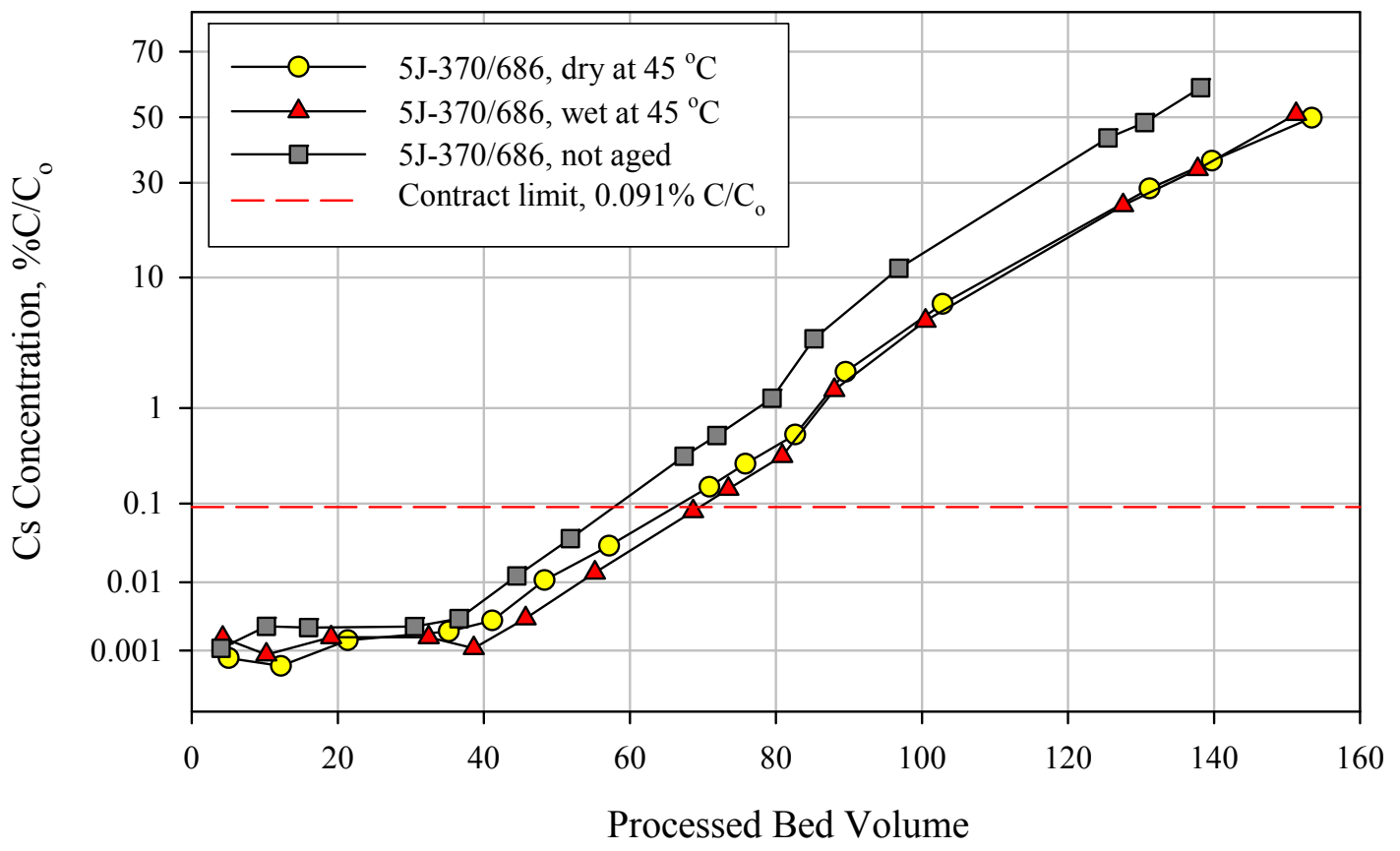

Figure 3.3. Microbeads Spherical RF Lot Number 5J-370/686 Cesium Breakthrough Profiles After One Year Storage and Aging in Wet and Dry Condition at $45^{\circ} \mathrm{C}$ 
Table 3.4. Effluent Cs Concentration During Loading

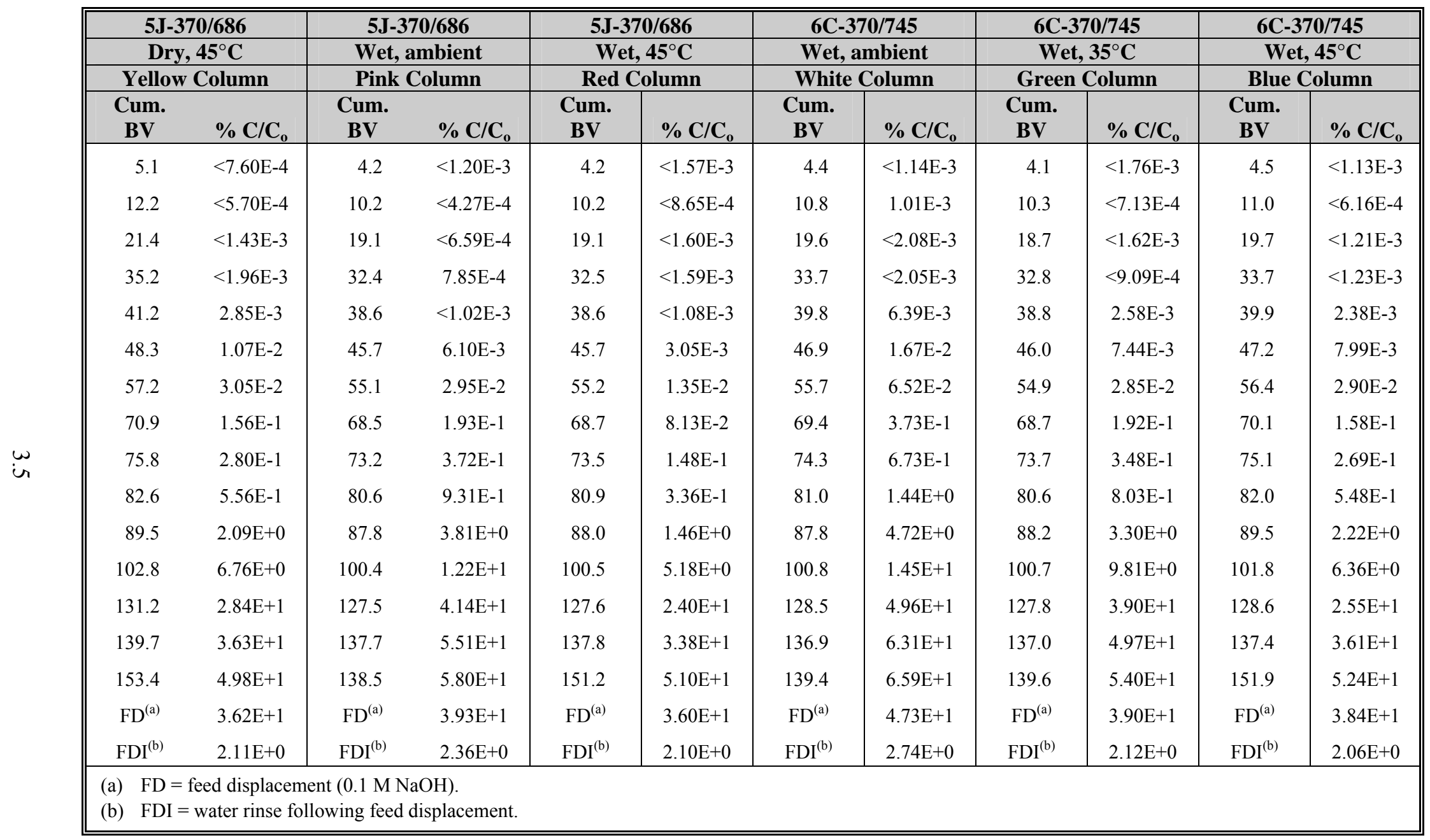


The un-aged resin loading curves generated shortly after resin receipt at PNNL and previously reported as part of test wave $4 \mathrm{a}$ and $4 \mathrm{~b}$ (Fiskum et al. 2006) are also shown in the figures as points of reference. Because all ion exchange processing variables, including stock simulant feed, columns and associated configurations, and process conditions, were constant between the un-aged and aged resin load and elute tests, the data are directly comparable.

Through the first four effluent samples, generally spanning 0 to $\sim 35 \mathrm{BVs}$, the effluent Cs concentrations were below the detection limit. The loading profiles beyond $35 \mathrm{BVs}$ were linear on the probability plots, indicating ideal loading characteristics. The transition at $\sim 80 \mathrm{BVs}$ corresponded with the flowrate change from 1.5 to $3.0 \mathrm{BV} / \mathrm{h}$.

No degradation of $\mathrm{Cs}$ ion exchange loading performance was observed. In all aspects of the loading characteristics (onset of Cs breakthrough, BVs processed before reaching contract limit, and BVs processed before reaching 50\% Cs breakthrough), the aged resins performed equal to, or better than the un-aged material. Both resin lots resulted in virtually identical loading profiles when stored at ambient temperature. Increasing the storage temperature improved the Cs loading profile. The Cs loading performance summaries are enumerated in Table 3.5 and Table 3.6.

Table 3.5. Cs Loading Parameters for Resin Lot MB 6C-370/745

\begin{tabular}{||l|c|c|c|c||}
\hline \multirow{2}{*}{ Parameter } & \multirow{3}{|c|}{ Aged } \\
\cline { 3 - 5 } & Un-aged & Wet at $\sim \mathbf{2 2}^{\mathbf{0}} \mathbf{C}$ & Wet at $\mathbf{3 5}^{\mathbf{0}} \mathbf{C}$ & Wet at $\mathbf{4 5}^{\mathbf{0}} \mathbf{C}$ \\
\hline Cs breakthrough onset, BV & 37 & 34 & 37 & 37 \\
\hline Cs contract limit breakthrough, BV & 61 & 58 & 63 & 65 \\
\hline $50 \%$ Cs breakthrough, BV & 131 & 129 & 137 & 150 \\
\hline Change in 50\% Cs breakthrough & -- & $-1.5 \%$ & $+4.6 \%$ & $+15 \%$ \\
\hline Total Cs load, mg & 14.9 & 14.1 & 14.6 & 15.4 \\
\hline Cs concentration, mg/g & 2.42 & 2.41 & 2.47 & 2.54 \\
\hline Cs concentration, $\mathrm{mg} / \mathrm{mL}$ & 0.71 & 0.71 & 0.74 & 0.80 \\
\hline
\end{tabular}

Table 3.6. Cs Loading Parameters for Resin Lot 5J-370/686

\begin{tabular}{|l|c|c|c|c|}
\hline \multirow{2}{*}{ Parameter } & & \multicolumn{3}{|c|}{ Aged } \\
\cline { 3 - 5 } & Un-aged & Wet at $\sim \mathbf{2 2}^{\mathbf{0}} \mathbf{C}$ & Wet at $\mathbf{4 5}^{\mathbf{0}} \mathbf{C}$ & Dry at $\mathbf{4 5}^{\mathbf{}} \mathbf{C}$ \\
\hline Cs breakthrough onset, BV & $35-40$ & 40 & 40 & 40 \\
\hline Cs contract limit breakthrough, BV & 58 & 63 & 70 & 66 \\
\hline $50 \%$ Cs breakthrough, BV & 132 & 134 & 150 & 154 \\
\hline Change in 50\% Cs breakthrough & -- & $+1.5 \%$ & $+14 \%$ & $+17 \%$ \\
\hline Total Cs load, $\mathrm{mg}$ & 14.5 & 14.2 & 15.3 & 15.3 \\
\hline Cs concentration, $\mathrm{mg} / \mathrm{g}$ & 2.4 & 2.35 & 2.49 & 2.51 \\
\hline Cs concentration, $\mathrm{mg} / \mathrm{mL}$ & 0.72 & 0.72 & 0.80 & 0.81 \\
\hline \hline
\end{tabular}

The dry storage resulted in improved performance relative to the un-aged resin from all measured performance indicators. The wet form resulted in a slightly improved contract limit breakthrough relative to the dry form; however, the $50 \%$ breakthrough values were identical within the error of the method. 
The enhanced loading properties following the aging test indicated that the resins were well-protected from oxidation. Resin oxidation results in loss of capacity from the loss of Cs ion exchange sites. Based on the combination of slightly improved Cs capacity, slight decrease in resin expansion, and slight increase in resin density, increased resin crosslinking appeared to have occurred at temperatures greater than ambient. The improved exchange capacities of the solvated ion as a result of increased cross-linking has been previously described (Helfferich 1962).

The elution profile for each ion exchange test is shown in Figure 3.4 and Figure 3.5. Also shown for reference are the elution profiles of the un-aged resins. The elution characteristics were typical of other spherical RF elution tests. The Cs eluate concentration was low for the first four BVs collected; during this stage, the water rinse was displaced from the column system, and the resin contact fluid was neutralized. The Cs peak elution occurred at $6 \mathrm{BVs}$, offset by $\sim 1 \mathrm{BV}$ from the test with un-aged resin where a stronger eluant acid strength was used $\left(0.5 \mathrm{M} \mathrm{HNO}_{3}\right.$ as opposed to current testing with $0.45 \mathrm{M}$ $\mathrm{HNO}_{3}$ ). The remainder of the elution profile showed a long tailing effect (logarithmic scale) through the $20 \mathrm{BVs}$ processed, similar to previous observations.

The resins stored at higher temperature appeared to release Cs more slowly in the tailing region as shown by the higher $\mathrm{C} / \mathrm{C}_{\mathrm{o}}$ at a given $\mathrm{BV}>8$. The genesis of the shift or bump in the elution profile started at $\sim 8 \mathrm{BVs}$ and is particularly obvious for the resins that had been stored at $45^{\circ} \mathrm{C}$. This bump was less pronounced for the resin that had been stored at $35^{\circ} \mathrm{C}$ and was not apparent for the resins stored at ambient temperature. This effect is generally consistent with increased cross-linking of the ion exchange material, causing increased tortuosity and associated decrease of the diffusion coefficient (Helfferich 1962).

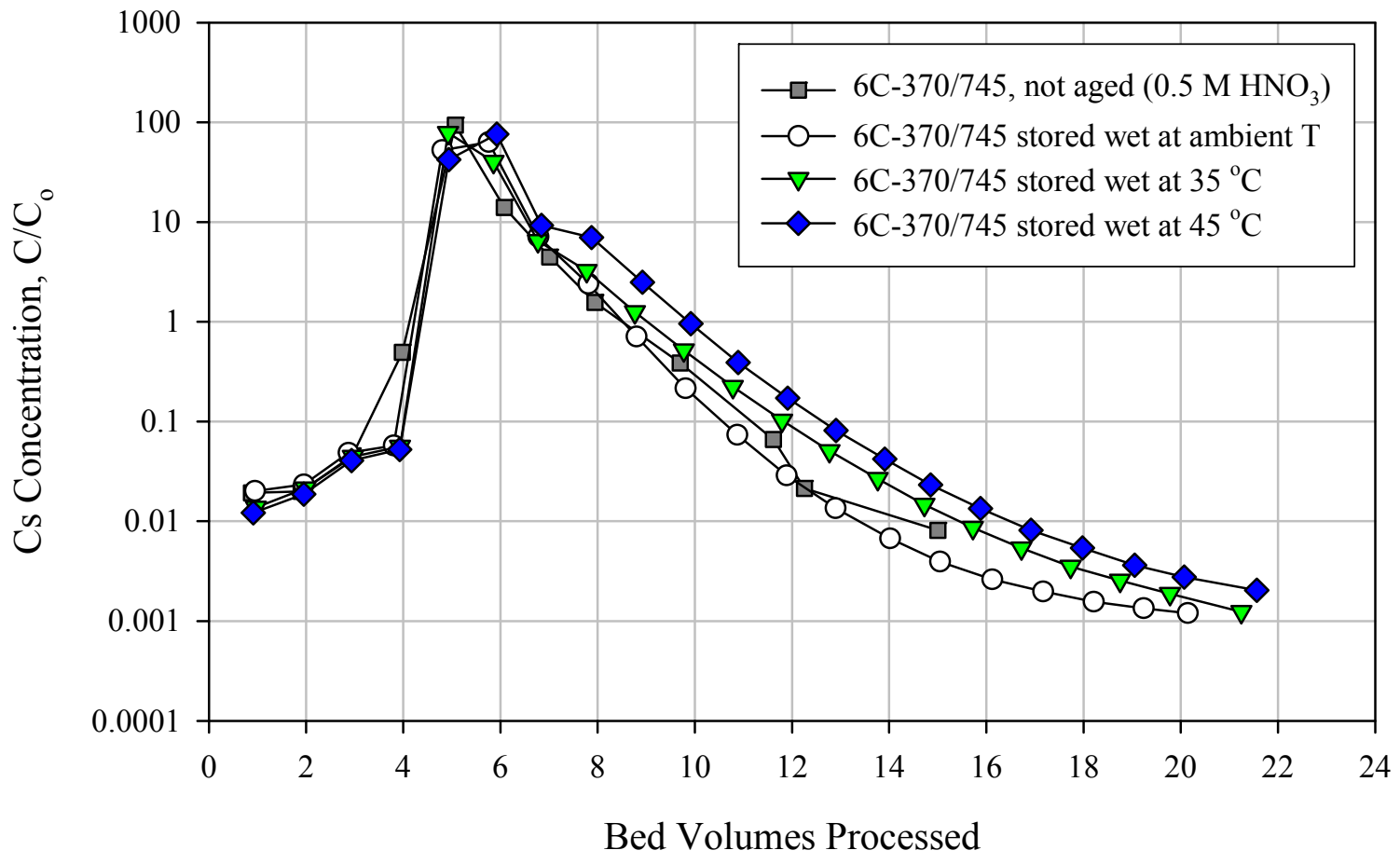

Figure 3.4. Elution Profiles for Resin 6C-370/745 


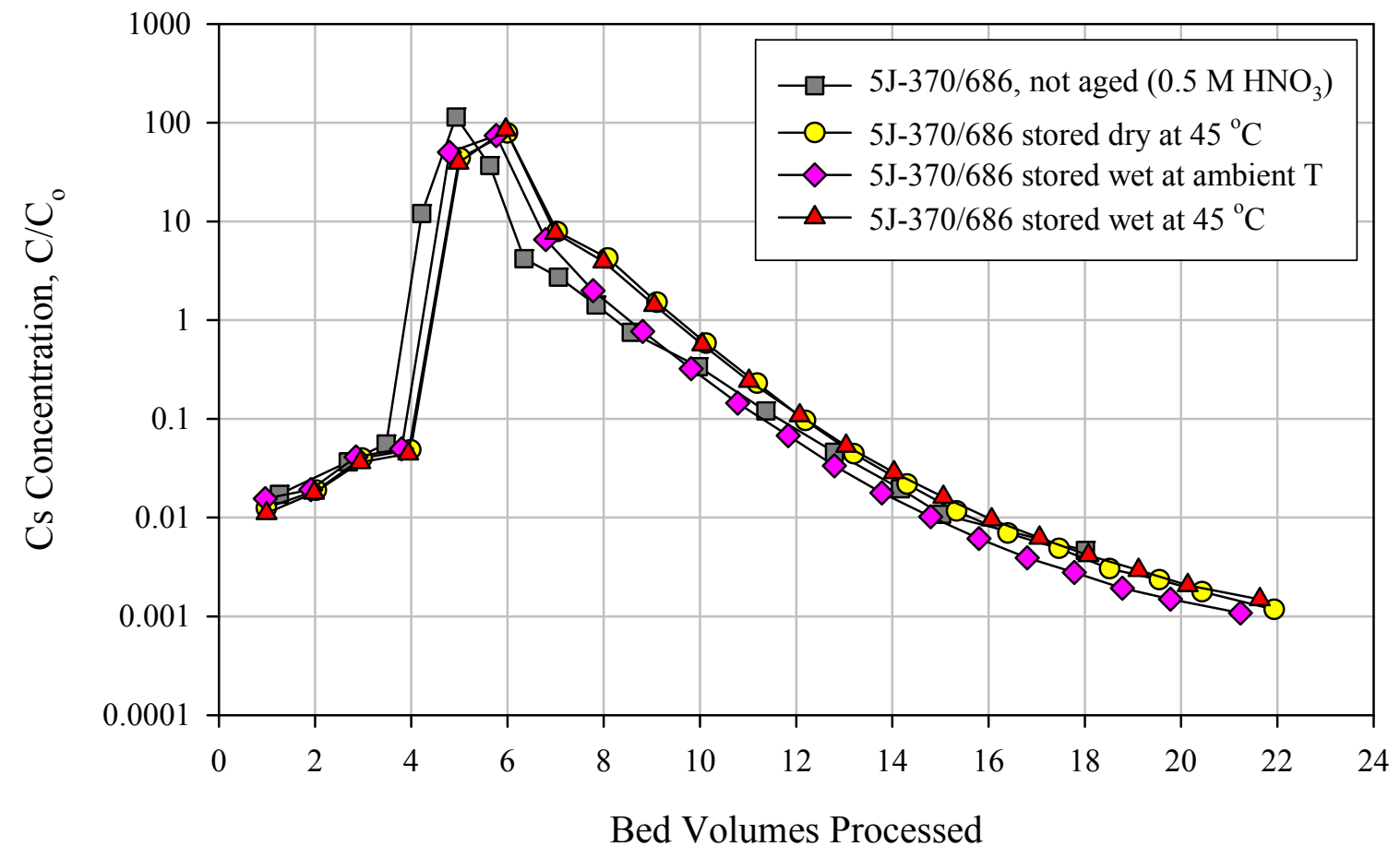

Figure 3.5. Elution Profiles for Resin 5J-370/686

The companion elution curves shown in Figure 3.6 and Figure 3.7 show the residual Cs concentrations on the resin bed as a function of processed volume. The design limit required to meet the spent-resin disposal target, $4.2 \mu \mathrm{g}$ Cs per g dry H-form resin, and the results from the un-aged resin test (Fiskum et al. 2006) are also shown. A clearer distinction of the resin storage temperature is evident in these figures; as the storage temperature increased, the volume required to meet the Cs removal design limit increased. Even in the worst-case test, the design limit was met after processing $12 \mathrm{BVs}$ of eluant. The average final residual Cs loading on the six resin beds following elution and water rinse was 0.33 $\mu \mathrm{g} / \mathrm{g} \pm 15 \%$. The observed variation was well within the overall uncertainty of the measurement, estimated at a factor of two.

The data used to generate the elution profiles are provided in Table 3.7 and Table 3.8. 


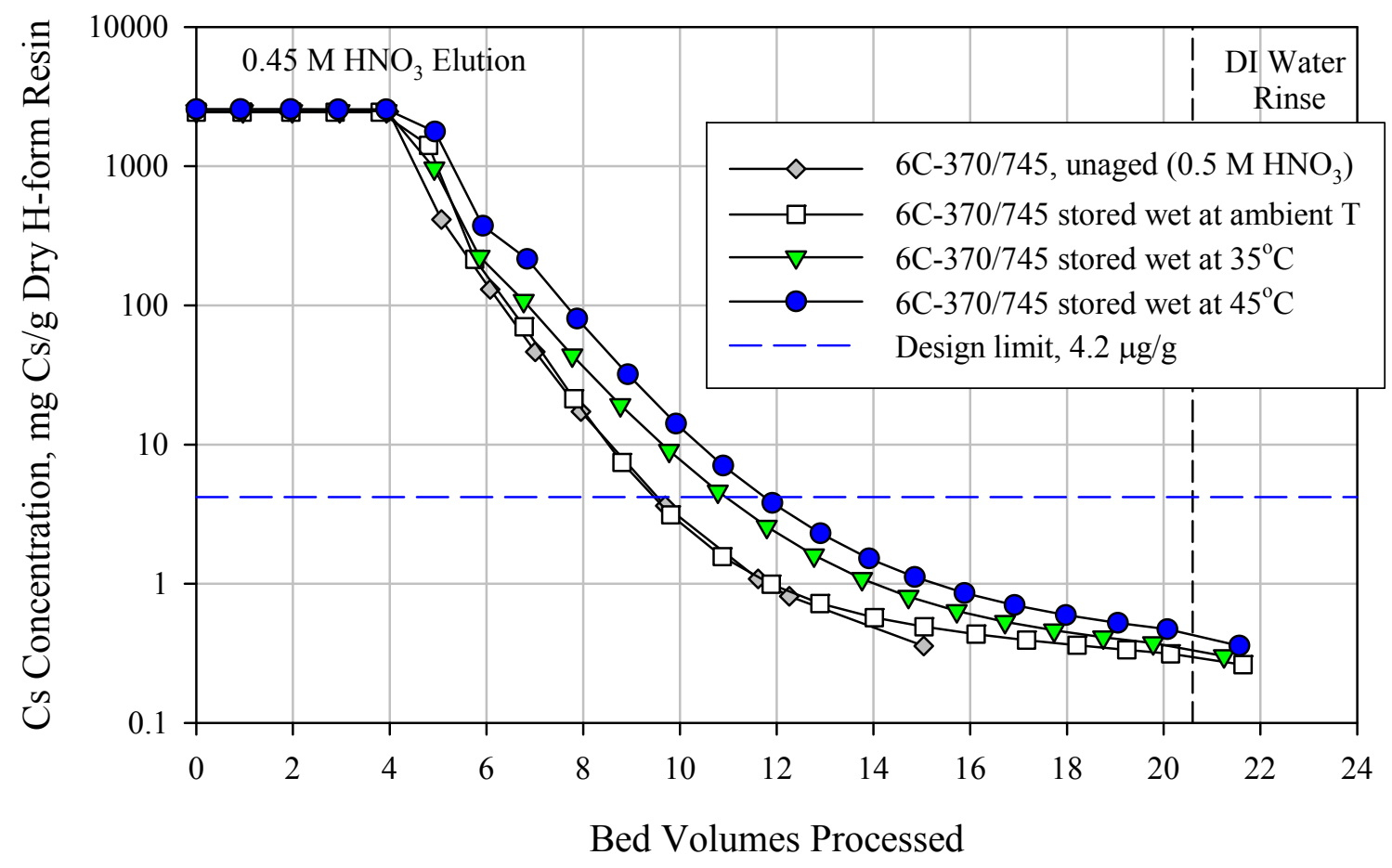

Figure 3.6. Residual Cs Concentration on Resin 6C-370/745 as a Function of Elution Volume

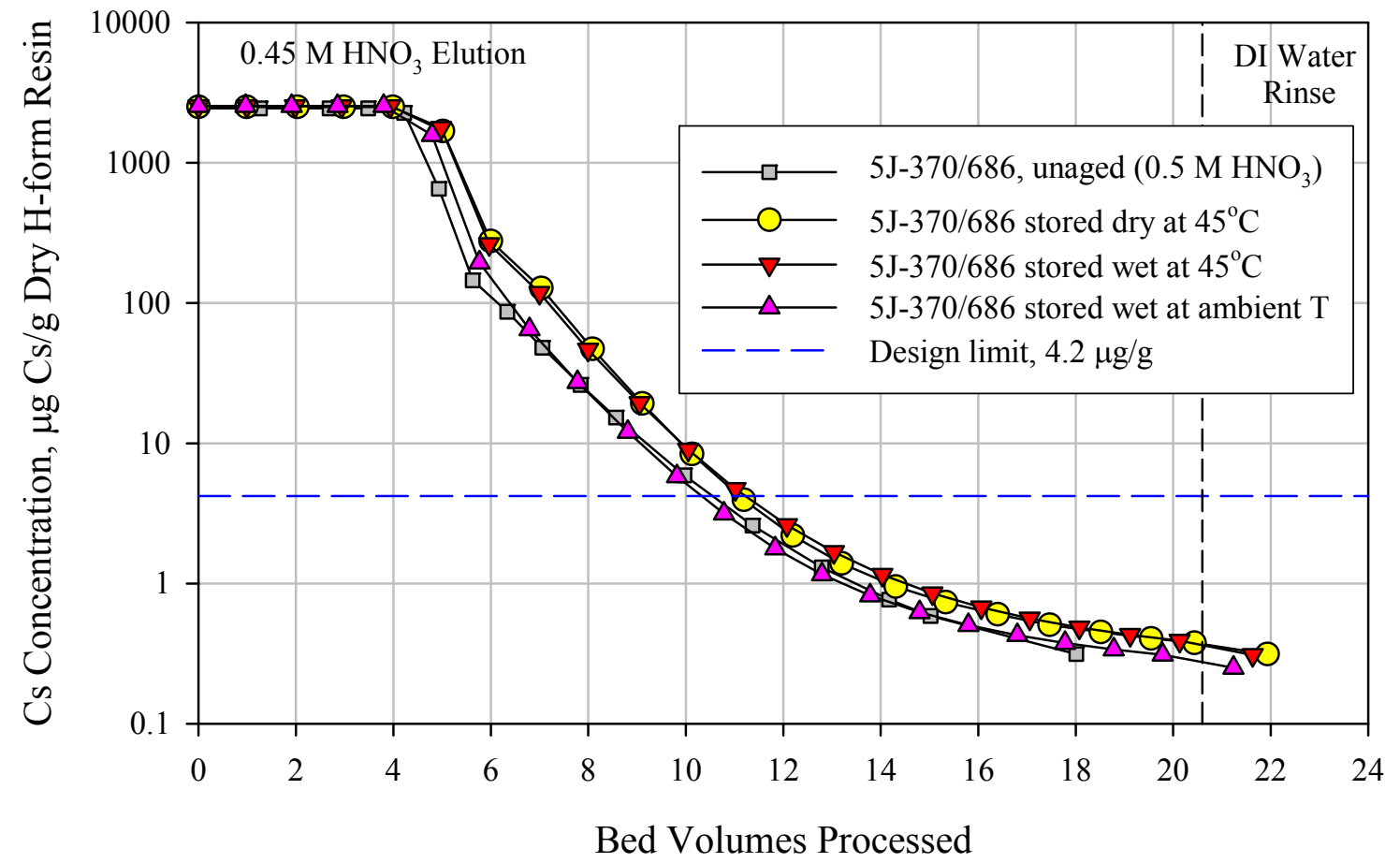

Figure 3.7. Residual Cs Concentration on Resin 5J-370/686 as a Function of Elution Volume 
Table 3.7. Effluent Cs Concentration During Elution of 5J-370/686

\begin{tabular}{|c|c|c|c|c|c|c|c|c|}
\hline \multicolumn{3}{|c|}{ Dry, $45^{\circ} \mathrm{C}$} & \multirow{2}{*}{\multicolumn{3}{|c|}{$\begin{array}{l}\text { Wet, ambient } \\
\text { Pink Column }\end{array}$}} & \multicolumn{3}{|c|}{ Wet, $45^{\circ} \mathrm{C}$} \\
\hline \multicolumn{3}{|c|}{ Yellow Column } & & & & \multicolumn{3}{|c|}{ Red Column } \\
\hline $\begin{array}{c}\text { Cum. } \\
\text { BV }\end{array}$ & $\mathrm{C} / \mathrm{C}_{\mathbf{0}}$ & $\begin{array}{c}\text { Resin Cs } \\
\text { Conc. }^{\text {(a) }}\end{array}$ & $\begin{array}{c}\text { Cum. } \\
\text { BV }\end{array}$ & $\mathrm{C} / \mathrm{C}_{\mathbf{0}}$ & $\begin{array}{c}\text { Resin Cs } \\
\text { Conc. }^{\text {(a) }}\end{array}$ & $\begin{array}{c}\text { Cum. } \\
\text { BV }\end{array}$ & $\mathrm{C} / \mathrm{C}_{\mathbf{0}}$ & $\begin{array}{c}\text { Resin Cs } \\
\text { Conc. }^{(a)}\end{array}$ \\
\hline 0.99 & $1.25 \mathrm{E}-2$ & $2.50 \mathrm{E}+3$ & 0.97 & $1.56 \mathrm{E}-2$ & $2.53 \mathrm{E}+3$ & 0.99 & $1.11 \mathrm{E}-2$ & $2.51 \mathrm{E}+3$ \\
\hline 2.03 & $1.89 \mathrm{E}-2$ & $2.50 \mathrm{E}+3$ & 1.91 & $1.91 \mathrm{E}-2$ & $2.53 \mathrm{E}+3$ & 1.98 & $1.78 \mathrm{E}-2$ & $2.51 \mathrm{E}+3$ \\
\hline 2.98 & $4.01 \mathrm{E}-2$ & $2.50 \mathrm{E}+3$ & 2.85 & $4.12 \mathrm{E}-2$ & $2.53 \mathrm{E}+3$ & 2.94 & $3.65 \mathrm{E}-2$ & $2.51 \mathrm{E}+3$ \\
\hline 3.99 & $4.86 \mathrm{E}-2$ & $2.50 \mathrm{E}+3$ & 3.80 & 4.97E-2 & $2.53 \mathrm{E}+3$ & 3.94 & 4.44E-2 & $2.51 \mathrm{E}+3$ \\
\hline 5.01 & $4.40 \mathrm{E}+1$ & $2.50 \mathrm{E}+3$ & 4.79 & $5.03 \mathrm{E}+1$ & $2.53 \mathrm{E}+3$ & 4.98 & $3.94 \mathrm{E}+1$ & $2.51 \mathrm{E}+3$ \\
\hline 6.00 & $7.87 \mathrm{E}+1$ & $1.68 \mathrm{E}+3$ & 5.77 & $7.40 \mathrm{E}+1$ & $1.58 \mathrm{E}+3$ & 5.96 & $8.46 \mathrm{E}+1$ & $1.77 \mathrm{E}+3$ \\
\hline 7.04 & $7.89 \mathrm{E}+0$ & $2.75 \mathrm{E}+2$ & 6.79 & $6.55 \mathrm{E}+0$ & $1.94 \mathrm{E}+2$ & 7.00 & $7.65 \mathrm{E}+0$ & $2.61 \mathrm{E}+2$ \\
\hline 8.09 & $4.25 \mathrm{E}+0$ & $1.28 \mathrm{E}+2$ & 7.78 & $1.99 \mathrm{E}+0$ & $6.50 \mathrm{E}+1$ & 8.00 & $3.92 \mathrm{E}+0$ & $1.17 \mathrm{E}+2$ \\
\hline 9.11 & $1.51 \mathrm{E}+0$ & $4.71 E+1$ & 8.81 & $7.68 \mathrm{E}-1$ & $2.72 \mathrm{E}+1$ & 9.05 & $1.42 \mathrm{E}+0$ & $4.63 \mathrm{E}+1$ \\
\hline 10.13 & $5.85 \mathrm{E}-1$ & $1.92 \mathrm{E}+1$ & 9.82 & $3.22 \mathrm{E}-1$ & $1.20 \mathrm{E}+1$ & 10.05 & $5.67 \mathrm{E}-1$ & $1.92 \mathrm{E}+1$ \\
\hline 11.19 & $2.30 \mathrm{E}-1$ & $8.36 \mathrm{E}+0$ & 10.78 & $1.45 \mathrm{E}-1$ & $5.82 \mathrm{E}+0$ & 11.02 & $2.43 \mathrm{E}-1$ & $8.94 \mathrm{E}+0$ \\
\hline 12.19 & $9.62 \mathrm{E}-2$ & $3.94 \mathrm{E}+0$ & 11.84 & $6.78 \mathrm{E}-2$ & $3.14 \mathrm{E}+0$ & 12.08 & $1.08 \mathrm{E}-1$ & $4.68 \mathrm{E}+0$ \\
\hline 13.20 & $4.45 \mathrm{E}-2$ & $2.19 \mathrm{E}+0$ & 12.79 & $3.36 \mathrm{E}-2$ & $1.78 \mathrm{E}+0$ & 13.04 & $5.33 \mathrm{E}-2$ & $2.60 \mathrm{E}+0$ \\
\hline 14.30 & $2.18 \mathrm{E}-2$ & $1.39 \mathrm{E}+0$ & 13.79 & $1.78 \mathrm{E}-2$ & $1.16 \mathrm{E}+0$ & 14.03 & $2.87 \mathrm{E}-2$ & $1.67 \mathrm{E}+0$ \\
\hline 15.33 & $1.16 \mathrm{E}-2$ & $9.50 \mathrm{E}-1$ & 14.80 & $1.02 \mathrm{E}-2$ & $8.20 \mathrm{E}-1$ & 15.06 & $1.62 \mathrm{E}-2$ & $1.15 \mathrm{E}+0$ \\
\hline 16.40 & $6.94 \mathrm{E}-3$ & 7.34E-1 & 15.80 & $6.15 \mathrm{E}-3$ & $6.22 \mathrm{E}-1$ & 16.06 & $9.54 \mathrm{E}-3$ & $8.47 \mathrm{E}-1$ \\
\hline 17.46 & $4.87 \mathrm{E}-3$ & $6.00 \mathrm{E}-1$ & 16.80 & $3.92 \mathrm{E}-3$ & $5.03 \mathrm{E}-1$ & 17.05 & $6.26 \mathrm{E}-3$ & $6.73 \mathrm{E}-1$ \\
\hline 18.51 & $3.03 \mathrm{E}-3$ & $5.07 \mathrm{E}-1$ & 17.78 & $2.79 \mathrm{E}-3$ & $4.28 \mathrm{E}-1$ & 18.07 & $4.15 \mathrm{E}-3$ & $5.61 \mathrm{E}-1$ \\
\hline 19.55 & $2.35 \mathrm{E}-3$ & 4.49E-1 & 18.78 & $1.93 \mathrm{E}-3$ & $3.76 \mathrm{E}-1$ & 19.12 & $2.94 \mathrm{E}-3$ & 4.84E-1 \\
\hline 20.44 & $1.77 \mathrm{E}-3$ & $4.05 \mathrm{E}-1$ & 19.78 & $1.50 \mathrm{E}-3$ & 3.39E-1 & 20.13 & $2.07 \mathrm{E}-3$ & $4.28 \mathrm{E}-1$ \\
\hline $\mathrm{EDI}^{(\mathrm{b})}$ & $1.17 \mathrm{E}-3$ & $3.77 \mathrm{E}-1^{(\mathrm{c})}$ & $\mathrm{EDI}^{(\mathrm{b})}$ & $1.09 \mathrm{E}-3$ & $3.10 \mathrm{E}-1^{(\mathrm{c})}$ & $\mathrm{EDI}^{(\mathrm{b})}$ & $1.48 \mathrm{E}-3$ & $3.90 \mathrm{E}-1^{(\mathrm{c})}$ \\
\hline $\begin{array}{ll}\text { (a) } & \mathrm{Co} \\
\text { (b) } & \mathrm{ED} \\
\text { (c) } & \text { Fir }\end{array}$ & ration of & $\begin{array}{l}\text { on resin as } n \\
\text { ater rinse. } \\
\text { he resin bed }\end{array}$ & grams & $\begin{array}{l}\text { ry } \mathrm{H} \text {-for } \\
\text { water rin }\end{array}$ & & & & \\
\hline
\end{tabular}


Table 3.8. Effluent Cs Concentration During Elution of 6C-370/745

\begin{tabular}{|c|c|c|c|c|c|c|c|c|}
\hline \multirow{2}{*}{\multicolumn{3}{|c|}{$\begin{array}{c}\text { Wet, ambient } \\
\text { White Column }\end{array}$}} & \multirow{2}{*}{\multicolumn{3}{|c|}{$\begin{array}{c}\text { Wet, } 35^{\circ} \mathrm{C} \\
\text { Green Column }\end{array}$}} & \multirow{2}{*}{\multicolumn{3}{|c|}{$\begin{array}{c}\text { Wet, } 45^{\circ} \mathrm{C} \\
\text { Blue Column }\end{array}$}} \\
\hline & & & & & & & & \\
\hline $\begin{array}{c}\text { Cum. } \\
\text { BV }\end{array}$ & $\mathrm{C} / \mathrm{C}_{0}$ & $\begin{array}{c}\text { Resin Cs } \\
\text { Conc. }{ }^{(\text {a) }}\end{array}$ & $\begin{array}{c}\text { Cum. } \\
\text { BV }\end{array}$ & $\mathrm{C} / \mathrm{C}_{0}$ & $\begin{array}{c}\text { Resin Cs } \\
\text { Conc. }{ }^{\text {(a) }}\end{array}$ & $\begin{array}{c}\text { Cum. } \\
\text { BV }\end{array}$ & $\mathrm{C} / \mathbf{C}_{0}$ & $\begin{array}{c}\text { Resin Cs } \\
\text { Conc. }^{\left({ }^{2}\right)} \\
\end{array}$ \\
\hline 0.95 & $2.01 \mathrm{E}-2$ & $2.44 \mathrm{E}+3$ & 0.97 & $1.38 \mathrm{E}-2$ & $2.49 \mathrm{E}+3$ & 0.91 & $1.21 \mathrm{E}-2$ & $2.56 \mathrm{E}+3$ \\
\hline 1.96 & $2.34 \mathrm{E}-2$ & $2.44 \mathrm{E}+3$ & 1.99 & $2.13 \mathrm{E}-2$ & $2.49 \mathrm{E}+3$ & 1.95 & $1.87 \mathrm{E}-2$ & $2.56 \mathrm{E}+3$ \\
\hline 2.87 & $4.86 \mathrm{E}-2$ & $2.44 \mathrm{E}+3$ & 2.96 & $4.44 \mathrm{E}-2$ & $2.49 \mathrm{E}+3$ & 2.94 & $4.08 \mathrm{E}-2$ & $2.56 \mathrm{E}+3$ \\
\hline 3.80 & $5.74 \mathrm{E}-2$ & $2.44 \mathrm{E}+3$ & 3.93 & $5.63 \mathrm{E}-2$ & $2.49 \mathrm{E}+3$ & 3.93 & $5.24 \mathrm{E}-2$ & $2.56 \mathrm{E}+3$ \\
\hline 4.80 & $5.24 \mathrm{E}+1$ & $1.41 \mathrm{E}+3$ & 4.92 & $7.85 \mathrm{E}+1$ & $9.64 \mathrm{E}+2$ & 4.94 & $4.24 \mathrm{E}+1$ & $1.77 \mathrm{E}+3$ \\
\hline 5.76 & $6.33 \mathrm{E}+1$ & $2.14 \mathrm{E}+2$ & 5.86 & $4.04 \mathrm{E}+1$ & $2.23 \mathrm{E}+2$ & 5.93 & $7.61 \mathrm{E}+1$ & $3.72 \mathrm{E}+2$ \\
\hline 6.78 & $7.13 \mathrm{E}+0$ & $7.02 \mathrm{E}+1$ & 6.77 & $6.44 \mathrm{E}+0$ & $1.08 \mathrm{E}+2$ & 6.84 & $9.28 \mathrm{E}+0$ & $2.15 \mathrm{E}+2$ \\
\hline 7.81 & $2.41 \mathrm{E}+0$ & $2.13 \mathrm{E}+1$ & 7.78 & $3.25 \mathrm{E}+0$ & $4.37 \mathrm{E}+1$ & 7.88 & $7.01 \mathrm{E}+0$ & $8.03 \mathrm{E}+1$ \\
\hline 8.80 & 7.11E-1 & $7.42 \mathrm{E}+0$ & 8.77 & $1.25 \mathrm{E}+0$ & $1.93 \mathrm{E}+1$ & 8.92 & $2.50 \mathrm{E}+0$ & $3.20 \mathrm{E}+1$ \\
\hline 9.81 & $2.16 \mathrm{E}-1$ & $3.12 \mathrm{E}+0$ & 9.77 & $5.19 \mathrm{E}-1$ & $9.04 \mathrm{E}+0$ & 9.92 & $9.61 \mathrm{E}-1$ & $1.41 \mathrm{E}+1$ \\
\hline 10.88 & $7.37 \mathrm{E}-2$ & $1.57 \mathrm{E}+0$ & 10.79 & $2.24 \mathrm{E}-1$ & $4.60 \mathrm{E}+0$ & 10.89 & $3.92 \mathrm{E}-1$ & $7.05 \mathrm{E}+0$ \\
\hline 11.89 & $2.89 \mathrm{E}-2$ & $9.89 \mathrm{E}-1$ & 11.79 & $1.03 \mathrm{E}-1$ & $2.57 \mathrm{E}+0$ & 11.91 & $1.72 \mathrm{E}-1$ & $3.80 \mathrm{E}+0$ \\
\hline 12.89 & $1.36 \mathrm{E}-2$ & 7.19E-1 & 12.77 & $5.07 \mathrm{E}-2$ & $1.60 \mathrm{E}+0$ & 12.91 & $8.15 \mathrm{E}-2$ & $2.30 \mathrm{E}+0$ \\
\hline 14.02 & $6.75 \mathrm{E}-3$ & $5.70 \mathrm{E}-1$ & 13.76 & $2.66 \mathrm{E}-2$ & $1.08 \mathrm{E}+0$ & 13.91 & $4.19 \mathrm{E}-2$ & $1.52 \mathrm{E}+0$ \\
\hline 15.05 & $3.92 \mathrm{E}-3$ & $4.90 \mathrm{E}-1$ & 14.73 & $1.47 \mathrm{E}-2$ & $8.06 \mathrm{E}-1$ & 14.85 & $2.31 \mathrm{E}-2$ & $1.11 \mathrm{E}+0$ \\
\hline 16.12 & $2.62 \mathrm{E}-3$ & $4.34 \mathrm{E}-1$ & 15.72 & $8.63 \mathrm{E}-3$ & $6.37 \mathrm{E}-1$ & 15.88 & $1.35 \mathrm{E}-2$ & $8.57 \mathrm{E}-1$ \\
\hline 17.16 & $1.98 \mathrm{E}-3$ & $3.94 \mathrm{E}-1$ & 16.72 & $5.39 \mathrm{E}-3$ & $5.32 \mathrm{E}-1$ & 16.92 & $8.12 \mathrm{E}-3$ & $7.01 \mathrm{E}-1$ \\
\hline 18.21 & $1.56 \mathrm{E}-3$ & $3.61 \mathrm{E}-1$ & 17.74 & $3.52 \mathrm{E}-3$ & $4.62 \mathrm{E}-1$ & 17.98 & $5.39 \mathrm{E}-3$ & $5.95 \mathrm{E}-1$ \\
\hline 19.24 & $1.35 \mathrm{E}-3$ & $3.34 \mathrm{E}-1$ & 18.75 & $2.54 \mathrm{E}-3$ & $4.11 \mathrm{E}-1$ & 19.05 & $3.63 \mathrm{E}-3$ & $5.22 \mathrm{E}-1$ \\
\hline 20.14 & $1.20 \mathrm{E}-3$ & $3.13 \mathrm{E}-1$ & 19.78 & $1.88 \mathrm{E}-3$ & $3.73 \mathrm{E}-1$ & 20.07 & $2.76 \mathrm{E}-3$ & $4.70 \mathrm{E}-1$ \\
\hline $\mathrm{EDI}^{(\mathrm{b})}$ & 8.63E-4 & $2.61 \mathrm{E}-1^{(\mathrm{c})}$ & $\mathrm{EDI}^{(\mathrm{b})}$ & $1.24 \mathrm{E}-3$ & $3.02 \mathrm{E}-1^{(\mathrm{c})}$ & $\mathrm{EDI}^{(\mathrm{b})}$ & $2.03 \mathrm{E}-3$ & $3.58 \mathrm{E}-1^{(\mathrm{c})}$ \\
\hline
\end{tabular}

The shrink-swell characteristics of the aged resin beds (in-column) are shown in Figure 3.8 and Figure 3.9 along with the previously reported shrink-swell data from tests on the un-aged resin. The reference volume was defined as the volume of resin in the first regeneration condition following $0.5 \mathrm{M}$ $\mathrm{NaOH}$ processing for the $\mathrm{P} 1-\mathrm{RF}$ pretreated resins. The $6 \mathrm{C}-370 / 745$ resin stored wet at $45^{\circ} \mathrm{C}$ resulted in slightly lower expansion and contraction factors than the other resins (15\% volume change versus $20 \%$ volume change) also indicative of increased cross-linkage. The 5J-370/686 resin shrink-swell results were more consistent with the original (un-aged) test. The actual resin volumes are reported in Table 3.9. The reported values are only significant to two figures; the third significant figure is provided only for indication. 


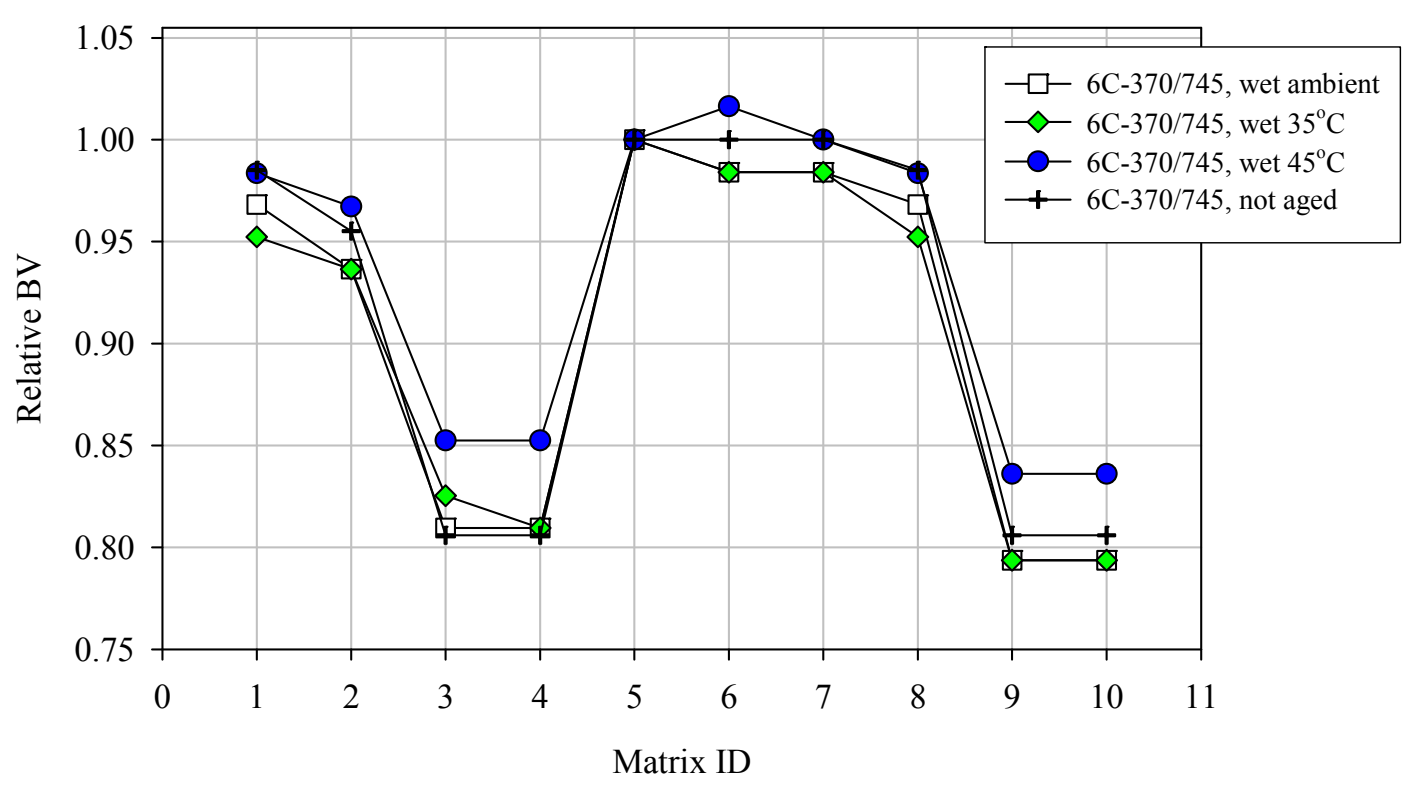

Figure 3.8. Shrink-Swell Characteristics of Aged 6C-370/745

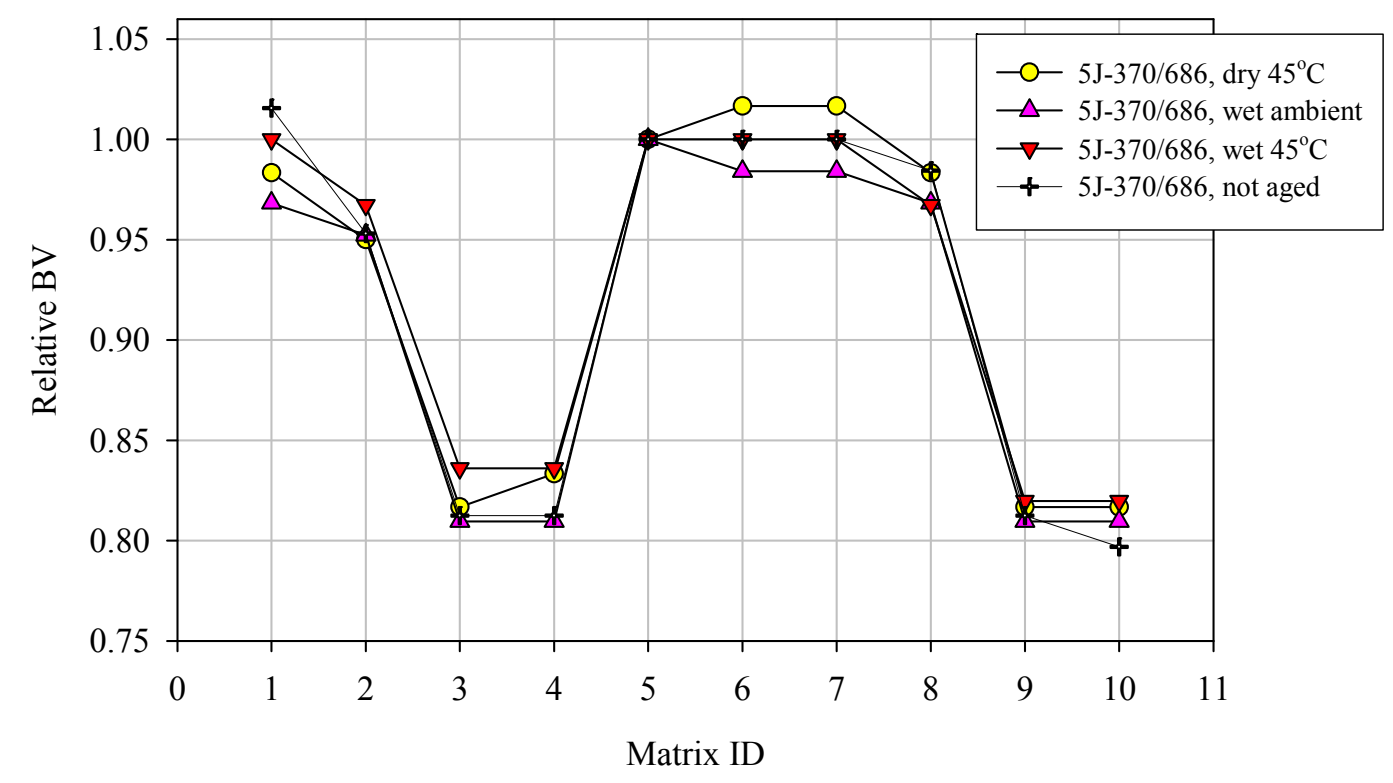

Figure 3.9. Shrink-Swell Characteristics of 5J-370/686

\author{
Matrix ID's
1: Loaded in column (Na-form)
2: DI water rinse
3: $0.5 \mathrm{M} \mathrm{HNO}_{3}$
4: DI water rinse
5: $0.5 \mathrm{M} \mathrm{NaOH}$

6: AP101 simulant

7: $0.1 \mathrm{M} \mathrm{NaOH}$ feed displacement

8: DI water

9: $0.45 \mathrm{M} \mathrm{HNO}_{3}$

10: DI water 
Table 3.9. Actual Resin Volume as a Function of Feed Matrix

\begin{tabular}{|c|c|c|c|c|c|c|c|}
\hline \multirow{3}{*}{\multicolumn{2}{|c|}{$\begin{array}{r}\text { Resin }> \\
\text { Column }> \\
\text { Storage condition }>\end{array}$}} & \multicolumn{3}{|c|}{$5 J-370 / 686$} & \multicolumn{3}{|c|}{ 6C-370/745 } \\
\hline & & Yellow & Pink & Red & White & Green & Blue \\
\hline & & Dry, $45^{\circ} \mathrm{C}$ & Wet, ambient & Wet, $45^{\circ} \mathrm{C}$ & Wet, ambient & Wet, $35^{\circ} \mathrm{C}$ & Wet, $45^{\circ} \mathrm{C}$ \\
\hline Matrix & Matrix ID & $\mathbf{m L}$ & $\mathbf{m L}$ & $\mathbf{m L}$ & $\mathbf{m L}$ & $\mathbf{m L}$ & $\mathbf{m L}$ \\
\hline Loaded Na-form & 1 & 18.5 & 19.2 & 19.2 & 19.2 & 18.8 & 18.8 \\
\hline DI rinse & 2 & 17.9 & 18.8 & 18.5 & 18.5 & 18.5 & 18.5 \\
\hline $0.5 \mathrm{M} \mathrm{HNO}_{3}$ & 3 & 15.4 & 16.0 & 16.0 & 16.0 & 16.3 & 16.3 \\
\hline DI water & 4 & 15.7 & 16.0 & 16.0 & 16.0 & 16.0 & 16.3 \\
\hline $0.5 \mathrm{M} \mathrm{NaOH}^{(\mathrm{a})}$ & 5 & 18.8 & 19.8 & 19.2 & 19.8 & 19.8 & 19.2 \\
\hline $\begin{array}{l}\text { Feed, AP101 } \\
\text { simulant }\end{array}$ & 6 & 19.2 & 19.5 & 19.2 & 19.5 & 19.5 & 19.5 \\
\hline $0.1 \mathrm{M} \mathrm{NaOH}$ & 7 & 19.2 & 19.5 & 19.2 & 19.5 & 19.5 & 19.2 \\
\hline DI water & 8 & 18.5 & 19.2 & 18.5 & 19.2 & 18.8 & 18.8 \\
\hline $0.45 \mathrm{M} \mathrm{HNO}_{3}$ & 9 & 15.4 & 16.0 & 15.7 & 15.7 & 15.7 & 16.0 \\
\hline DI water & 10 & 15.4 & 16.0 & 15.7 & 15.7 & 15.7 & 16.0 \\
\hline $\begin{array}{l}\text { Dry resin mass } \\
\text { (H-form) }\end{array}$ & na & $6.09 \mathrm{~g}$ & $6.05 \mathrm{~g}$ & $6.16 \mathrm{~g}$ & $5.84 \mathrm{~g}$ & $5.92 \mathrm{~g}$ & $6.06 \mathrm{~g}$ \\
\hline
\end{tabular}




\subsection{Conclusions}

The spherical RF resin can be stored for at least 1 year in an environment inerted with nitrogen at temperatures ranging from $22^{\circ} \mathrm{C}$ to $45^{\circ} \mathrm{C}$ without significant adverse effects on the Cs ion exchange loading and eluting characteristics. Both wet and dry storage conditions are tolerated. Two resin lots were evaluated with similar results.

The resins stored at elevated temperature resulted in slightly increased Cs exchange capacity as defined by the BVs required to reach $50 \%$ Cs breakthrough as compared to the un-aged results previously reported (Fiskum et al. 2006).

- The $45^{\circ} \mathrm{C}$ storage condition resulted in $15 \%$ higher BV loading to reach the $50 \%$ Cs breatkthrough.

- The $35^{\circ} \mathrm{C}$ storage condition resulted in $4.6 \%$ higher BV loading to reach the $50 \% \mathrm{Cs}$ breatkthrough.

- The ambient temperature condition resulted in no change from the un-aged resin test to reach the $50 \%$ Cs breatkthrough.

Resin stored in the dry condition at $45^{\circ} \mathrm{C}$ resulted in virtually identical Cs loading results as the resin stored in the wet condition.

- The $50 \%$ Cs breakthrough for the wet resin occurred after processing $150 \mathrm{BVs}$.

- The $50 \%$ Cs breakthrough for the dry resin occurred after processing 154 BVs.

General elution properties for the aged resins were similar as for the un-aged resins.

- Virtually $100 \%$ of the Cs loaded onto the ion exchanger was recovered in the eluate.

- The peak Cs concentration occurred at $6 \mathrm{BVs}$.

- Cesium concentration in the eluate tailed to $\sim 0.002 \mathrm{C} / \mathrm{C}_{\mathrm{o}}$ after processing $20 \mathrm{BVs}$.

- The resins aged at a higher temperature released residual $\mathrm{Cs}$ in the tailing region more slowly than resins stored at ambient temperature.

- The Cs eluted from the resin beds after processing $20 \mathrm{BVs}$ of eluate to reach $\sim 0.33 \mu \mathrm{g}$ Cs per g of dry $\mathrm{H}$-form resin.

Physical properties of the aged resins were not significantly different from the un-aged resins.

- Resin bed densities ranged from 0.36 to $0.38 \mathrm{~g} / \mathrm{mL}$ (dry $\mathrm{H}$-form resin settled in the hydrated form). There was an indication that the resins stored at higher temperatures may have had slightly higher densities than the low-temperature stored resins.

- The shrink-swell properties were similar to those of the original un-aged resins. However, one of the three resins stored at $45^{\circ} \mathrm{C}$ demonstrated about $5 \%$ less volume change.

- The overall expansion of resins in storage was $<3 \%$.

- The overall expansion upon conversion from the aged as-received $\mathrm{H}$-form to the pretreated $\mathrm{H}$-form ranged from $21 \%$ to $26 \%$. 
The differences in Cs ion exchange performance and physical properties were attributed to increased cross-linkage of the RF polymer structure. 


\section{Appendix A}

Direction for Resin Testing from the BNI R\&T Lead 


\section{Appendix A: Direction for Resin Testing from the BNI R\&T Lead}

The following e-mail from MR Thorson (BNI R\&T Lead) to SK Fiskum (PNNL) (cc ST Arm and TC Valenti) provided the specific BNI direction required to implement the test plan.

Sandy, as we discussed today per Test Plan TP-RPP-WTP-440, Rev 0, the WTP R\&T lead for this task needs to provide work direction for which resins to test and the processing condition.

Please test six columns of resin as described below in near identical load tests using the AP-101 simulant used for these resins when tested in the A-225 work:

1. Resin 6C-370/745 (same as labeled as MB lot 6C-370/744 in the test plan) stored for one year submerged in water at $45^{\circ} \mathrm{C}$.

2. Resin $6 \mathrm{C}-370 / 745$ stored for one year submerged in water at $35^{\circ} \mathrm{C}$.

3. Resin $6 \mathrm{C}-370 / 745$ stored for one year submerged in water at $22^{\circ} \mathrm{C}$.

4. Resin $5 \mathrm{~J}-370 / 686$ stored for one year submerged in water at $45^{\circ} \mathrm{C}$.

5. Resin $5 \mathrm{~J}-370 / 686$ stored for one year submerged in water at $22^{\circ} \mathrm{C}$.

6. Resin $5 \mathrm{~J}-370 / 686$ stored for one year dry at $45^{\circ} \mathrm{C}$.

Also please follow the process conditions specified in Table 2 below. The items highlighted in blue show the new specified details. The load conditions should match the previous A-225 work. The elution conditions should match the previous A-225 work except for the acid strength and the elution volume. The most important point is the six column load and elution operations should be identical so the performances can be compared.

Murray

Table 2. Ion Exchange Processing Parameters

\begin{tabular}{|c|c|c|c|c|}
\hline Process Step & Matrix/Range & $\begin{array}{l}\text { Volume } \\
\text { (BV) }\end{array}$ & $\begin{array}{r}\text { Flow } \\
\text { direction }\end{array}$ & $\begin{array}{l}\text { Flowrate, } \\
\text { BV/h }\end{array}$ \\
\hline Regeneration & $0.5 \mathrm{M} \mathrm{NaOH}$ & 6 & down & 3 \\
\hline Feed & AP-101 simulant & $>50 \% \mathrm{BT}$ & down & $\begin{array}{l}1.5 \text { for } \sim 80 \\
\text { BV then } 3\end{array}$ \\
\hline $\begin{array}{c}\text { Feed } \\
\text { displacement }\end{array}$ & $0.1 \mathrm{M} \mathrm{NaOH}$ & 3 & down & 3 \\
\hline Water rinse & $\mathrm{H}_{2} \mathrm{O}$ & 3 & down & 3 \\
\hline Elution & $0.45 \mathrm{M} \mathrm{HNO}_{3}$ & 20 & down & 1.4 \\
\hline Water rinse & $\mathrm{H}_{2} \mathrm{O}$ & 3 & down & 1.4 \\
\hline
\end{tabular}


Appendix B

AP-101 Simulant Formulation 


\section{Appendix B: AP-101 Simulant Formulation}

Table B. 1 describes the input reagents to the AP-101 simulant. The full simulant preparation was described by Russell et al. (2003).

Table B.1. Reagent Masses for 1-L of AP-101 Simulant Solution

\begin{tabular}{|c|c|c|c|c|}
\hline Compound Name & Formula & $\begin{array}{l}\text { Formula } \\
\text { Weight, } \\
\text { g/mole }\end{array}$ & $\begin{array}{c}\text { Amount } \\
\text { Added (g) per } \\
\text { 1-L Volume }\end{array}$ & Molarity \\
\hline Sodium acetate & $\mathrm{NaCH}_{3} \mathrm{CO}_{2}$ & 82.03 & 2.029 & $2.47 \mathrm{E}-2$ \\
\hline Sodium oxalate & $\mathrm{Na}_{2} \mathrm{C}_{2} \mathrm{O}_{4}$ & 134 & 2.385 & $1.78 \mathrm{E}-2$ \\
\hline $\begin{array}{l}\text { Aluminum nitrate nonahydrate }(60 \% \\
\text { solution) }\end{array}$ & $\mathrm{Al}\left(\mathrm{NO}_{3}\right)_{3}-9 \mathrm{H}_{2} \mathrm{O}$ & 375.13 & 161.75 & $4.31 \mathrm{E}-1$ \\
\hline Barium nitrate & $\mathrm{Ba}\left(\mathrm{NO}_{3}\right)_{2}$ & 261.35 & 0.000552 & $2.11 \mathrm{E}-6$ \\
\hline Beryllium oxide & $\mathrm{BeO}$ & 25.01 & 0.003247 & $1.30 \mathrm{E}-4$ \\
\hline Cadmium nitrate tetrahydrate & $\mathrm{Cd}\left(\mathrm{NO}_{3}\right)_{2}-4 \mathrm{H}_{2} \mathrm{O}$ & 308.47 & 0.004885 & $1.58 \mathrm{E}-5$ \\
\hline Calcium nitrate tetrahydrate & $\mathrm{Ca}\left(\mathrm{NO}_{3}\right)_{2}-4 \mathrm{H}_{2} \mathrm{O}$ & 236.16 & 0.04036 & $1.71 \mathrm{E}-4$ \\
\hline Cesium nitrate & $\mathrm{CsNO}_{3}$ & 194.92 & 0.008784 & $4.51 \mathrm{E}-5$ \\
\hline Rubidium nitrate & $\mathrm{RbNO}_{3}$ & 147.47 & 0.006091 & $4.13 \mathrm{E}-5$ \\
\hline Copper nitrate trihydrate & $\mathrm{Cu}\left(\mathrm{NO}_{3}\right)_{2}-3 \mathrm{H}_{2} \mathrm{O}$ & 241.6 & 0.005399 & $2.23 \mathrm{E}-5$ \\
\hline Iron nitrate nonahydrate & $\mathrm{Fe}\left(\mathrm{NO}_{3}\right)_{3}-9 \mathrm{H}_{2} \mathrm{O}$ & 404 & 0.01606 & $3.98 \mathrm{E}-5$ \\
\hline Lead nitrate & $\mathrm{Pb}\left(\mathrm{NO}_{3}\right)_{2}$ & 331.226 & 0.02132 & $6.44 \mathrm{E}-5$ \\
\hline Lithium nitrate & $\mathrm{LiNO}_{3}$ & 69 & 0.002982 & $4.32 \mathrm{E}-5$ \\
\hline Nickel nitrate hexahydrate & $\mathrm{Ni}\left(\mathrm{NO}_{3}\right)_{2}-6 \mathrm{H}_{2} \mathrm{O}$ & 290.81 & 0.03488 & $1.20 \mathrm{E}-4$ \\
\hline Zinc nitrate hexahydrate & $\mathrm{Zn}\left(\mathrm{NO}_{3}\right)_{2}-6 \mathrm{H}_{2} \mathrm{O}$ & 297.47 & 0.02266 & $7.62 \mathrm{E}-5$ \\
\hline Boric acid & $\mathrm{H}_{3} \mathrm{BO}_{3}$ & 61.83 & 0.08164 & $1.32 \mathrm{E}-3$ \\
\hline Molybdenum oxide & $\mathrm{MoO}_{3}$ & 143.95 & 0.01930 & $1.34 \mathrm{E}-4$ \\
\hline Sodium chloride & $\mathrm{NaCl}$ & 58.44 & 2.390 & $4.09 \mathrm{E}-2$ \\
\hline Sodium fluoride & $\mathrm{NaF}$ & 41.99 & 0.1180 & $2.81 \mathrm{E}-3$ \\
\hline Sodium dihydrogen phosphate & $\mathrm{Na}_{2} \mathrm{H}_{2} \mathrm{PO}_{4}$ & 119.98 & 1.492 & $1.24 \mathrm{E}-2$ \\
\hline Sodium sulfate & $\mathrm{Na}_{2} \mathrm{SO}_{4}$ & 142.04 & 5.298 & $3.73 \mathrm{E}-2$ \\
\hline Sodium nitrate & $\mathrm{NaNO}_{3}$ & 84.99 & 60.00 & $7.06 \mathrm{E}-1$ \\
\hline Potassium nitrate & $\mathrm{KNO}_{3}$ & 101.11 & 20.02 & $1.98 \mathrm{E}-1$ \\
\hline Sodium hydroxide ( $50 \%$ solution) & $\mathrm{NaOH}$ & 40 & 238.4 & $5.96 \mathrm{E}+0$ \\
\hline Tungstic acid & $\mathrm{H}_{2} \mathrm{WO}_{4}$ & 249.86 & 0.0344 & $1.38 \mathrm{E}-4$ \\
\hline Sodium meta-silicate & $\mathrm{Na}_{2} \mathrm{SiO}_{3}-9 \mathrm{H}_{2} \mathrm{O}$ & 284.2 & 1.234 & $4.34 \mathrm{E}-3$ \\
\hline Sodium chromate & $\mathrm{Na}_{2} \mathrm{CrO}_{4}$ & 161.97 & 0.4735 & $2.92 \mathrm{E}-3$ \\
\hline Sodium formate & $\mathrm{HCOONa}$ & 68.01 & 1.614 & $2.37 \mathrm{E}-2$ \\
\hline Sodium nitrite & $\mathrm{NaNO}_{2}$ & 69 & 48.78 & $7.07 \mathrm{E}-1$ \\
\hline Sodium carbonate & $\mathrm{Na}_{2} \mathrm{CO}_{3}$ & 105.99 & 20.03 & $1.89 \mathrm{E}-1$ \\
\hline Potassium carbonate & $\mathrm{K}_{2} \mathrm{CO}_{3}$ & 138.21 & 35.52 & $2.57 \mathrm{E}-1$ \\
\hline
\end{tabular}




\section{Appendix C}

\section{Photographs of Retrieved Resins Following Storage}




\section{Appendix C: Photographs of Retrieved Resins Following Storage}

Figures C.1 through C.6 document the appearance of the resins following the 1-year storage time at the target temperatures. The photographed color striations originating from approximately the center point of the vials and jars were an artifact of the room lighting and reflections on the glassware. The variations were not apparent to the naked eye. The darkened band at the surface of the wetted resins stored at $35^{\circ} \mathrm{C}$ and $45^{\circ} \mathrm{C}$ were apparent on direct observation. Below the darkened band, the resins appeared uniform in color.

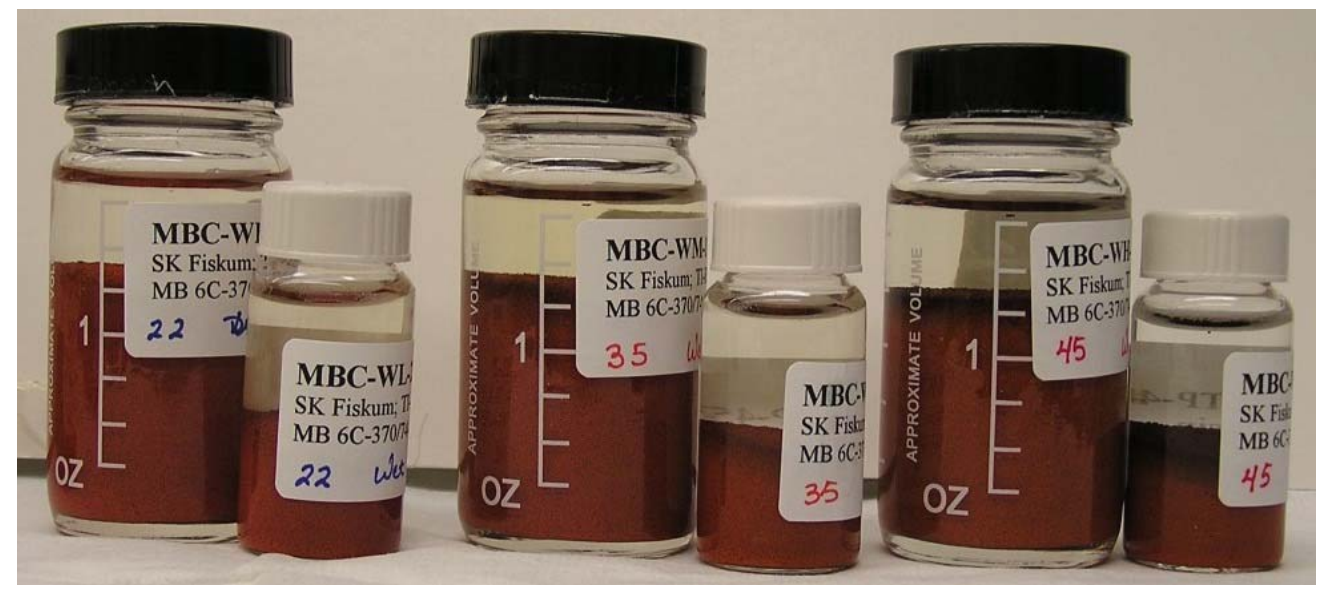

Figure C.1. Microbeads $6 \mathrm{C}-370 / 745$ Resins Stored Wet at Ambient Temperature, $35^{\circ} \mathrm{C}$ and $45^{\circ} \mathrm{C}$, from left to right: MBC-WL-1, MBC-WL-2, MBC-WM-1, MBC-WM-2, and MBC-WH-1, MBC-WH-2

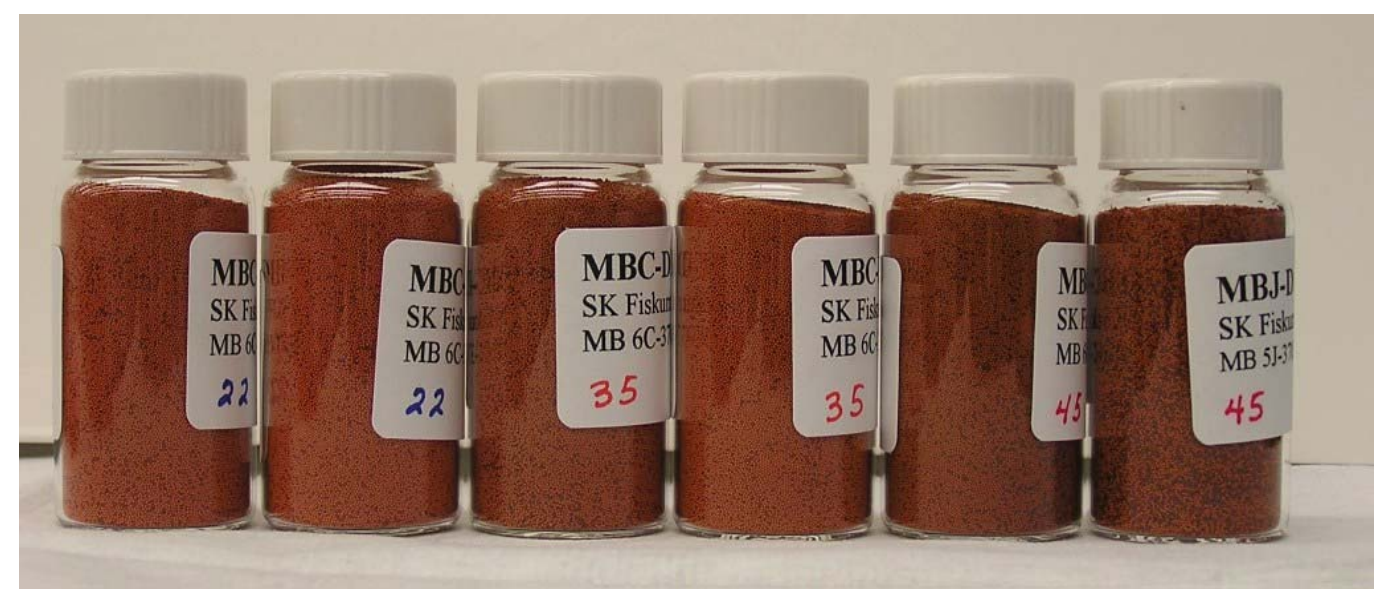

Figure C.2. Microbeads $6 \mathrm{C}-370 / 745$ Resins Stored Dry at Ambient Temperature, $35^{\circ} \mathrm{C}$ and $45^{\circ} \mathrm{C}$, from left to right: MBC-DL-1, MBC-DL-2, MBC-DM-1, MBC-DM-2, and MBC-DH-1, MBC-DH-2 


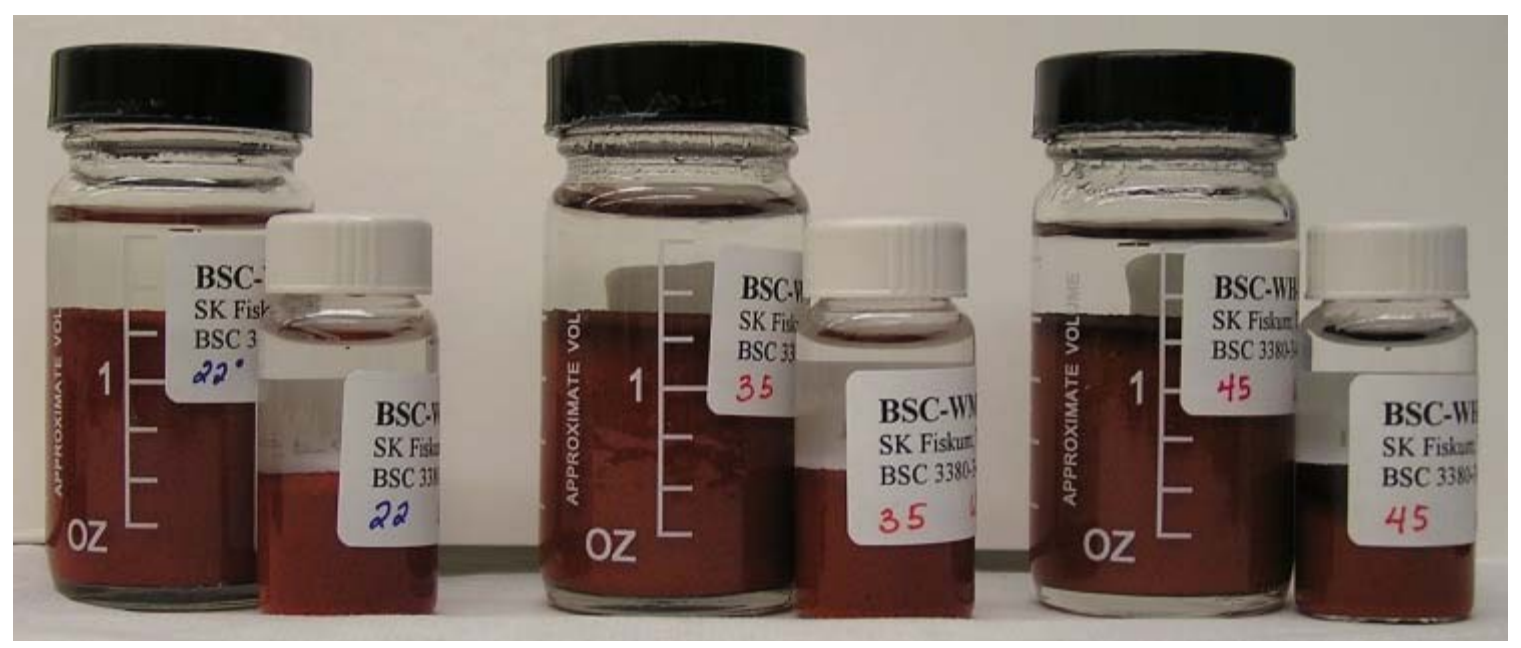

Figure C.3. Boulder Scientific Corporation 3380-3-0200 Resins Stored Wet at Ambient Temperature, $35^{\circ} \mathrm{C}$ and $45^{\circ} \mathrm{C}$, from left to right: BSC-WL-1, BSC-WL-2, BSC-WM-1, BSC-WM-2, and BSC-WH-1, BSC-WH-2

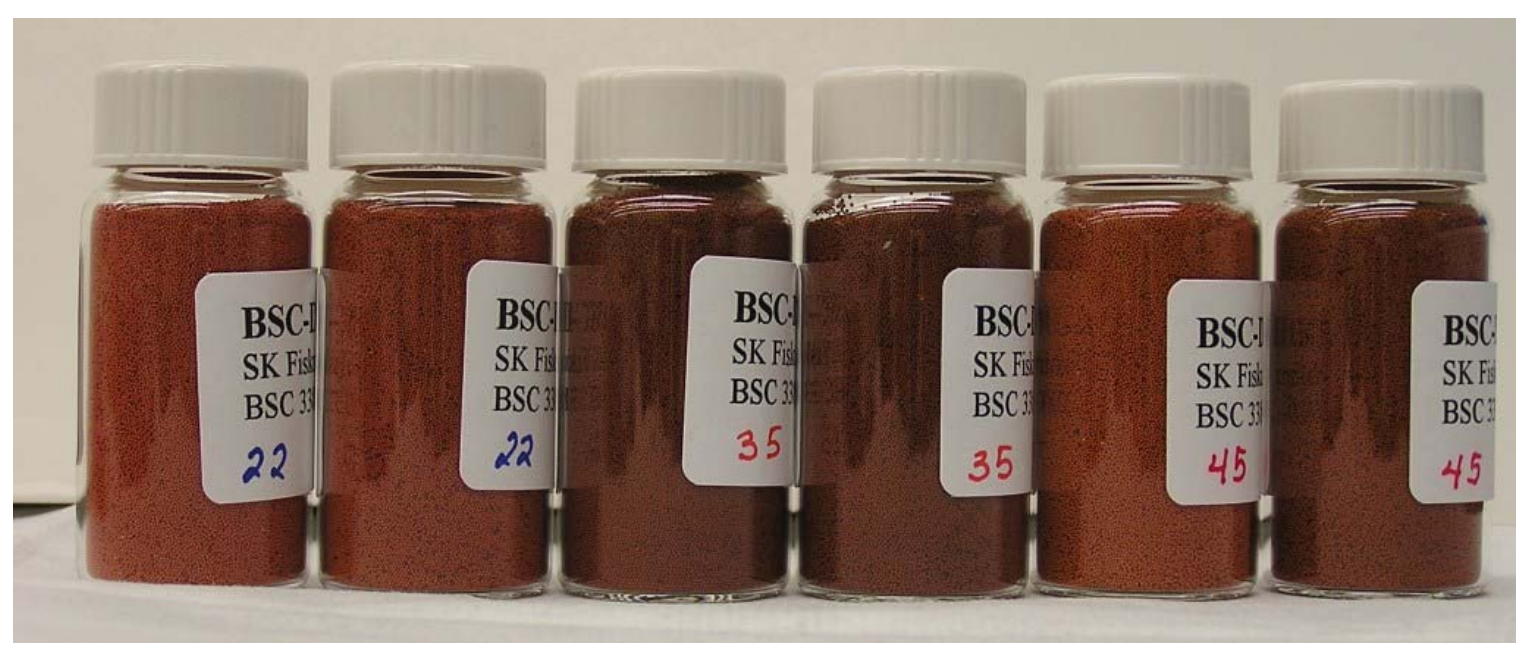

Figure C.4. Boulder Scientific Corporation 3380-3-0200 Resins Stored Dry at Ambient Temperature, $35^{\circ} \mathrm{C}$ and $45^{\circ} \mathrm{C}$, from left to right: BSC-DL-1, BSC-DL-2, BSC-DM-1, BSC-DM-2, and BSC-DH-1, BSC-DH-2 


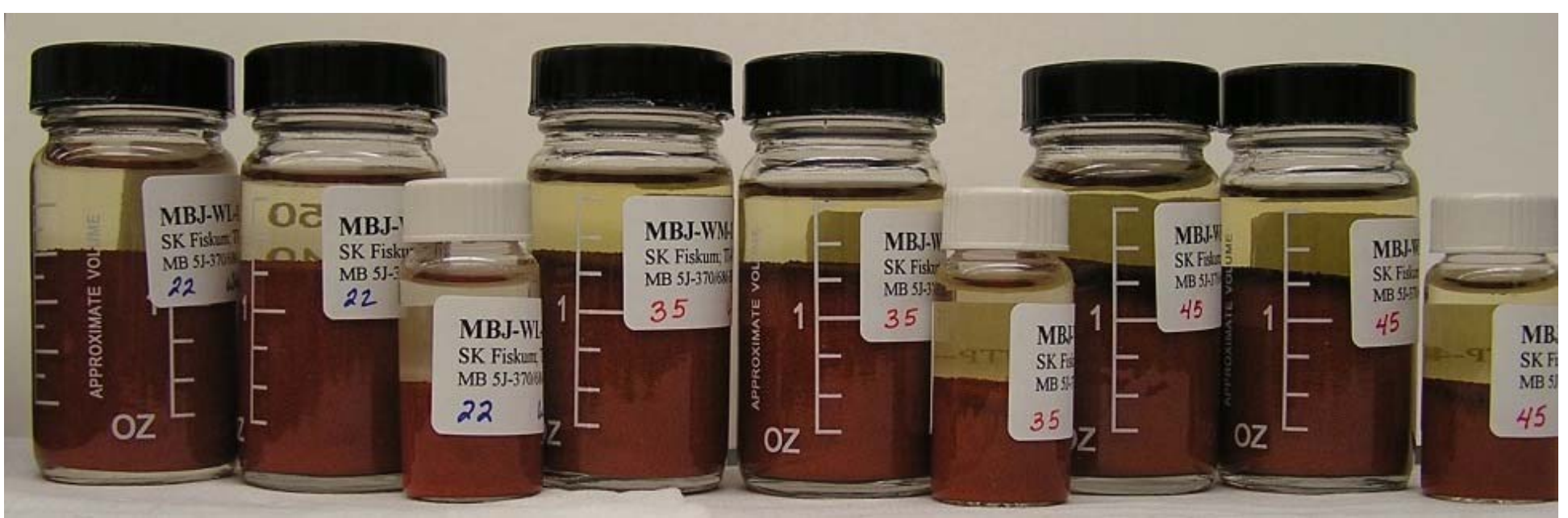

Figure C.5. Microbeads 5J-370/686 Resins Stored Wet at Ambient Temperature, $35^{\circ} \mathrm{C}$ and $45^{\circ} \mathrm{C}$, from left to right: $\mathrm{MBJ}-\mathrm{WL}-1$, MBJ-WL-2, MBJ-WL-3, MBJ-WM-1, MBJ-WM-2, MBJ-WM-3, MBJ-WH-1, MBJ-WH-2, and MBJ-WH-3

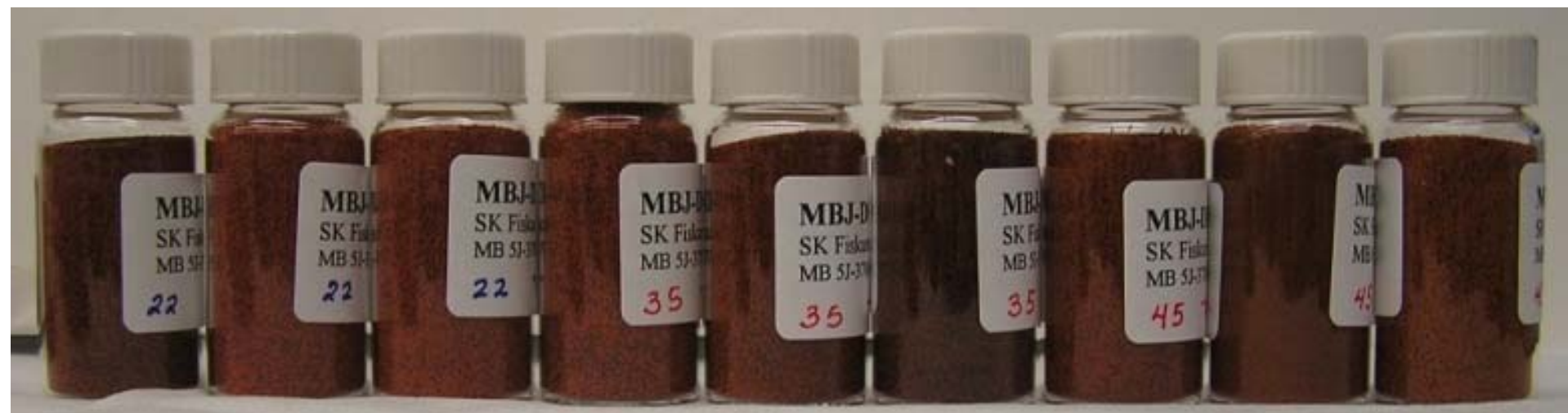

Figure C.6. Microbeads 5J-370/686 Resins Stored Dry at Ambient Temperature, $35^{\circ} \mathrm{C}$ and $45^{\circ} \mathrm{C}$, from left to right: MBJ-DL-1, MBJ-DL-2, MBJ-DL-3, MBJ-DM-1, MBJ-DM-2, MBJ-DM-3, MBJ-DH-1, MBJ-DH-2, and MBJ-DH-3 
PNNL-16832

WTP-RPT-148, Rev 0

\section{Distribution}

No. of

Copies

OFFSITE

1 Savannah River National Laboratory Richard Edwards

Savannah River National Laboratory

Westinghouse SA

Aiken, SC 29808-0001
No. of

Copies

ONSITE

7 Pacific Northwest National Laboratory
S. K. Fiskum
P7-22
S. T. Arm
$\mathrm{P} 7-28$
M. K. Edwards
$\mathrm{P} 7-25$
D. E. Kurath
$\mathrm{P} 7-28$
M. J. Steele
$\mathrm{P} 7-22$
K. K. Thomas
$\mathrm{P} 7-22$
Project Files
P7-28

3 Bechtel National, Inc.
D. Alford (2)
H4-02
M. R. Thorson
H4-02 